\title{
THE FATE OF ALKALI SPECIES IN ADVANCED COAL CONVERSION SYSTEMS
}

Gopala N. Krishnan

Bernard J. Wood

SRI Project 4352

Prepared for:

United States Department of Energy Morgantown Energy Technology Center 3610 Collins Ferry Road Morgantown, WV 26505

Attention: Dr. Norman Holcombe Technical Program Manager

Contract No.: DE-AC21-87MC24012

Approved:

Jerry L. Jones, Direclur

Chemical Engineering Development Center

David M. Golden

Vice President

Physical Sciences Division 


\section{ACKNOWLEDGMENTS}

The project team included the following staff members who made major contributions to this research program:

Gregory P. Smith - Laser-based diagnostic techniques

Robert D. Brittain - Thermodynamic equilibrium calculations

Robert H. Lamoreaux - Thermodynamic equilibrium calculations

Robert M. Platz - Particle collection devices

Eldon P. Farley - X-ray diffraction measurements

Victor Wong - Combustion experiments

In addition, Dr. Thomar: P. Milre of the Solar Research Institute served as a consultant and contributed significant and helpful suggestions on the design of the high-pressure, molecular-beam sampling mass spectrometer.

Two successive DOE-METC technical program managers, Dr. Mark Williams and Dr. Norman Holcombe, maintained close liaison with the SRI project leader over the duration of the program, and generously provided help and guidance in both technical and administrative matters. 


\section{EXECUTIVE SUMMARY}

The fate of alkali species during coal combustion and gasification was determined experimentally in a fluidized bed reactor. A molecular-beam sampling mass spectrometer was used to identify and measure the concentration of vapor phase sodium species in the high temperature environment. Concurrent collection and analysis of the ash established the distribution of sodium species between gas-entrained and residual ash fractions.

Two coals, Beulah Zap lignite and Ilinois No. 6 bituminous, were used under combustion and gasification conditions at atmospheric pressure. Steady-state bed temperatures were in the range $800-950^{\circ} \mathrm{C}$. An extensive calibration yrocedure ensured that the mass spectrometer was capable of detecting sodium-containing vapor species at concentrations as low as $50 \mathrm{ppb}$.

In the temperature range $800^{\circ}$ to $950^{\circ} \mathrm{C}$, the concentrations of vapor phase sodium species ( $\mathrm{Na}, \mathrm{Na}_{2} \mathrm{O}, \mathrm{NaCl}$, and $\mathrm{Na}_{2} \mathrm{SO}_{4}$ ) are less than $0.05 \mathrm{ppm}$ under combustion conditions with excess air. However, under gasification conditions with Beulah Zap lignite, sodium vapor species are present at about $14 \mathrm{ppm}$ at a temperature of $820^{\circ} \mathrm{C}$. Of this amount, $\mathrm{NaCl}$ vapor constitutes about 5 ppm and the rest is very likely $\mathrm{NaOH}$. Sodium in the form of $\mathrm{NaCl}$ in coal enhances the vaporization of sodium species during combustion. Vapor phase concentration of both $\mathrm{NaCl}$ and $\mathrm{Na}_{2} \mathrm{SO}_{4}$ increased when $\mathrm{NaCl}$ was added to the Beulah Zap lignite.

Ash particles account for nearly $100 \%$ of the sodium in the coal during combustion in the investigated temperature range. The fine fly-ash particles $(<10 \mu \mathrm{m})$ are enriched in sodium, mainly in the form of sodium sulfate. The amount of sodium species in this ash fraction may be as high as $30 \mathrm{wt} \%$ of the total sodium. Sodium in the coarse ash particle phase retained in the bed is mainly in amorphous forms.

Thermodynamic equilibrium calculations predict concentrations of vapor phase sodium species higher than those observed by about an order of magnitude. However, these calculations neglect any role of ash particles as adsorbents for vapor species and make simplied assumptions to compensate for the unavailability of accurate thermodynamic data for ash constituents such as silicates and al!minosilicates that are potential sink for sodium species. A few sodium silicates and aluminosilicates were included, but this list is not exhaustive. Solutions of sodium in glassy phases were not included also. In view of these simplifications, the degree of agreement between measured and calculated values must be considered reasonable. 
The molecular-beam sampling mass spectrometer can be used as a tool to measure tracelevel alkali species from a high temperature reactor in which coal is gasified or burned under fluidized bed conditions. This technique provides unambiguous identification and measurement of important vapor species, including those containing sodium, without interference from entrained particles (fume). 


\title{
CONTENTS
}

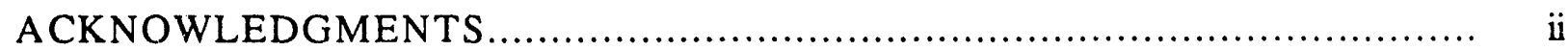

EXECUTIVE SUMMARY ................................................... iii

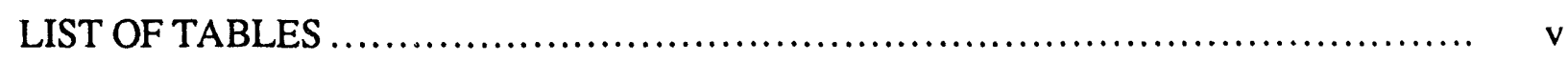

LIST OF ILLUSTRATIONS ................................................. vii

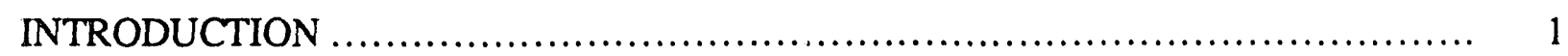

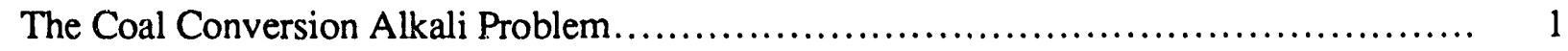

Approach to the Problem ........................................................ 3

Objectives ................................................................ 4

EXPERIMENTAL APPROACH................................................... 5

Fluidized Bed Reactor Design ................................................. 5

Design of High-Pressure Sampling Mass Spectrometer System ........................ 7

Experimental Procedure ..................................................... 13

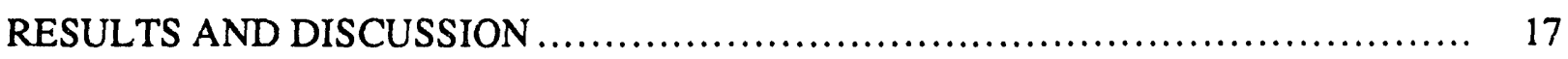

Calibration of the Mass Spectrometer System .................................... 17

Combustion Experiments..................................................... 28

Gasification Experiments.................................................... 44

THERMODYNAMIC EQUILIBRIUM CALCULATIONS .......................... 49

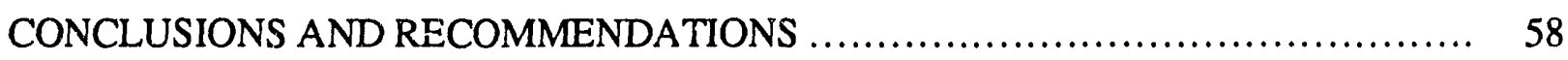

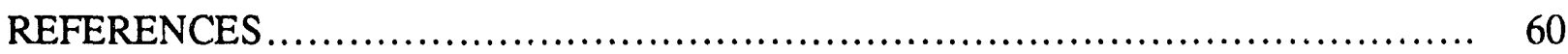

\begin{abstract}
APPENDIX A: LASER INDUCED FLUORESCENCE DETECTION STRATEGIES FOR SODIUM ATOMS AND COMPOUNDS IN HIGH PRESSURE COMUSTORS

APPENDIX B: DESIGN CALCULATIONS FOR THE MOLECULAR BEAM SAMPLING MASS SPECTROMETER
\end{abstract}




\section{LIST OF TABLES}

1. Analysis of the tested coals (as-received basis) .............................. 15

2. Comparison of measured and reported isotopic abundances of noble gases .......... 16

3. Observed mass spectrometer signal intensities during sampling of laboratory air under ambient conditions......................................................... 20

4. Observed mass spectrometer signal intensities during calibration using $\mathrm{NaCl}$ vapor.... 26

5. Vapor species monitored during combustion runs................................... 29

6. Typical signal intensities of sodium species observed during combustion of Beulah Zap lignite at $810^{\circ} \mathrm{C}$

7. Solid and vapor phase sodium species observed during combustion of Beulah Zap lignite at $890^{\circ} \mathrm{C}$ at an air/coal ratio of $7.7(\mathrm{~g} / \mathrm{g})$

8. Solid and vapor phase sodium species observed during combustion of Beulah Zap lignite at $810^{\circ} \mathrm{C}$ at an air/coal ratio of $12.3(\mathrm{~g} / \mathrm{g})$

9. Solid and vapor phase sodium species observed during combustion of Beulah Zap

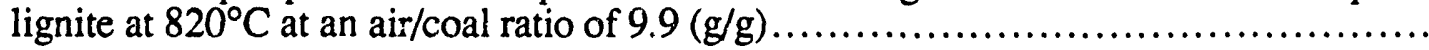

10. Solid and vapor phase sodium species observed during combustion of Beulah Zap lignite at $810^{\circ} \mathrm{C}$ at an air/coal ratio of $9.7(\mathrm{~g} / \mathrm{g})$

11. Solid and vapor phase sodium species observed during combustion of Beulah Zap lignite at $950^{\circ} \mathrm{C}$ at an air/coal ratio of $9.9(\mathrm{~g} / \mathrm{g})$

12. Solid and vapor phase sodium species observed during combustion of Illinois \#6 coal at $810^{\circ} \mathrm{C}$ at an air/coal ratio of $11.7(\mathrm{~g} / \mathrm{g})$

13. Signal intensities of gaseous sodium species observed during combustion of sodiumadded Beulah Zap lignite

14. Comparison of vapor phase sodium species during combustion of Beulah Zap lignite. 36

15. Distribution of elements in the ash particles during combustion of Beulah Zap lignite.. 38

16. Auger spectroscopic analysis of fly ash particle surfaces......................... 44

17. Typical signal intensities of sodium species observed during gasification of Beulah Zap lignite at $820^{\circ} \mathrm{C}$ 
18. Observed concentration of atomic sodium species during heating of Beulah Zap lignite

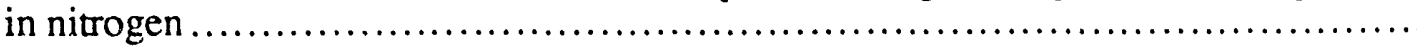

19. Equilibrium distribution of sodium species present at $800^{\circ} \mathrm{C}$ as a function of partial

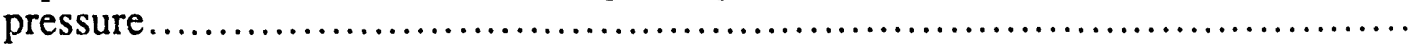

20. Equilibrium distribution of sodium species present at $1000^{\circ} \mathrm{C}$ as a function of partial pressure

21. Equilibrium distribution of sodium species present at $1200^{\circ} \mathrm{C}$ as a function of partial

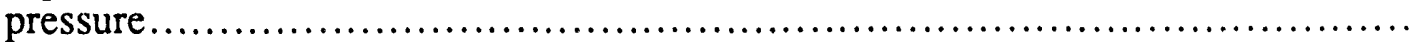




\section{LIST OF ILLUSTRATIONS}

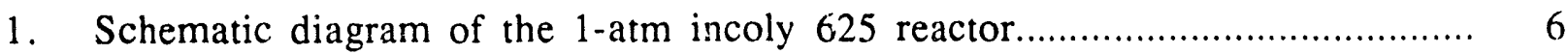

2. Schematic diagram of high-pressure sampling, molecular-beam mass spectrometer... 8

3. Vacuum circuit for molecular-beam sampling mass spectrometer $\ldots \ldots \ldots \ldots \ldots \ldots \ldots \ldots$

4. Schematic diagram of molecular-beam sampling mass spectrometer vacuum chamber. 12

5. Observed clustering of argon at 1 -atm inlet pressure $\ldots \ldots \ldots \ldots \ldots \ldots \ldots \ldots \ldots \ldots \ldots \ldots$

6. Variation of signal intensity as a function of concentration of noble gases ............ 19

7. Schematic diagram of the reactor used to measure vaporization of $\mathrm{NaCl}$ as a function

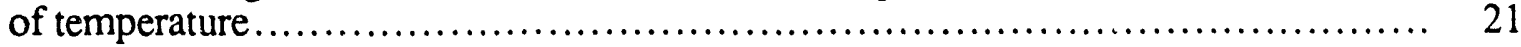

8. Equilibrium vapor pressure of sodium species as a function of temperature .......... 23

9. Effect of carrier gas flow rate on $\mathrm{Na}^{+}($from $\mathrm{NaCl}$ ) signal intensity $\ldots \ldots \ldots \ldots \ldots \ldots . \ldots . \ldots . \ldots$

10. Heat of vaporization of $\mathrm{NaCl}$ impregnated in a graphite felt bed......................... 25

11. The signal intensity as a function of equilibrium partial pressure of $\mathrm{NaCl}$ vapor ...... 27

12. X-ray diffraction spectrum of ash collected in the filter........................ 37

13. X-ray diffraction spectrum of ash deposited on the reactor interior walls ............ 39

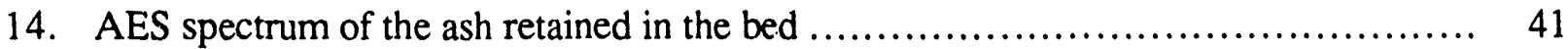

15. AES spectrum of the ash deposited on the reactor walls.......................... 42

16. AES spectrum of the ash collected in the ceramic filters .......................... 43

17. Evolution of vapor phase sodium species during gasification of Beulah Zap lignite ... 46

18. Equilibrium partial pressures of gaseous species as a function of $\mathrm{p}\left(\mathrm{O}_{2}\right)$ during at $800^{\circ} \mathrm{C}$ during conversion of Beulah Zap lignite .............................. 54

19. Equilibrium partial pressures of gaseous species as a function of $p\left(\mathrm{O}_{2}\right)$ during at $1000^{\circ} \mathrm{C}$ during conversion of Beulah Zap lignite.................................. 55

20. Equilibrium partial pressures of gaseous species as a function of $p\left(\mathrm{O}_{2}\right)$ during at $1200^{\circ} \mathrm{C}$ during conversion of Beulah Zap lignite. 


\section{INTRODUCTION}

\section{THE COAL CONVERSION ALKALI PROBLEM}

Both inorganic and organometallic impurities in coal are converted to corrosive species in the environment of high-temperature, high-pressure gasification and combustion reactors. Experience with coal-fired power plants has indicated that alkali metal, sulfur, and chlroine species are the most aggressive constituents in hot corrosion (Hastie et al., 1981). For example, alkali metal sulfates will condense on exposed surfaces at temperatures below about $900^{\circ} \mathrm{C}$ to form a coating that captures fly-ash particles and leads to fouling and erosion. Although this fouling and erosion process can be mitigated by using particulate control devices such as cyclones and ceramic filters, vapors and submicron particles (fume) penetrate filters and remain a potentially severe hot corrosion problem.

In addition to alkali sulfates, alkali chlorides and hydroxides have been known to cause corrosion (Robson and Blecher, 1980). Depending on the temperature, these alkali metal compounds may exist as solids or liquid aerosols or in the vapor state. Whatever their precise composition or form, they are an extremely corrosive component in the high temperature fluid, so much so that the total alkali species concentration in coal gas to be used to drive turbines in combined-cycle power generating systems must not exceed $70 \mathrm{ppb}$ per $150 \mathrm{Btu} / \mathrm{scf}$ (Robson and Blecher, 1980). Because of the great current and long-term interest in the use and development of such systems, the elimination of these corrosive substances is highly desirable .

Proposed methods of controlling corrosive alkali species depend on their chemical and physical states in the hot coal gas. Conditions in gasifiers and combustors can vary over broad limits. Temperature, pressure, and fluid dynamic forces are severe in the complex chemical environment of these reactors. Hence, the mechanisms by which alkali species are released, transported, and deposited are not known; indeed, all the species that might be involved have not been identified (Hastie et al., 1981).

Theoretical and experimental studies have been reported in the literature concerning the fate of alkali species in coal combustion conditions. Data from operational gasifiers and combustors are summarized in several reviews (Alvin et al., 1989; Sondreal et al., 1985). They indicate that the alkali concentrations range from several parts-per-billion (ppb) to nearly $150 \mathrm{ppm}$. No reliable 
correlations have been developed between the release of alkali and the operational parameters such as temperatures, coal feed type, and pressure. Generally, the measured alkali levels were lower than those calculated from equilbrium thermodynamic data.

The distribution of sodium in fly ash particles has been the subject of several investigations. To elucidate the vaporization and condensation of sodium, Neville and Sarofim (1985) measured the distribution of sodium in different sizes of fly ash produced during combustion of Montana lignite. This study showed that the fraction of sodium condensing on the submicron fume was influenced both by the amount of total ash vaporized during combustion and by the Kelvin effect. The Kelvin effect leads to a higher or lower than normal vapor pressure for a condensate on a curved surface depending on whether the surface is convex or concave. Thus, condensation is inhibited or vaporization is enhanced on fine particle surfaces. The mass fraction of sodium found on the ash showed a particle size dependence; the results were explained by a diffusion control mechanism for the heterogeneous condensation of sodium vapor on the fume particles. Gallagher et al. (1990) studied the capture of alkali species by the ash particles during combustion of six different coals and showed that sodium is enriched in the small particle size range. The fraction of sodium, $\mathrm{N}$, appearing on particles with diameter, $\mathrm{d}$, in the range 0.5 to 10 $\mu \mathrm{m}$ increased as the size of the particles decreased $\left(\mathrm{N} \approx 1 / \mathrm{d}^{2}\right)$. Hodges and Richards (1989) investigated the fate of sodium, chlorine, sulfur, and other elements in a laboratory-scale fluidized bed combustor and showed that chlorine plays a major role in sodium vaporization; an increase of $25 \%$ in the chlorine content of the coal resulted in a four-fold increase in the vaporization of sodium species.

Direct measurements of vapor phase alkali have been attempted. Lee and Carls (1989) measured the vapor phase alkali in a pressurized fluidized bed combustor by contacting the effluent with a bed of activated alumina after the flue gas had passed through a cyclone and a SiC candle filter. The vapor phase sodium is retained by reaction or absorption in the sorbent bed. With this technique, they estimated the average sodium vapor phase concentration produced by combustion of Beulah lignite to be about 1.4 ppmw.

Westinghouse researchers used a sampling probe inserted directly into the gasifier product gas suream (Westinghouse, 1983). The probe had a ceramic filter in the tip to remove particles, and the vapor phase alkali was collected downstream in a cold packed-bed condenser. Measurements with this technique indicated vapor phase alkali concentrations in the range 0.3 to $16 \mathrm{ppm}$.

An in-situ monitor that measured sodium vapor concentrations on the basis of the intensity of the Na D-line emission was fabricated and tested at the U.S. Department of Energy Morgantown 
Energy Technology Center (FOAM) and at the Ames National Laboratory (AMES monitor). These instruments have been used to measure alkali levels in pilot-scale combustors and gasifiers (Haas et al., 1986; Hansel et al., 1987) but extraction of reliable samples from the hot gas stream has been a problem.

The molecular-beam sampling mass spectrometric technique has been applied to measure vapor phase alkali species in laboratory-based combustion systems. Greene et al. (1979) measured both vapor phase sodium and potassium species in a laboratory burner and found that the intensity of the $\mathrm{Na}^{+}$signal decreased approximately exponentially as the distance from the burner to the mass spectrometer inlet increased. However, a small increase in $\mathrm{NaOH}^{+}$was observed at about 4 $\mathrm{mm}$ from the burner. Greene et al. $(1986,1987,1988)$ also used the mass spectrometric technique to investigate the release of vapor-phase sodium species from a single burning particle of coal. This study provided only limited information on the fate of sodium species during coal combustion, and it did not elucidate the role of particles in the capture of vapor phase sodium.

These cited studies provide only fragmentary information on the formation and disposition of sodium species during coal combustion or gasification, but they do demonstrate the formidable problems of sampling and analyzing high temperature gaseous species in a particle-laden gas stream.

\section{APPROACH TO THE PROBLEM}

An effective systematic study of the alkali problem requires accurate experimental measurements of the composition and concentration of alkali species in the vaprr and condensed phases present in gasifier and combustor effluents. To provide a realistic source of such effluents, a bench-scale fluidized bed reactor was constructed that could simulate conditions representative of various sections of an operating combustor or gasifier. Simplicity and flexibility were the key design elements, sô inat the cost of fabrication and operation could be kept low. Parameters of interest included type of coal, temperature, pressure, feedgas composition, and residence time.

However, the scope of an effective experimental program is limited by the time and expense of making measurements under difficult and demanding process conditions. Therefore, modeling is also neeled to predict alkali behavior under conditions that cannot be examined experimentally and to aid in developing strategies for keeping deleterious alkali species from reaching turbine components. 
A variety of analytical techniques were considered to determine the composition and concentration of sodium-containing species under the high-temperature conditions prevailing within the reactor. Optical spectroscopic diagnostics are attractive for studies of high temperature gases because they require no physical sampling, and exploratory studies were conducted with laser-based optical techniques (Appendix A). However, among currently available analytical techniques, mass spectrometry was the only proved method that could identify the molecular states of inorganic species in a high temperature environment. Consequently, that technique was chosen as the analytical centerpoint of the experimental study. Ash samples were collected from different parts of the fluidized bed reactor system and subsequently analyzed for their sodium content to complement the mass spectrometric measurements of vapor phase alkali.

\section{OBJECTIVES}

The overall objective of this research program was to understand the formation and nature of the alkali species produced in PFB gasifiers and combustors that are corrosive to turbines and other components in combined cycle power generation facilities. The specific objectives were to identify the nature, distribution, and concentrations of these corrosive alkali species, particularly vapor phase sodium species. 


\section{EXPERIMENTAL APPROACH}

\section{FLUIDIZED BED REACTOR DESIGN}

A bench-scale reactor was designed to simulate the chemical conditions representative of larger units. The design permitted measurements of the nature and concentration of sodium species as a function of temperature, pressure, air/coal ratio, residence time, and other relevant parameters. Two reactors were fabricated. For atmospheric pressure experiments at temperatures up to $1050^{\circ} \mathrm{C}$, a metal reactor $(5-\mathrm{cm} \mathrm{ID}, 200 \mathrm{~cm}$ long) was made from Inconel alloy 625 tubing (Figure 1). This alloy has excellent oxidation resistance at high temperature; weight changes of less than 1 $\mathrm{mg} / \mathrm{cm}^{2}$ have been reported during thermal cycling in air at temperatures up to $980^{\circ} \mathrm{C}$ over a period of $1000 \mathrm{~h}$. It also has adequate creep rupture properties at $1000^{\circ} \mathrm{C}$ for atmospheric pressure operation. Other high temperature alloys such as Inconel alloy 750 have a higher oxidation resistance than Inconel alloy 625 , but they were not available in the tubular form. Ceramics such as alumina and silica were not chosen because of their possible interaction with the sodium species. For high pressure experiments (up to $300 \mathrm{psi}$ ), a carbon steel pressure vessel of $30 \mathrm{~cm} \mathrm{ID} \mathrm{and} 200$ $\mathrm{cm}$ length was constructed as a containment shell for Inconel alloy 625 reactor liners.

Coal in the size range of 0.2 to $1.4 \mathrm{~mm}$ was fed into the reactor through an inclined port just above the distributor plate. The coal was metered from a storage hopper using a $2.5-\mathrm{cm}$ diameter screw feeder that had a range of 5 to $50 \mathrm{~g} / \mathrm{min}$. If required, an increased coal feed rate could have been obtained by changing the pitch of the metering screw. A small flow of inert gas such as nitrogen was maintained through the feeder to prevent heating and possible caking of the coal in the feed port. Air for combustion or air/steam mixture for gasification was preheated to about $450^{\circ} \mathrm{C}$ in the bottom section of the reactor and entered the reactor through a stainless steel frit distributor plate. Ash that accumulated in the bottom of the bed could be periodically withdrawn through another port. The reactor shell was surrounded by electrical resistance heaters to achieve the desired temperature profile along the reactor length. Ceramic blanket insulation (Manville Cerablanket) was used to minimize the heat losses. The temperature was measured by using chromel-aiumel thermocouples located at about 25 -cm intervals. Radial temperature differences were typically within $\pm 5^{\circ} \mathrm{C}$, while the axial temperature was constant to $\pm 25^{\circ} \mathrm{C}$. Product gases and entrained fly ash left the reactor through a port near the top and passed sequentially through an 8-cm-diameter cyclone, which removed coarse particles $(>5 \mu \mathrm{m})$, and a ceramic fiber filter, which 


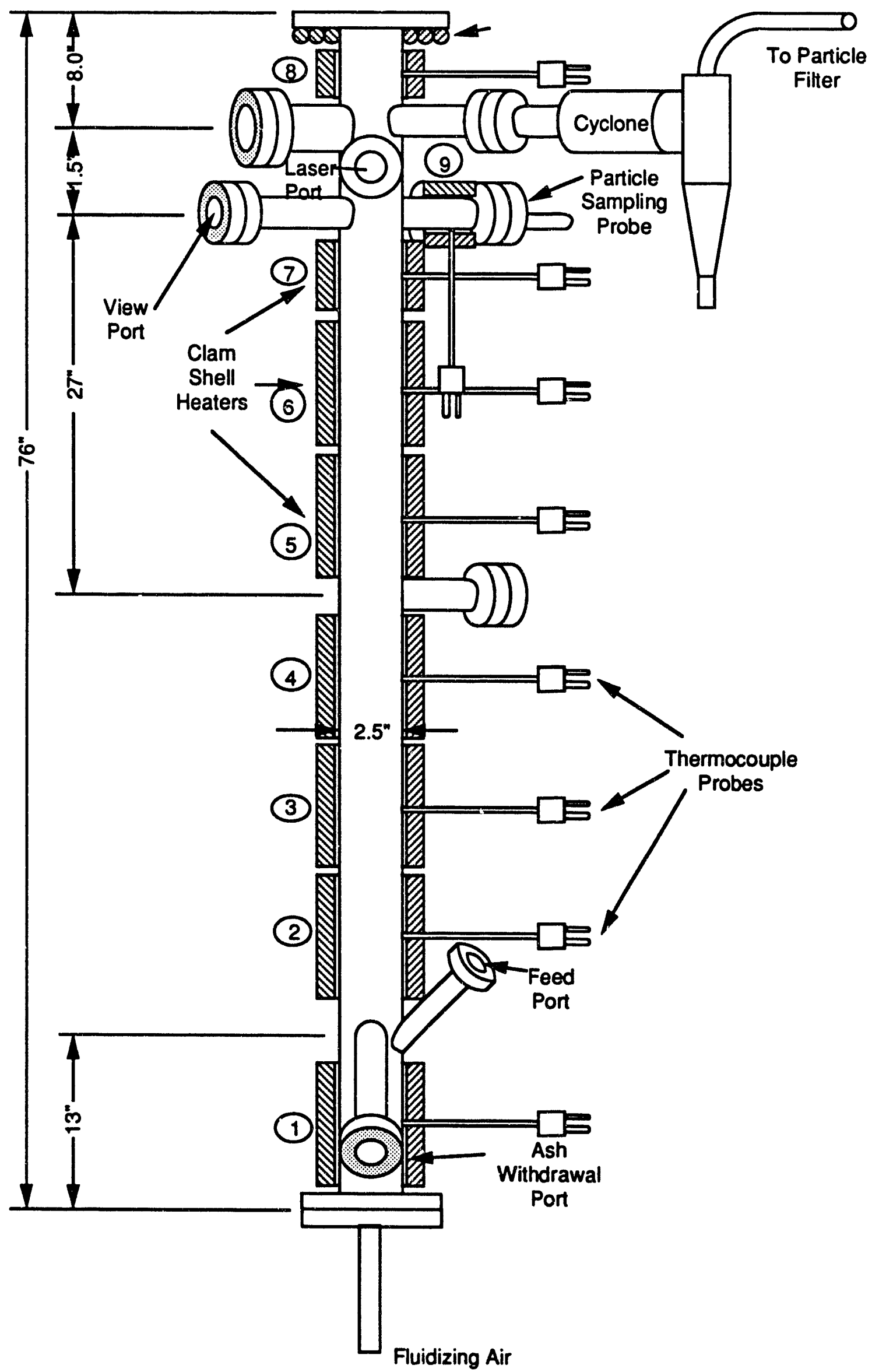

RAM-4352-3

Figure 1. Schematic diagram of the 1-atm incoloy 625 reactor. 
collected the finer particles. Both the cyclone and the filter were insulated to prevent condensation of steam. Another port at the top of the reactor accommodated the inlet orifice, through which a portion of the reactor effluent was sampled into a molecular-beam mass spectrometer.

\section{HIGH-PRESSURE SAMPLING MASS SPECTROMETER SYSTEM}

Molecular-beam sampling mass spectrometry was chosen as the primary method of determining alkali vapor levels because of its ability to "freeze" the chemical state of the high temperature vapor. This technique has been used to stıdy high temperature reacting systems over the past 25 years; there have been several efforts to characterize aspects of coal and natural gas combustion processes. Stearns et al. $(1977,1978,1979)$ have reported extensive studies of alkaliand sulfu:-seeded flames. Hastie et al. (1981) have characterized transpiration of $\mathrm{NaCl}$ and formation of $\mathrm{Na}_{2} \mathrm{SO}_{4}$ in $\mathrm{NaCl}-\mathrm{SO}_{2}-\mathrm{O}_{2}$ systems and Milne and Beachey (1977) studied alkaliseeded $\mathrm{CH}_{4}$ /air flames. More recently, Greene et al. $(1986,1987)$ has addressed alkali vaporization from individual coal particles exposed to air at high temperatures. Thus, the usefulness of this technique for identifying high temperature gaseous species has been demonstrated.

In the molecular-beam mass spectrometric technique, gases from the reactor are sampled as a supersonic jet through a small orifice, into a vacuum chamber, with rapid transition from viscous to molecular flow (Figure 2) accompanying the formation of a supersonic free jet. Along the centerline of the jet, all the gas molecules are moving in nearly the same direction and at nearly identical velocities; that is, they form a molecular beam. A conical, thin-edge orifice (skimmer) placed inside the mach disk (an imaginary plane where the gas velocity reaches the velocity of sound) admits only the center region of the beam into a second chamber, in which the pressure is kept sufficiently low to drastically reduce collisions between molecules in the beam and those in the background gas. This selected molecular beam emerging from the skimmer passes through a collimating aperture into the third chamber, where it is ionized and mass analyzed to yield the chemical identity and quantity of the beam's constituents. To minimize changes in the chemical composition of the beam between the sampling orifice and the mass spectrometer, the pressures in the various stages must be maintained as low as possible.

A compact three-stage vacuum chamber that can be mounted on top of the fluidized bed reactor was designed and fabricated (Figure 3). The design is a modification of a system in operation at the Solar Energy Research Institute (Soltys and Milne, 1982). Appendix B details the calculations involved in the system design. The gases from the reactor are sampled through a small 


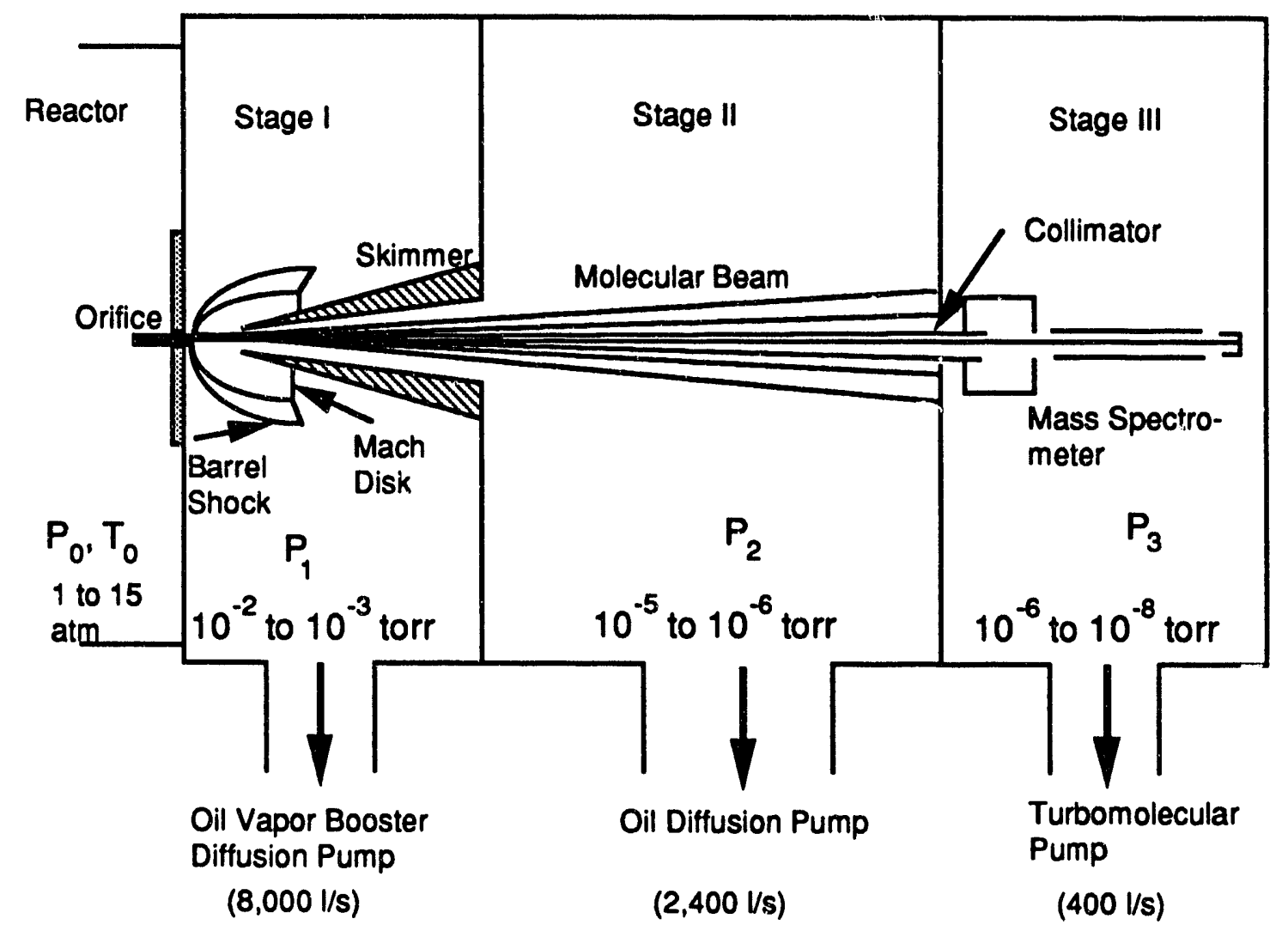

RAM-4352-4

Figure 2. Schematic diagram of high-pressure sampling, molecular-beam mass spectrometer. 


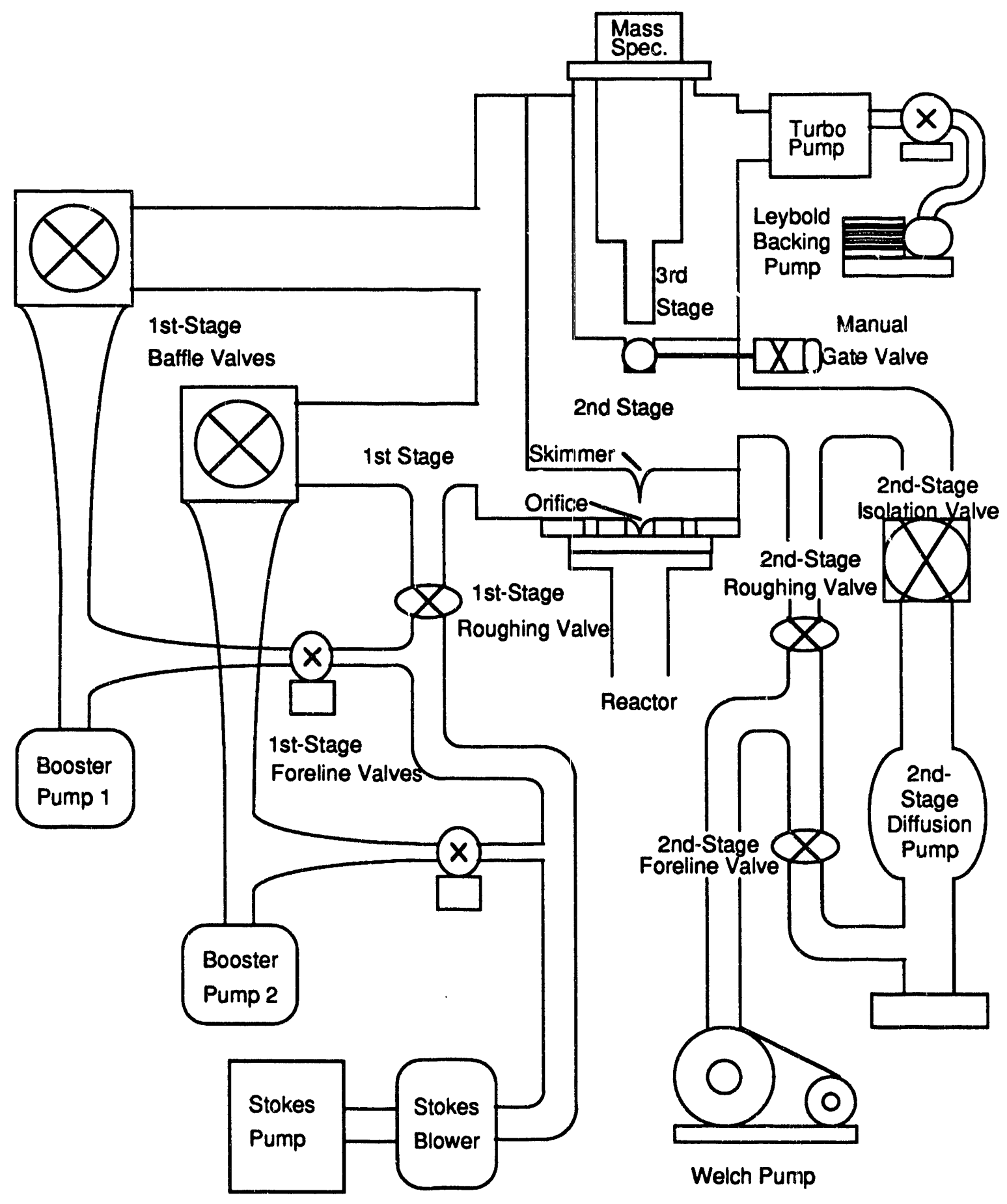

RAM-4352-5

Figure 3. Vacuum circuit for molecular-beam sampling mass spectrometer. 
orifice into a cylindrical first-stage chamber that is pumped by two oil vapor booster diffusion pumps with a total pumping speed of 4,000 $\mathrm{l} / \mathrm{s}$. The diffusion pumps were backed by a single 300 cfm mechanical pump. Backdiffusion of oil vapors from the pump into the vacuum chamber was minimized by using water-cooled baffles. The second stage was pumped by an oil vapor diffusion pump (2500-1/s pumping speed), and a liquid nitrogen trap was used to minimize back diffusion of oil vapor. The third stage was pumped by a $400-1 / \mathrm{s}$ turbomolecular pump backed by a double stage $15 \mathrm{cfm}$ mechanical pump. A molecular sieve trap in the foreline prevented oil vapor back diffusion. When the system was not in use, an ultrahigh vacuum gate valve situated between the second and third stages kept the mass spectrometer chamber in a clean, high vacuum environment.

A stainless steel cone with a $0.5 \mathrm{~mm}$ hole in its apex was used as the sampling orifice. The cone $(\sim 1 \mathrm{~cm}$ high), welded to a stainless steel backing plate, was not cooled externally. Hence, the orifice was maintained at a high temperature so that the gas stream entering the mass spectrometer would not cool significantly until adiabatic expansion occurred. The relatively large orifice was needed to minimize the possibility of plugging by the fly ash particles. A tungsten-wire stylet was positioned inside the orifice cone by means of a tubular support structure. The wire passed through an o-ring gland so that, from outside the vacuum chamber, the stylet could be manually advanced and retracted through the orifice. This procedure was used periodically during the experimental runs to clear the orifice of any accumulated particles.

The skimmer (purchased from Beam Dynamics Inc., Minneapolis, MN) was made of electroformed nickel and had a conical shape with an extremely thin, sharp 1.4-mm-diameter circular opening at the apex. The distance between the skimmer and the orifice was varied by using stainless steel ring spacers. The optimum separation distance $(3.0 \mathrm{~cm})$ was determined experimentally by maximizing the mass spectrometer signal as a function of position. A copper disk with an orifice $3.2 \mathrm{~mm}$ in diameter situated between the second and third stages was used as the collimator. The pressure in the first-stage chamber was measured by using a Pirani-type vacuum gauge (Granville Phillips Convectron). The vacuum levels in the second and third stages were measured by using a cold cathode discharge ionization and hot filament ionization gauges, respectively.

The distance between the first-stage orifice and the mass spectrometer ionization region is only $24 \mathrm{~cm}$, a relatively low value that ensured an intense beam of sampled gas in the ionization chamber of the mass spectrometer. The vacuum chamber design allowed operation of the mass spectrometer at the same distance from the orifice both in axial and cross-beam ionization modes. The axial mode, which has a higher sensitivity than the cross-beam mode, was used in this study 
because interference from particles that might have been present in the molecular beam was not severe.

An Extranuclear Laboratories (now called Extrel Corporation) mass spectrometer system was used to measure the gaseous cornposition in the molecular beam entering the third chamber. The system consisted of Model 162-S quadrupole mass filter with $9.5 \mathrm{~mm}$ rods, Model 041-1 axial electron impact ionizer, and Model 051-5 electron multiplier consisting of 21 stages of $\mathrm{Cu}-\mathrm{Be}$ dynodes. The atomic mass unit (amu) range of the system is from 2 to 800 and the mass filter was connected to the Model 011-1 power supply through a "high-Q head" to obtain maximum RF (radio-frequency) potential to the mass filter. The electron multiplier was operated in the analog mode at a voltage of $2.5 \mathrm{kV}$ to yield a gain of about $5 \times 10^{6}$. The signal from the electron multiplier was measured using an electrometer and recorded on a chart recorder. The emission current in the ionizer was set at $2.5 \mathrm{~mA}$ and the ion energy was nominally set at $30 \mathrm{eV}$. Ion energies as iow as $10 \mathrm{eV}$ were also used in some cases to discriminate between different gaseous species such as sodium hydroxide and argon. As expected, the signal intensity of the mass spectrometer was reduced significantly at the lower ion energy.

Both the 1-atm reactor and the 15-atm pressure containment vessel can be attached to the bottom flange of the mass spectrometer chamber (Figure 4). With the first stage sampling orifice opened to ambient atmosphere, the pressures in the first, second, and third stages were $1.2 \times 10^{-2}$, $6 \times 10^{-5}$, and $6 \times 10^{-7}$ torr, respectively. The flow of gas from the reactor into the mass spectrometer chamber under ambient conditions was measured at about $2000 \mathrm{~cm}^{3} \cdot \mathrm{min}^{-1}$. During coal gasification and combustion runs at atmospheric pressures, the pressures in the various stages remained nearly the same. Under both static and dynamic sampling conditions, the observed pressures in the various stages were in acceptable ranges and in agreement with calculated values within a factor of 2 . Optimal alignment of the orifice, skimmer, and collimator produced a strong signal from the mass spectrometer, indicating a well-defined molecular beam. A radial displacement of the orifice $3 \mathrm{~mm}$ from its aligned position caused the signal intensity to decrease by a factor of 100 .

A motor-driven chopper was incorporated between the second and third stages to allow pulsing of the molecular beam and phase-sensitive detection of the corresponding signal. But static measurement provided sufficient sensitivity so that this signal/noise enhancement was not used. However, the chopper was used to block the molecular beam so that background signal levels could be determined. Typically, when the beam was blocked the signal level decreased to about $1 \%$ of the open position value. 


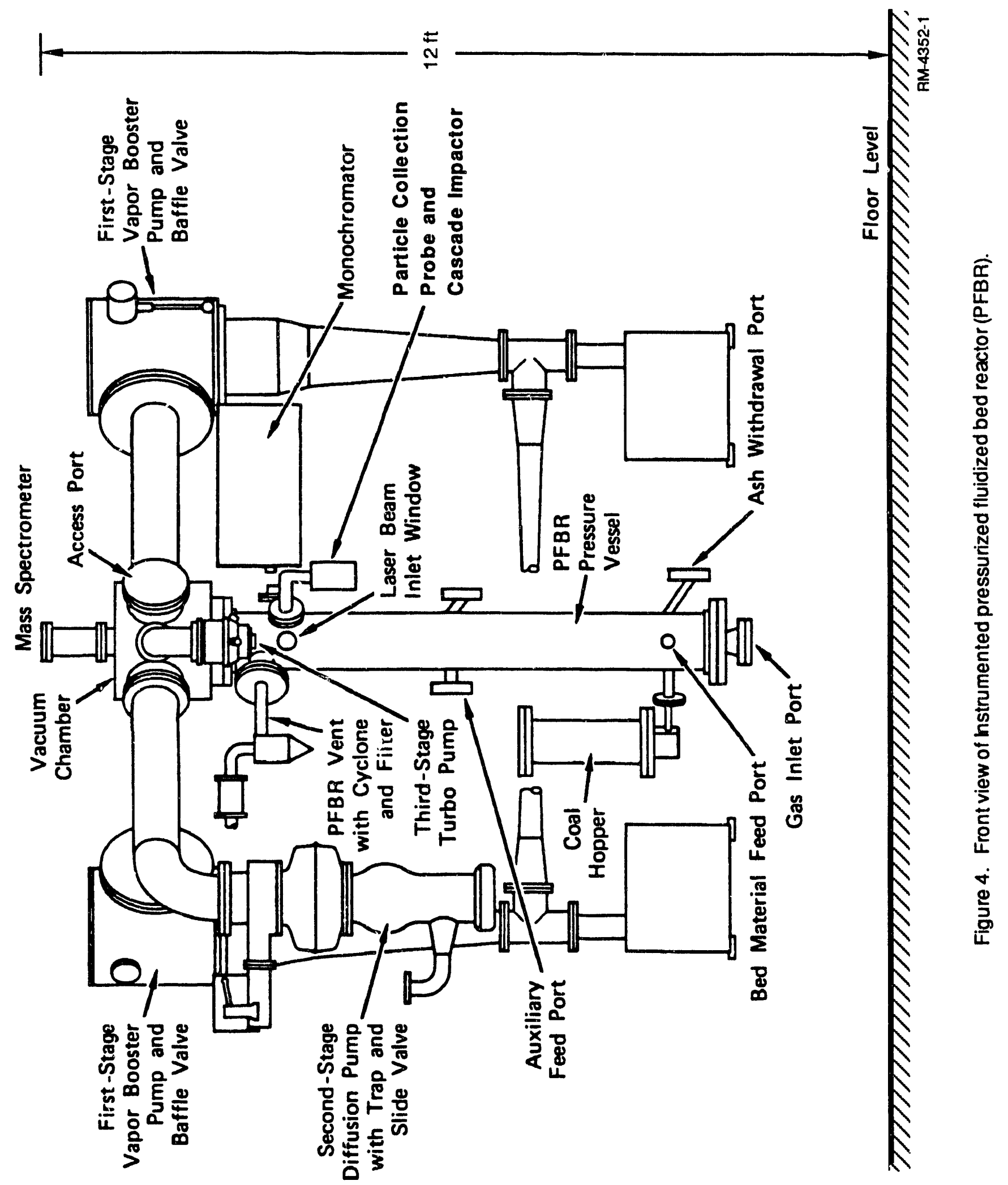




\section{EXPERIMENTAL PROCEDURE}

Two coals, Beulah Zap lignite and Illinois \#6 subbituminous (Crown II composite), were used in coal combustion and gasification studies (Table 1). The Beulah lignite is high in sodium, but low in potassium, chlorine, and sulfur. More than $90 \%$ of the sodium in Beulah lignite is organically bound in the coal matrix (Benson and Holm, 1985). The Illinois \#6 coal has a sodium content lower than that of Beulah lignite but contains more sulfur and chlorine.

Several fluidized-bed combustion experiments were conducted at $1 \mathrm{~atm}$ pressure and at various temperatures ranging from $8 \mathrm{C}^{\circ}$ to $1000^{\circ} \mathrm{C}$. At temperatures higher than $1000^{\circ} \mathrm{C}$, the oxidation rate of the Incoloy became rapid enough to damage the reactor within a few hours. The as-received coal was crushed and sieved to obtain particles in the size range of 0.7 to $1.4 \mathrm{~mm}$. The coal was fed into the reactor through a side port by using the screw feeder, typically at a rate of about $5.5 \mathrm{~g} / \mathrm{min}$. A flow of dry nitrogen was maintained in the feed port to prevent heating of the coal until it reached the fluidized bed. The fluidizing air was preheated to about $500^{\circ} \mathrm{C}$ and introduced into the reactor through a stainless steel frit distributor. The air/coal ratio used ranged from 7.7 to $12.2 \mathrm{~g} / \mathrm{g}$, corresponding to 20 to $90 \%$ excess of stoichiometric combustion. The calculated gas residence time in the reactor was in the range of 1.7 to $2.7 \mathrm{~s}$, depending on the flow rate of air and the reactor temperature.

For gasification experiments, a coal particle size in the range of 0.2 to $0.7 \mathrm{~mm}$ was used. The fluidizing gas consisted of both steam and air. Steam was introduced by using a calibrated positive displacement pump to inject liquid water at a known rate into the preheating section of the reactor. The air/coal and steam/coal ratios were 4.4 and $0.8 \mathrm{~g} / \mathrm{g}$, respectively. These values are similar to those used in the KRW fluidized bed gasifier (Haldipur et al., 1989). The temperature of the gasification run with Beulah Zap lignite was $820^{\circ} \mathrm{C}$, and the calculated gas residence time was $3.7 \mathrm{~s}$.

The mass resolution and the sensitivity of a quadrupole mass spectrometer is influenced by the RF and DC voltage applied to the quadrupole rods. Although the instrument can be operated in constant resolution $(\mathrm{m} / \Delta \mathrm{m}=$ constant) or constant $\Delta \mathrm{m}$ mode, it was operated somewhat in between the two extremes to avoid gross changes in sensitivity with the mass. The mass spectrometer control parameters were optimized using the argon $(a m u=40)$ signal, but at the same time ensuring that a near unit mass resolution was achieved at an amu of 132. These parameters were held constant during subsequent experimental runs. The measured ratio of several noble gas 
isotopes agreed well with the published values (Table 2) indicating that the peak resolution in the range of interest 10 to $150 \mathrm{amu}$ is adequate.

Because the alkali species were present in trace level quantities, and gases such as ritrogen, oxygen, carbon dioxide, and steam were present at percentage levels, an automated scanning of the mass spectrum was not practical. Hence, the mass spectrum was scanned manually at peaks of interest. Both signals at the top of a peak and at the bottom (usually at about $0.5 \mathrm{amu}$ from the top of the peak) were recorded. This procedure allowed us to determine the true peak height at the amu of interest even when there were changes in the background level. 
Table 1

ANALYSIS OF THE TESTED COALS (AS-RECEIVED BASIS)

Proximate analysis (wt\%)
Moisture
Volatile matter
Fixed carbon
Ash
Ultimate Analysis
Hydrogen
Carbon
Nitrogen
Chlorine
Sulfur
Oxygen
Ash
Moisture
the ash
Silica
Aluminum oxide
Ferric oxide
Titanium dioxide
Phosphorous pentoxide
Calcium oxide
Magnesium oxide
Sodium oxide
Potassium oxide
Sulfur trioxide

Beulah Zap Lianite llinois \#6 Coal

33.8

16.2

27.5

32.0

5.0

36.0

39.5

8.4

ysis

Hydrogen

5.95

4.25

49.35

0.58

58.87

$<0.01$

1.06

37.75

5.0

1.06

0.10

3.21

7.99

8.35

a

16.17

a Included in the elemental analysis.

17.80

9.90

9.30

0.71

1.40

19.80

6.10

8.50

0.10

25.5
49.11

17.82

19.99

0.96

0.24

3.86

0.90

1.56

2.09

3.10 


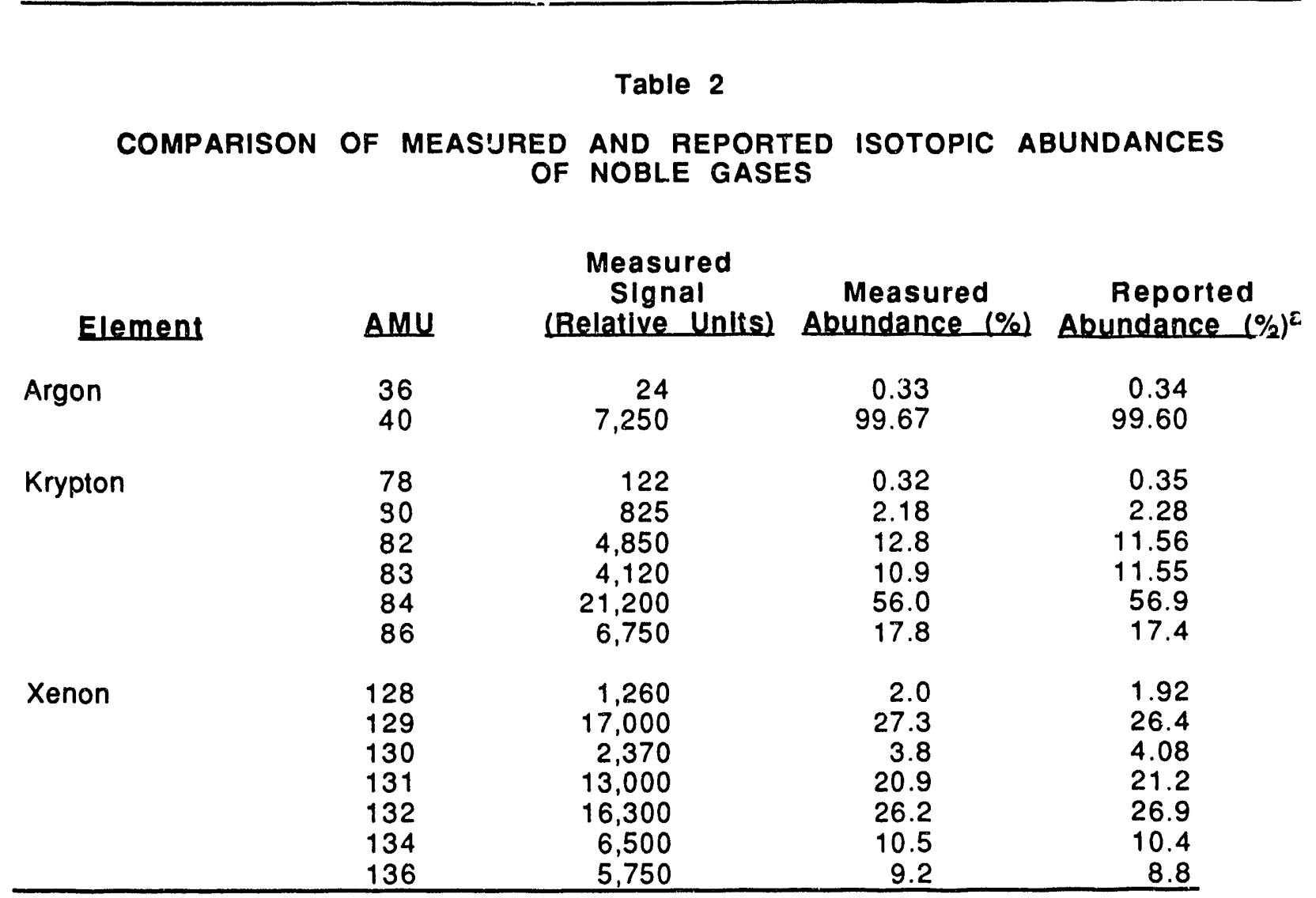

a CRC Handbook of Chemistry and Physics, 53rd ed. 


\section{RESULTS AND DISCUSSION}

\section{CALIBRATION OF THE MASS SPECTROMETER}

The sensitivity of the mass spectrometer system to trace level species of interest was demonstrated in several experiments. In the first, ambient air was sampled to detect and measure the concentrations of the normal major and minor constituents. As shown in Table 3, the lower atornic weight components ( $\mathrm{He}$ and $\mathrm{Ne}$ ) were observed, at their nominal fractional concentrations, as low as $5 \mathrm{ppm}$. The observed concentrations of molecules heavier than nitrogen were found to be augumented over their nominal levels. Such augumentation is characteristic of molecular-beam sampling because of the preferential drift of lighter species to the beam edge owing to their higher random thermal velocities. This effect depends not only on the orifice geometry and the distance between the orifice and the mass spectrometer but also on the mass and the heat capacity ratios of the sampled molecules (Sharma, Knuth, and Young, 1976).

In another experiment, molecular cluster formation during argon sampling was observed. The gas stream passing through the orifice supersonically expands and because of this rapid adiabatic expansion, the gas temperature decreases rapidly, leading to formation of clusters of gas molecules. A sensitive means of evaluating the molecular beam performance (e.g., absence of shock fronts, unobstructed orifices, lack of species interacticn in the beam, degree of collimation) is the measurement of argon clusters formed when pure argon is sampled at atmospheric pressure. Figure 5 illustrates the observed signal ratio of argon clusters up to $\mathrm{Ar}_{6}$. The signal intensities of argon clusters observed in our instrument is equal to or higher than those reported by Soltys and Milne (1982) using an instrument of similar design at the Solar Energy Research Institute.

In a third experiment, a custom-blended noble gas mixture containing $100 \mathrm{ppm}$ each of $\mathrm{Ne}$, $\mathrm{Ar}, \mathrm{Kr}$, and $\mathrm{Xe}$, with the balance $\mathrm{He}$, was used to sheck the sensitivity of the mass spectrometer. Calibrated mass flow controllers were used to blend this noble gas mivture with nitrogen to obtain concentrations of noble gases in the range of 50 to $1500 \mathrm{ppb}$. Signals from $\mathrm{Kr}^{84}$ and $\mathrm{Xe}^{129}$ were measured in subparts-per-billion concentration levels (Figure 6). At a Xe ${ }^{129}$ concentration of 26 $\mathrm{ppb}$, the signal was observed to be an order of magnitude higher than the noise level. 


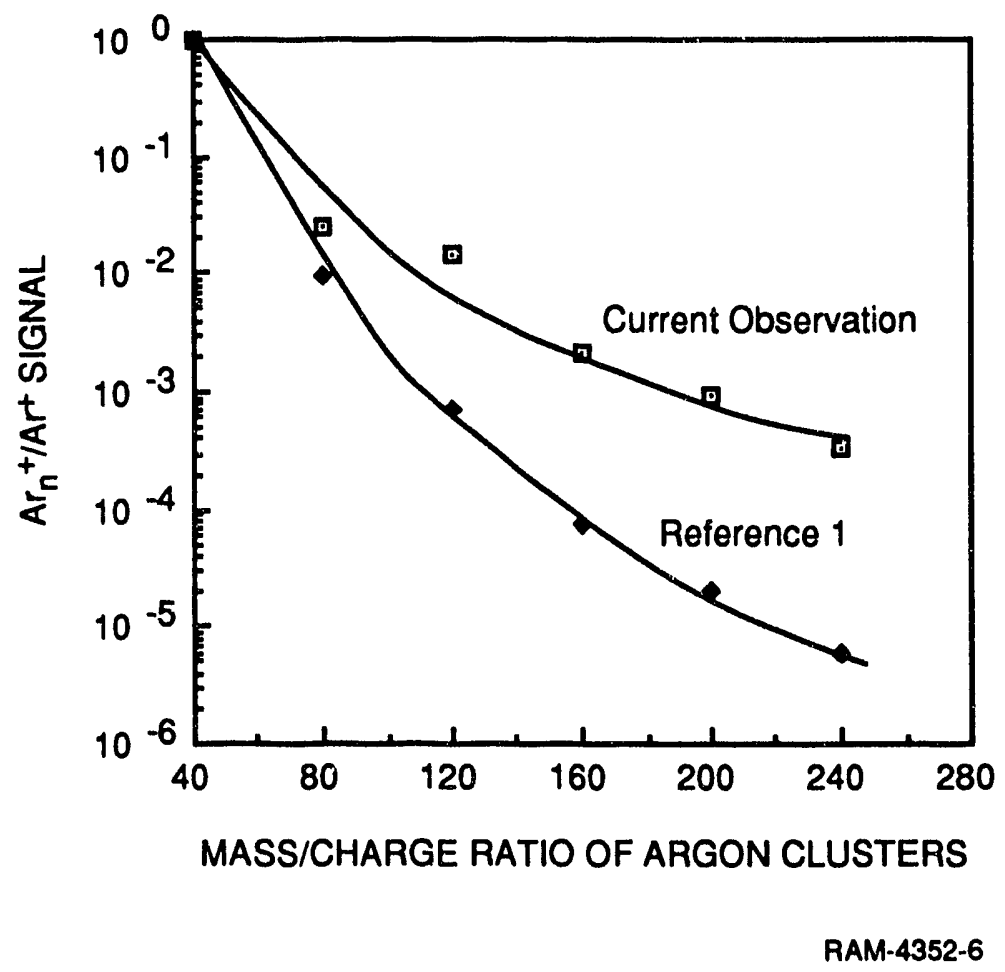

Figure 5. Observed clustering of argon at 1-atm inlet pressure. 


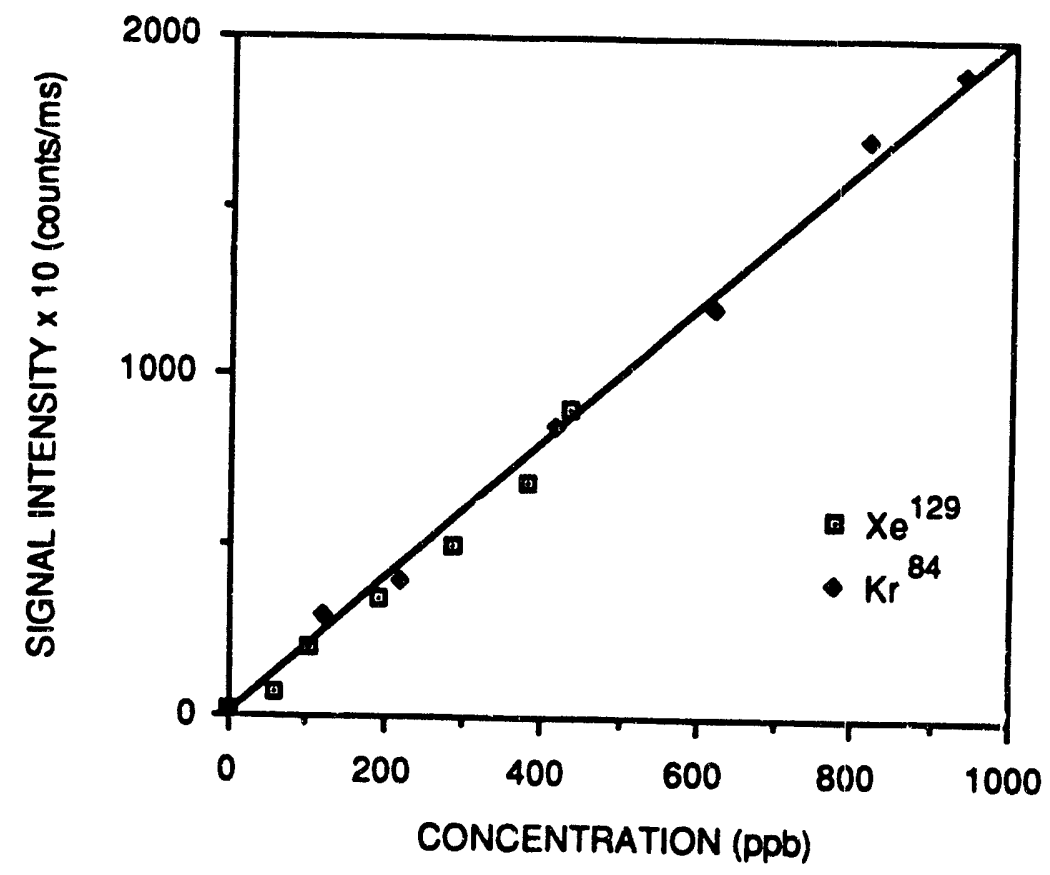

RAM-4352-7

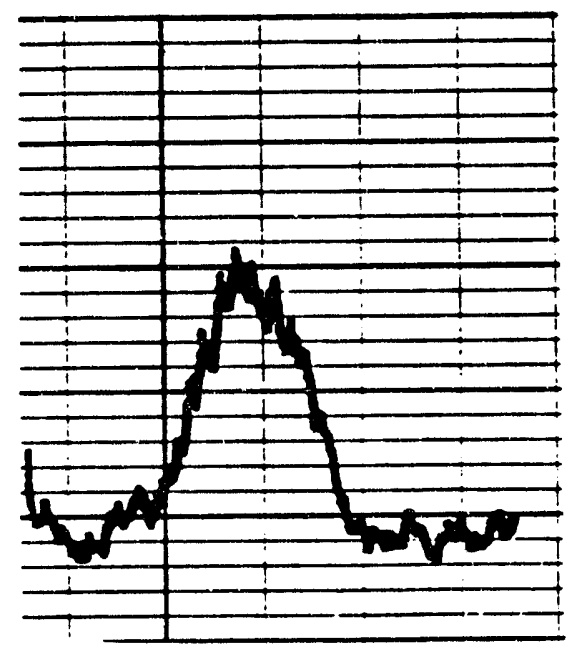

Figure 6. Variation of signal intensity as a function of concentration of noble gases. Recorder trace of $\mathrm{Xe}^{129}$ ion signal at $26 \mathrm{ppb}$ is also shown. 
Table 3

OBSERVED MASS SPECTROMETER SIGNAL INTENSITIES DURING SAMPLING OF LABORATORY AIR UNDER AMBIENT CONDITIONS

\begin{tabular}{ccrrr} 
Specles & Mass & $\begin{array}{c}\text { Nominal } \\
\text { Concentrationa }\end{array}$ & $\begin{array}{c}\text { Signal Intensity } \\
\text { (Belative Units) }\end{array}$ & $\begin{array}{c}\text { Observed } \\
\text { Concentrationc }\end{array}$ \\
$\mathrm{He}$ & 4 & $5.2 \times 10^{-6}$ & 5 & $5.0 \times 10^{-6}$ \\
$\mathrm{Ne}$ & 20 & $18.2 \times 10^{-6}$ & 26 & $26.3 \times 10^{-6}$ \\
$\mathrm{~N} 2$ & 28 & 0.78 & 780,000 & 0.78 \\
$\mathrm{O}_{2}$ & 32 & 0.209 & 210,000 & 0.21 \\
$\mathrm{Ar}$ & 40 & $9.34 \times 10^{-3}$ & 40,000 & $40 \times 10^{-3}$ \\
$\mathrm{CO}_{2}$ & 44 & $3.3 \times 10^{-4}$ & 9,000 & $9.0 \times 10^{-3}$ \\
\hline
\end{tabular}

a CRC Handbook of Chemistry and Physics, 53rd edition, p F174.

b lonization energy of mass spectrometer $=30 \mathrm{\theta V}$.

C Normalized to $\mathrm{N}_{2}$ peak $=0.78$. Not corrected for ionization, transmission and detection efficiencies.

Finally, in the crucial experiment, the mass spectrometer was calibrated for sodium species by vaporizing sodium chloride impregnated on a graphite felt substrate. The felt was placed inside a 2.2-cm-diameter by $45-\mathrm{cm}$-long stainless steel reactor that was heated by a 3-zone electric furnace (Figure 7). The bottom (25-cm-long) section of the tube, filled with steel balls, preheated the gas to within $50^{\circ} \mathrm{C}$ of the desired $\mathrm{NaCl}$ bed temperature. Immediately above this section, a $10-\mathrm{cm}$-long section contained the salt-impregnated felt (actual length of the felt bed was $7.5 \mathrm{~cm}$ centrally located within that section). The bed temperature was varied from $500^{\circ}$ to $630^{\circ} \mathrm{C}$, and the temperature gradients, measured both across and along the length of the salt bed with thermo-couples, were typically less than $5^{\circ} \mathrm{C}$. The top $10-\mathrm{cm}$ section of the reactor was open and kept at a constant temperature of $700^{\circ} \mathrm{C}$. The upper end of the tube was situated close to the mass spectrometer sampling orifice. Keeping the top section of the tube at a temperature higher than that of the bed ensured that condensation of salt vapor would be inhibited in the vicinity of the mass spectrometer sampling region. Furthermore, the gas entering the sampling orifice was kept at a nearly constant temperature irrespective of the bed temperature. 


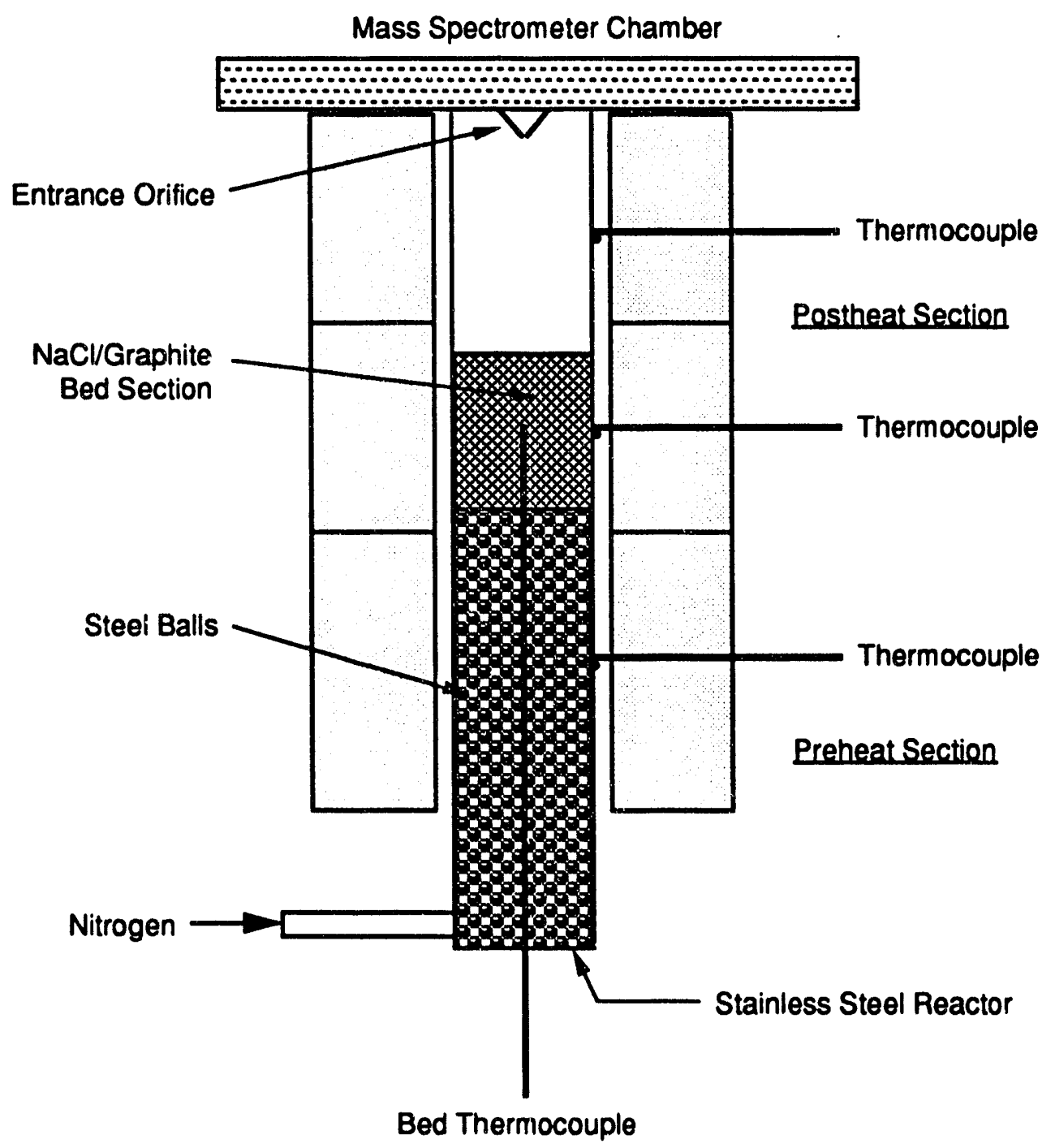

RAM-4352-8

Figure 7. Schematic diagram of the reactor used to measure the vaporization of $\mathrm{NaCl}$ as a function of temperature. 
The equilibrium vapor pressures (Figure 8) of $\mathrm{NaCl}$ species were calculated as a function of temperature from the published thermodynamic data (Chase et al., 1985). In the temperature range of $500^{\circ}$ to $650^{\circ} \mathrm{C}$, the equilibrium vapor pressure of $\mathrm{NaCl}$ varies from $2 \times 10^{-8}$ to $6 \times 10^{-6}$ atm. The parent species arising from sodium chloride vapor produces signals at atomic mass units (AMU) $58\left(\mathrm{NaCl}^{35+}\right)$ and $60\left(\mathrm{NaCl}^{37+}\right)$, associated with the two naturally occurring chlorine isotopes $\left(\mathrm{Cl}^{35} / \mathrm{Cl}^{37}\right)$ at relative abundances of $0.75 / 0.25$. Because of electron impact fragmentation of $\mathrm{NaCl}$ in the mass spectrometer ionizer, a signal is also observed at AMU 23 corresponding to $\mathrm{Na}^{+}$. The vaporization of $\mathrm{NaCl}$ also produced dimers $(\mathrm{NaCl})_{2}$ that gave signals at AMU 81 and 83 corresponding to $\mathrm{Na}_{2} \mathrm{Cl}^{+}$generated by fragmentation of the dimer in the ionizer. However, these signals were about five times less intense than of the monomer signals and hence were not used for calibration.

The flow rate of gas through the reactor had an effect on the observed vapor pressure of $\mathrm{NaCl}$. At flow rates of less than $2100 \mathrm{~cm}^{3} \cdot \mathrm{min}^{-1}$, air intruded from the open top end of the reactor into the mass spectrometer chamber. At flow rates greater than $2500 \mathrm{~cm}^{3} \cdot \mathrm{min}^{-1}$, a signifiant decrease in the signal intensity was observed (Figure 9). Hence, the flow rate of the carrier gas was kept at $2500 \mathrm{~cm}^{3} \cdot \mathrm{min}^{-1}$. From the measured signal intensities of sodium species, the heat of vaporization $(\Delta \mathrm{H})$ of $\mathrm{NaCl}$ was calculated. The $\Delta \mathrm{H}$ value is a sensitive indicator of the level of equilibrium attained during the vaporization of $\mathrm{NaCl}$ in the reactor. If complete equilibrium vaporization is not achieved, then the actual value for the partial pressure of $\mathrm{NaCl}$ will be less than the calculated value. The experimental $\Delta H$ value will then be lower than the reported equilibrium value. In calibration experiments, the heat of vaporization calculated from the experimental data was $49.4 \mathrm{kcal} / \mathrm{mol}$ (Figure 10, Table 4), in good agreement with the reported value of 54.9 $\mathrm{kcal} / \mathrm{mol}$ (Chase et ai., 1985). The observed isotopic ratio between $\mathrm{NaCl}^{35}$ and $\mathrm{NaCl}^{37}$ signal $(0.79 \pm 0.1)$ agrees well the published value of 0.76 except at very low concentrations. This agreement demonstrates the capability of the mass spectrometer system for sampling high temperature species from a bench-scale reactor. The small deviation of the isotopic ratio from the accepted value is prpbably due to contribution of a background signal. Previous similar studies (Bonnell and Hastie 1979) of equilibrium vaporization of $\mathrm{NaCl}$ have used either no carrier gas (vacuum) or extraordinarily low gas flow rates $\left(8 \mathrm{~cm}^{3} \cdot \mathrm{min}^{-1}\right)$. At the carrier gas flow rates used in this study, the observed values of $\Delta \mathrm{H}$ are somewhat lower than reported, as expected. 


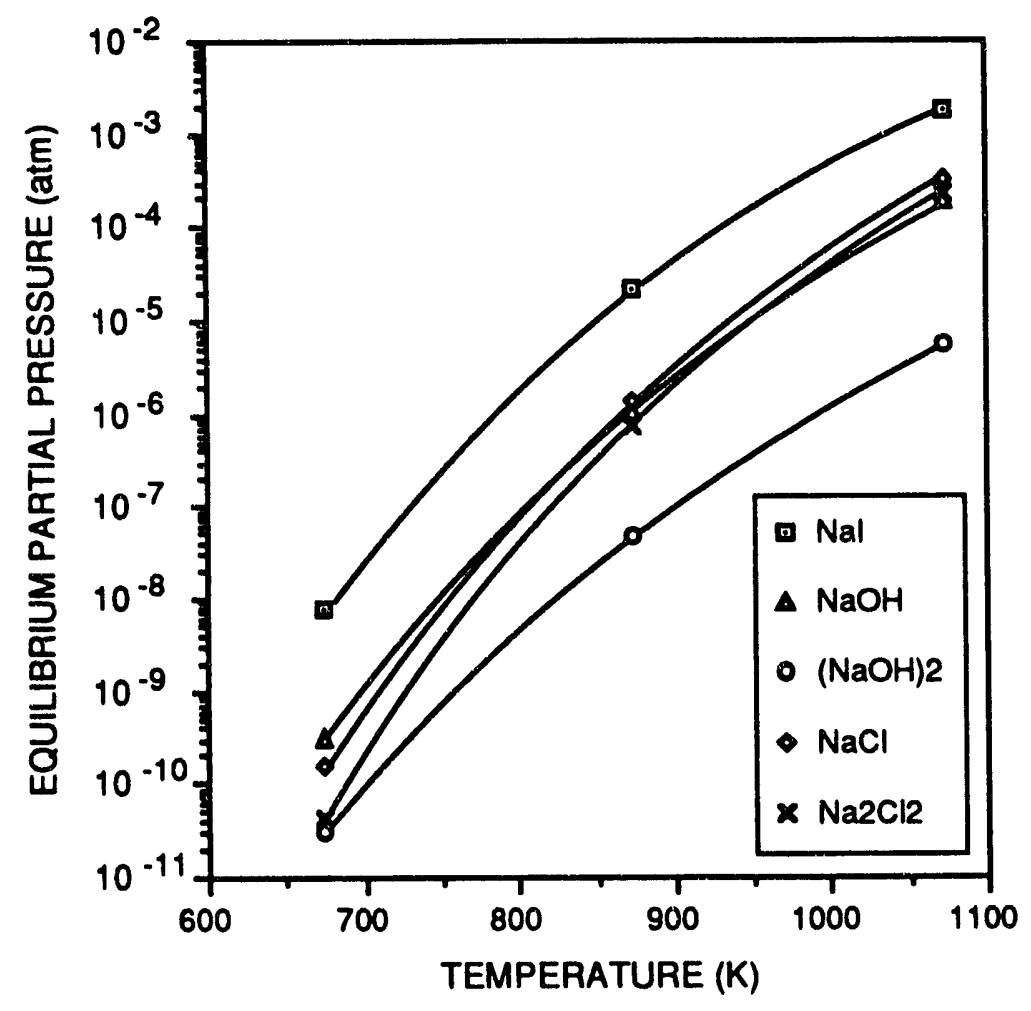

RAM-4352-9

Figure 8. Equilibrium vapor pressure of sodium species as a function of temperature. 


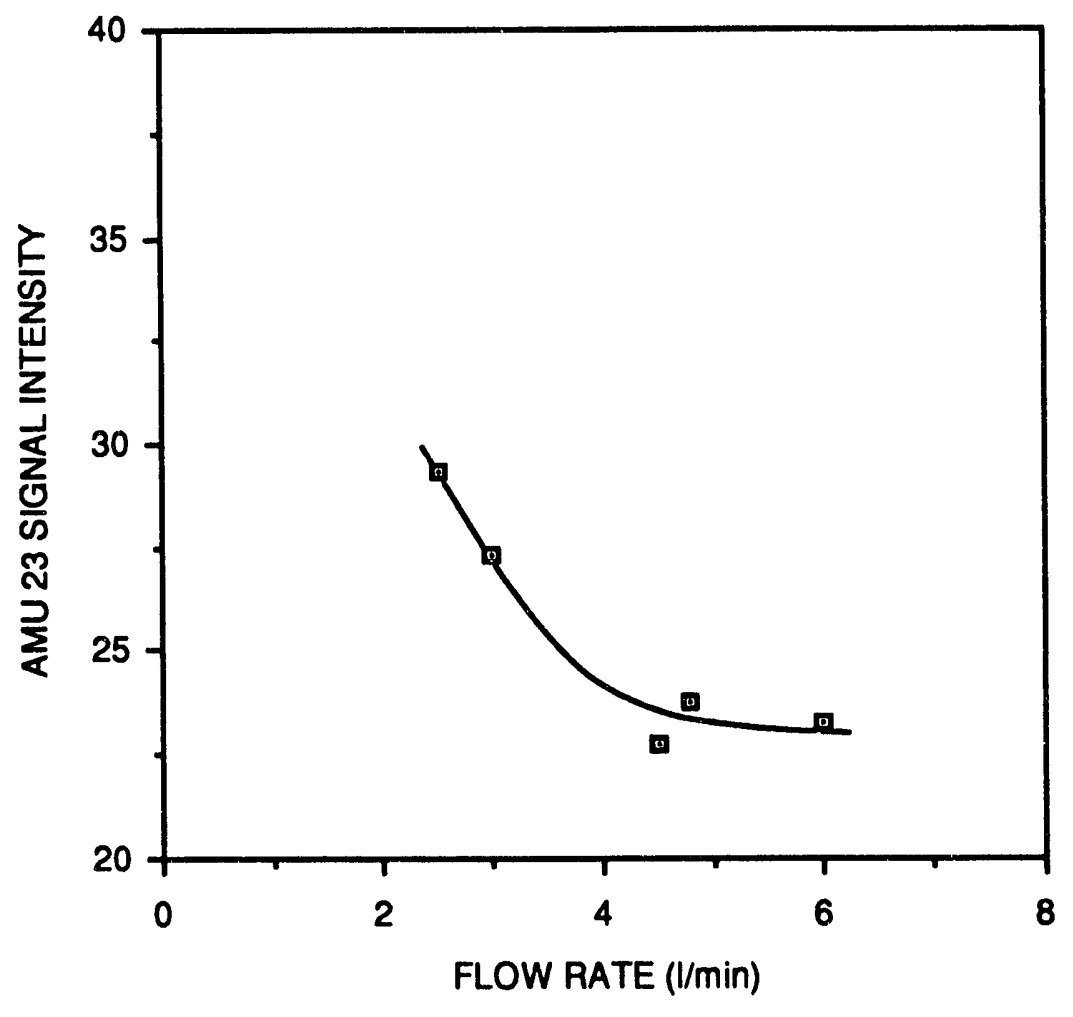

RAM-4352-10

Figure 9. Effect of carrier gas flow rate on $\mathrm{Na}^{+}$(from $\mathrm{NaCl}$ ) signal intensity. 


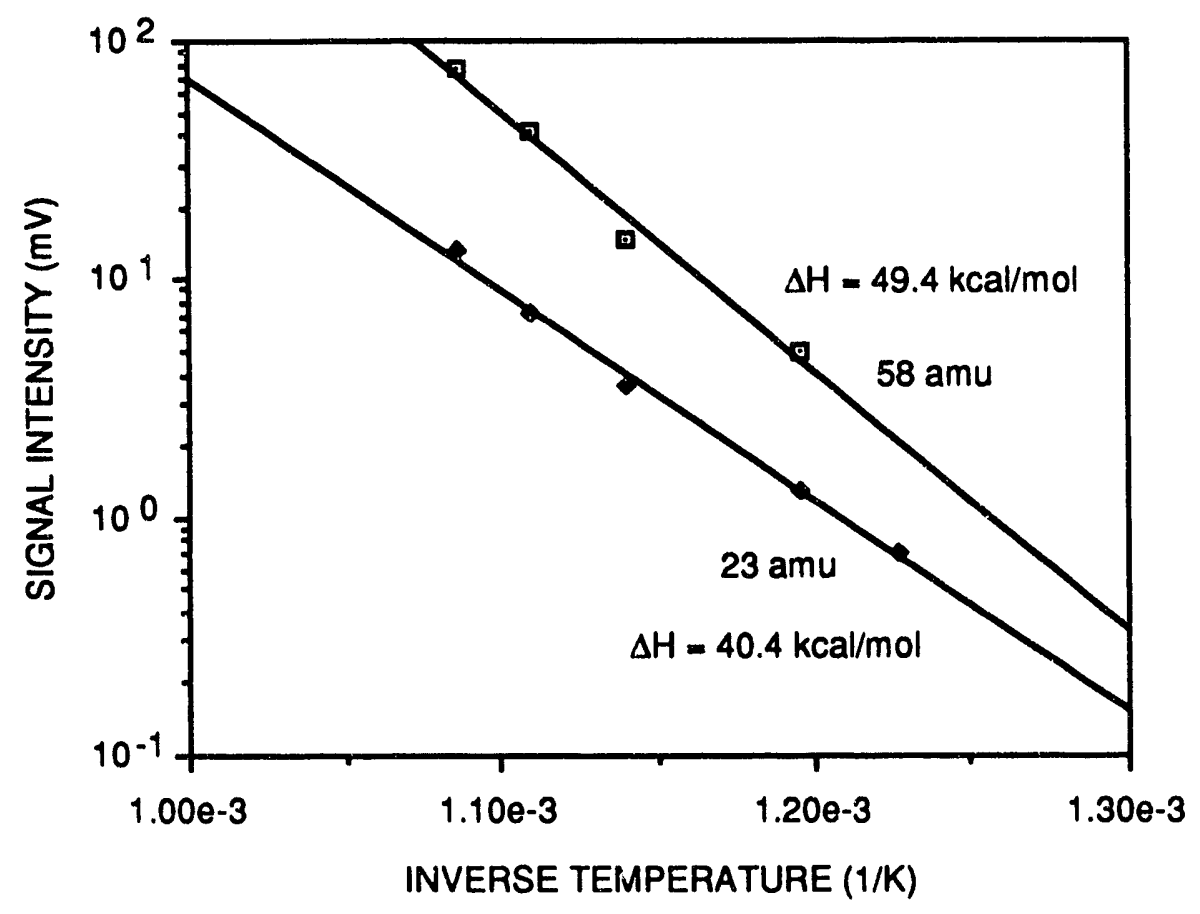

RAM-4352-11

Figure 10. Heat of vaporization of $\mathrm{NaCl}$ impregnated in a graphite felt bed. 
Table 4

OBSERVED MASS SPECTROMETER SIGNAL INTENSITIES DURING CALIBRATION USING NaCI VAPOR

\section{Temperature} (ㄷ)

815

836

877

901

926

945

969
Signal Intensities (Relative Units)

AMU 23

0.7

1.3

3.5

7.2

13.2

18.2

25.7
AMU 58

6.5

5.0

14.5

42.0

76.0

107.0

152.0
AMU 60

1.0

1.2

2.9

18.0

27.0

33.0

50.0
Observed Isotopic

Abundance $^{a}$

0.87

0.81

0.83

0.70

0.74

0.76

0.75

a [Signal intensity at AMU58]/Signal intensity at AMU 58+Signal intensity at AMU60)]

From these results, the sensitivity of the mass spectrometer system for $\mathrm{NaCl}$ vapor can be extended to trace level quantities. The sensitivity of the system is about $10 \mathrm{mv} / \mathrm{ppm}$ of $\mathrm{NaCl}$ vapor. A change of $0.5 \mathrm{mv}$ in the signal level can be measured, and hence $\mathrm{NaCl}$ vapor concentration above $50 \mathrm{ppb}$ can be detected. The change in the signal intensity was linear with the change in the partial pressure of $\mathrm{NaCl}$ vapor (Figure 11).

Experimental calibration of the mass spectrometer for sodium species other than $\mathrm{NaCl}$ is complicated. An attempt was made to vaporize $\mathrm{NaOH}$ in a manner similar to that used for $\mathrm{NaCl}$. However, $\mathrm{NaOH}$ was partially reduced by the carbon felt, and hence the vapor pressure of $\mathrm{NaOH}$ was not known under experimental conditions. Use of a platinum-lined crucible to hold the $\mathrm{NaOH}$ liquid was not successful because of the creepage of the liquid caustic. Experimental calibration of the system for $\mathrm{Na}_{2} \mathrm{SO}_{4}$ is also complicated, because $\mathrm{Na}_{2} \mathrm{SO}_{4}$ vaporizes according to the following reactions (Bonnell and Hastie, 1979):

$$
\begin{aligned}
& \mathrm{Na}_{2} \mathrm{SO}_{4}(\mathrm{l})=2 \mathrm{Na}(\mathrm{g})+\mathrm{SO}_{2}(\mathrm{~g})+\mathrm{O}_{2}(\mathrm{~g}) \\
& \mathrm{Na}_{2} \mathrm{SO}_{4}(\mathrm{l})=\mathrm{Na}_{2} \mathrm{SO}_{4}(\mathrm{~g}) \\
& \mathrm{Na}_{2} \mathrm{SO}_{4}(\mathrm{l})=\mathrm{Na}_{2} \mathrm{O} \text { (solution or gas) }+\mathrm{SO}_{2}(\mathrm{~g})+1 / 2 \mathrm{O}_{2}(\mathrm{~g})
\end{aligned}
$$




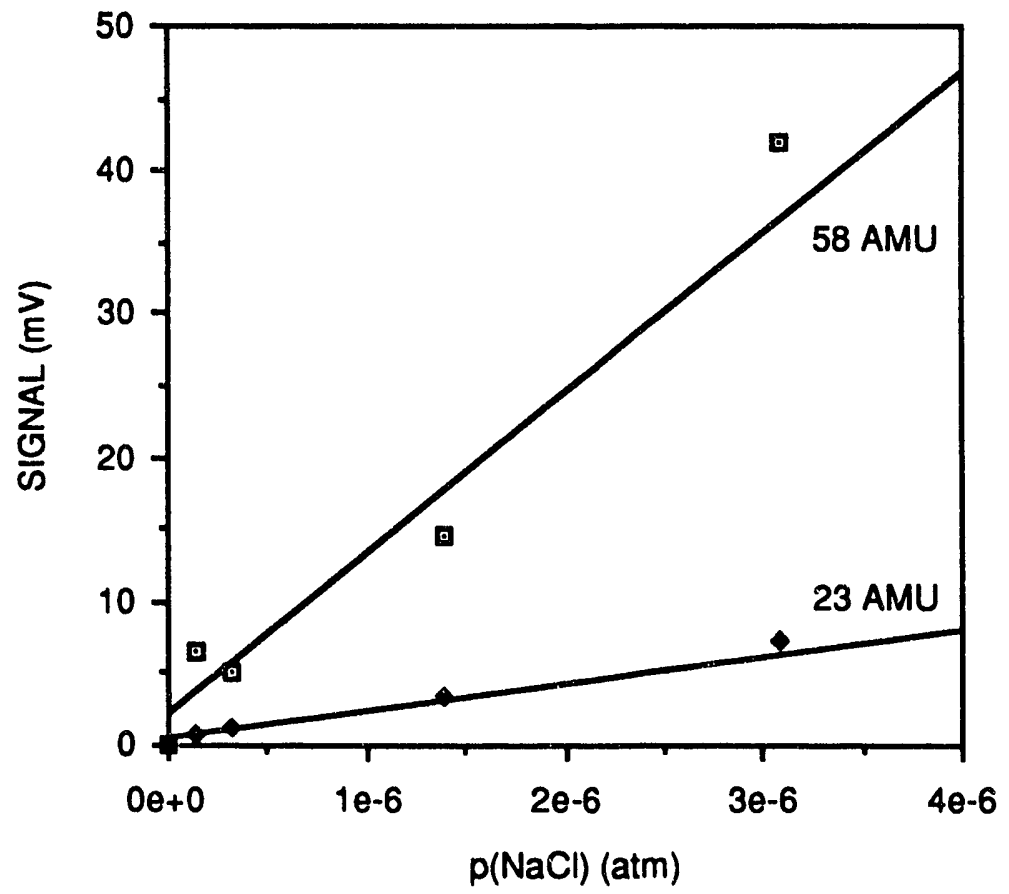

RAM-4352-12

Figure 11. The signal intensity as a function of equilibrium partial pressure of $\mathrm{NaCl}$ vapor. 
Bonnell and Hastie (1979) were able to determine the equilibrium constant for the dissociative vaporization of $\mathrm{Na}_{2} \mathrm{SO}_{4}$ (1) under closed system conditions, but under gas flow conditions a significant amount of scatter was observed. The interaction of $\mathrm{SO}_{2}$ and $\mathrm{O}_{2}$ with the tantalum liners and the dissolution of $\mathrm{SO}_{2}$ in the $\mathrm{Na}_{2} \mathrm{SO}_{4}$ (l) were the primary cause for the deviation from the equilibrium. Hence, direct calibration for $\mathrm{Na}_{2} \mathrm{SO}_{4}$ vapor is difficult and prone to significant errors.

For sodium species other than $\mathrm{NaCl}$, the partial pressures was estimated from the relation as:

$$
\mathrm{p}(\mathrm{x})=\mathrm{C} \cdot \mathrm{I}(\mathrm{x}) / \mathrm{Q}_{\mathrm{x}}
$$

where $C$ is an intstrument constant, $Q_{x}$ is the ionization cross section, $p(x)$ is the partial pressure of species $\mathrm{x}$, and $\mathrm{I}(\mathrm{x})$ is the observed signal intensity. The instrumentation constant was calculated from the observed $\mathrm{NaCl}$ vaporization data. The ionization cross section of molecules was calculated from the sum of atomic ionization cross sections (Hildenbrand et al., 1990). The atomic ionization cross-section data were taken from the compilation by Mann (1967).

\section{COMBUSTION EXPERIMENTS}

Several combustion experiments, each 3 to 6 hours long, were conducted in the fluidized bed reactor at atmospheric pressure in the bed temperature range of $800^{\circ}$ to $950^{\circ} \mathrm{C}$ with Beulah Zap lignite and with Illinois \#6 coal. During these combustion runs, the gas stream from the reactor was analyzed for 10 different species, 5 of which contained sodium, at intervals of about 15 min (Table 5). At the end of each run, ash in the reactor, the cyclone, and the filter was separately collected and weighed, then analyzed for sodium content. Selected ash samples were also analyzed by $\mathrm{X}$-ray diffraction, scanning electron microscopy, and Auger electron spectroscopy.

\section{Sodium in the Gas and Solid Phases}

At temperatures below $950^{\circ} \mathrm{C}$, the combustion gas produced by Beulah Zap lignite burned with excess air contained negligibly small levels of $\mathrm{Na}_{2} \mathrm{O}, \mathrm{NaCl}$, and $\mathrm{Na}_{2} \mathrm{SO}_{4}$. On the basis of the sensitivity of the mass spectrometer system demonstrated in our extensive and detailed calibration procedure, the absence of any detectable increase in the signals at AMUs corresponding to these species (and also signal at 23 AMU resulting from the fragmentation of sodium species), indicates that these species could be present only at concentrations less than $0.05 \mathrm{ppm}$. 
Table 5

VAPOR SPECIES MONITORED DURING COMBUSTION RUNS

AMU

23

32

34

36

40

44

52

58

60

64

80

142

\section{Specles}

$\mathrm{Na}^{+}$

$\mathrm{O}_{2}^{+}$

$\mathrm{O}_{2}+\mathrm{H}_{2} \mathrm{~S}^{+}$

$\mathrm{HCl}+$

$\mathrm{Ar}^{+}, \mathrm{NaOH}^{+}$

$\mathrm{CO}_{2}^{+}$

$\mathrm{Na}_{2} \mathrm{O}^{+}$

$\mathrm{NaCl}^{+}$

$\mathrm{NaCl}^{+}, \mathrm{COS}^{+}$

$\mathrm{SO}_{2}+$

$\mathrm{SO}_{3}+$

$\mathrm{Na}_{2} \mathrm{SO}_{4}{ }^{+}$ 
Table 6 illustrates the typical signal intensities of mass spectrometric peaks associated with sodium species. In comparing the signal intensities of sodium species before the introduction of coal and during coal combustion, it is evident that no significant changes in the intensities of mass spectrometric peaks associated with sodium species were observed in the combustion gas stream during fluidized bed combustion of Beulah Zap lignite. A significant decrease in the signal at AMU 60 was observed, but this decrease could not be correlated with any possible species that cat، be present in air at the reaction temperature. A signal at AMU 60 can be generated from several organic compounds such as carbonyl sulfide $(\mathrm{COS})$, urea $\left(\mathrm{CH}_{4} \mathrm{~N}_{2} \mathrm{O}\right)$, propanol $\left(\mathrm{C}_{3} \mathrm{H}_{8} \mathrm{O}\right)$, and cyanogen chloride $(\mathrm{CCIN})$; but these compounds are unstable in air at $800^{\circ} \mathrm{C}$.

Table 6

TYPICAL SIGNAL INTENSITIES OF SODIUM SPECIES OBSERVED DURING COMBUSTION OF BEULAH ZAP LIGNITE AT $810^{\circ} \mathrm{C}$

\begin{tabular}{ccc} 
& \multicolumn{2}{c}{ Signal Intensity (Arbitary Units) } \\
\cline { 2 - 3 } AMU & Ne CoalFeed & During Sombustion \\
23 & 3.5 & 3.1 \\
36 & 49.0 & 51.0 \\
40 & 360.0 & 330.0 \\
52 & 4.5 & 3.4 \\
58 & 15.0 & 14.6 \\
60 & 25.0 & 15.0 \\
142 & 0.5 & 0.5
\end{tabular}

In the mass spectrometer, argon and $\mathrm{NaOH}$ have parent peaks at AMU40. Hence, $\mathrm{NaOH}$ at parts-per-million (ppm) levels would be masked by the argon present at about 2,500 ppm in the commercially blended synthetic air used in our experimental runs (ambient air contains about $1 \%$ argon). To circumvent this problem, nitrogen and oxygen was mixed to provide a synthetic air that contained only $22 \mathrm{ppm}$ argon. In principle, the hydroxide vapor can be distinguished from argon by operating the mass spectrometer ionizer at a potential of about $12 \mathrm{eV}$, which is greater than the ionization potential of $\mathrm{NaOH}(<10 \mathrm{eV})$ but less than that of $\operatorname{Ar}(15.76 \mathrm{eV})$. However, this operation reduces the sensitivity of the mass spectrometer by an order of magnitude. On the basis 
of these considerations, the absence of a measurable $\mathrm{NaOH}$ signal led us to conclude that the $\mathrm{NaOH}(\mathrm{g})$ concentration during all of the Beulah Zap combustion runs was less than $0.5 \mathrm{ppm}$.

Combustion of Beulah Zap at $950^{\circ} \mathrm{C}$ resulted in a higher concentration of sodium species. The $\mathrm{NaCl}(\mathrm{g})$ and $\mathrm{Na}_{2} \mathrm{SO}_{4}(\mathrm{~g})$ were measured at 0.1 and $0.05 \mathrm{ppm}$, respectively. During combustion of Illino; \#6 coal at $900^{\circ} \mathrm{C}$ with $43 \%$ excess air, the $\mathrm{NaCl}(\mathrm{g})$ concentration was less than $0.05 \mathrm{ppm}$ but the signal intensity at AMU 142 increased from a background value of $1.5 \mathrm{mV}$ to $2.5 \mathrm{mV}$. From this data concentration of $\mathrm{Na}_{2} \mathrm{SO}_{4}$ is estimated to be about 0.05 ppm. Tables 7 through 12 summarizes the mass balance of sodium in the ash during combustion of Beulah Zap lignite and Illinois \#6 coals.

Table 7

SOLID AND VAPOR PHASE SODIUM SPECIES OBSERVED DURING COMBUSTION OF BEULAH ZAP LIGNITE AT $890^{\circ} \mathrm{C}$ AT AN AIR/COAL RATIO OF $7.7(g / g)$

$\begin{array}{lccc}\text { Location } & \text { Wt\% Ash } & \text { Wt\% Na in Ash } & \begin{array}{r}\text { \% Na In Coal } \\ \text { Accounted In Ash }\end{array} \\ \text { Bed } & 76.0 & 5.62 & 63.5 \\ \text { Reactor wall } & 8.6 & 7.82 & 10.0 \\ \text { Cyclone } & 2.5 & 7.39 & 2.7 \\ \text { Filter } & 2.5 & 26.09 & 9.7 \\ \text { Total } & 89.6 & & 85.9\end{array}$

Vapor phase analysis: $\mathrm{Na}(\mathrm{g})=<0.5 \mathrm{ppm}, \mathrm{NaCl}(\mathrm{g})=<0.5 \mathrm{ppm}, \mathrm{Na}_{2} \mathrm{SO}_{4}(\mathrm{~g})=<0.5 \mathrm{ppm}$ 
Table 8

SOLID AND VAPOR PHASE SODIUM SPECIES OBSERVED DURING COMBUSTION OF BEULAH ZAP LIGNITE AT $810^{\circ} \mathrm{C}$ AT AN AIR/COAL RATIO OF $12.3(\mathrm{~g} / \mathrm{g})$

\begin{tabular}{|c|c|c|c|}
\hline Lecation & Wt\% Ash & $\mathrm{Wt} \% \mathrm{Na}$ in Ash & $\begin{array}{r}\% \mathrm{Na} \text { in } \\
\text { Accounted }\end{array}$ \\
\hline Bed & 82.0 & 5.12 & 61.7 \\
\hline Reactor wall & 13.0 & 5.74 & 11.0 \\
\hline Cyclone & 2.4 & 6.33 & 15.2 \\
\hline Filter & 3.5 & 27.01 & 13.9 \\
\hline Total & 100.9 & & 101.8 \\
\hline
\end{tabular}

Vapor phase analysis: $\mathrm{Na}(\mathrm{g})=<0.05 \mathrm{ppm}, \mathrm{NaCl}(\mathrm{g})=<0.05 \mathrm{ppm}_{1} \mathrm{Na}_{2} \mathrm{SO}_{4}(\mathrm{~g})=<0.05 \mathrm{ppm}, \mathrm{NaOH}=<0.5$ $\mathrm{ppm}$

Table 9

SOLID AND VAPOR PHASE SODIUM SPECIES OBSERVED DURING COMBUSTION OF BEULAH ZAP LIGNITE AT $820^{\circ} \mathrm{C}$ AT AN AIR/COAL RATIO OF $9.9(\mathbf{g} / \mathbf{g})$

$\begin{array}{lccc}\text { Lecation } & \text { Wt\% Ash } & \text { Wt\% Na in Ash } & \begin{array}{r}\% \text { Na in Coal } \\ \text { Accounted in Ash }\end{array} \\ \text { Bed + Wall } & 84.4 & 4.52 & 63.2 \\ \text { Cyclone } & 7.9 & 7.30 & 9.5 \\ \text { Filter } & 7.7 & 29.33 & 37.3 \\ \text { Total } & 100.0 & & 110.0\end{array}$

Vapor phase analysis: $\mathrm{Na}(\mathrm{g})=<0.05 \mathrm{ppm}, \mathrm{NaCl}(\mathrm{g})=<0.05 \mathrm{pum}_{1} \mathrm{Na}_{2} \mathrm{SO}_{4}(\mathrm{~g})=<0.05 \mathrm{ppm}, \mathrm{NaOH}=$ $<0.5 p p m$ 
SOLID AND VAPOR PHATE SODIUM SPECIES OBSERVED DURING COMBUSTION OF BEULAH ZAP LIG,VITE AT $810^{\circ} \mathrm{C}$ AT AN AIR/COAL RATIO OF $9.7(\mathrm{~g} / \mathrm{g})$

$\begin{array}{lccc}\text { Lecation } & \text { WH Ash } & \text { Wr\% Na in Ash } & \begin{array}{c}\text { \% Na in Coal } \\ \text { Accounted in Ash }\end{array} \\ \text { Bed + Wall } & 68.4 & 6.13 & 47.7 \\ \text { Cyclone } & 8.6 & 7.60 & 7.6 \\ \text { Filter } & 9.0 & 29.33 & 30.8 \\ \text { Total } & 86.0 & & 85.9\end{array}$

Vapor phase analysis: $\mathrm{Na}(\mathrm{g})=<0.05 \mathrm{ppm}, \mathrm{NaCl}(\mathrm{g})=<0.05 \mathrm{ppm}_{1} \mathrm{Na}_{2} \mathrm{SO}_{4}(\mathrm{~g})=<0.05 \mathrm{ppm}, \mathrm{NaOH}=<0.5$ ppm

Table 11

SOLID AND VAPOR PHASE SODIUM SPECIES OBSERVED DURING COMBUSTION OF BEULAH ZAP LIGNITE AT $950^{\circ} \mathrm{C}$ AT AN AIR/COAL RATIO OF $9.9(\mathrm{~g} / \mathrm{g})$

\begin{tabular}{lccc} 
Lecation & Wt\% Ash & Wt\% Na In Ash & $\begin{array}{c}\text { \% Na in Coal } \\
\text { Accounted in Ash }\end{array}$ \\
\cline { 2 - 4 } Distributor & 69.6 & 6.08 & 62.3 \\
Reactor wall & $19.0^{\mathrm{a}}$ & 1.27 & 3.4 \\
Cyclone & 5.5 & 11.52 & 9.3 \\
Filter & 5.7 & 26.93 & 22.7 \\
Total & & & 97.7
\end{tabular}

Vapor Phase Analysis: $\mathrm{Na}(\mathrm{g})=<0.02 \mathrm{ppm}, \mathrm{NaCl}(\mathrm{g})=0.1 \mathrm{ppm}, \mathrm{Na}_{2} \mathrm{SO}_{4}(\mathrm{~g})=0.05 \mathrm{ppm}, \mathrm{NaOH}=<0.5 \mathrm{ppm}$

a The ash collected from the walls contained oxidized metal fragments from the reactor walls. 
Table 12

SOLID AND VAPOR PHASE SODIUM SPECIES OBSERVED DURING COMBUSTION OF ILLINOIS \#6 COAL AT $900^{\circ} \mathrm{C}$ AT AN AIR/COAL RATIO OF $11.7(\mathrm{~g} / \mathrm{g})$

$\begin{array}{lccc}\text { Lecation } & \text { Wt\% Ash } & \text { Wt\% Na in Ash } & \begin{array}{r}\% \text { Na in Coal } \\ \text { Accounted in Ash }\end{array} \\ \text { Bed } & 81.0 & 1.06 & 79.8 \\ \text { Cyclone } & 8.0 & 1.37 & 21.3 \\ \text { Filter } & 2.0 & 2.94 & 5.1 \\ \text { Total } & 91.0 & & 106.2\end{array}$

Vapor phase analysis: $\mathrm{Na}(\mathrm{g})=<0.05 \mathrm{ppm}, \mathrm{NaCl}(\mathrm{g})=<0.05 \mathrm{ppm}, \mathrm{Na}_{2} \mathrm{SO}_{4}(\mathrm{~g})=0.05 \mathrm{ppm}, \mathrm{NaOH}=$ $<0.5 p p m$.

Chlorine in the coal has been shown to enhance the vaporization of sodium species during combustion (Hodges and Richards, 1989). The chlorine content of the coals tested is low $(<0.01$ to $0.1 \mathrm{wt} \%$ ). Sodium in Beulah Zap lignite is present in an organically bound form (sodium carboxylates). Hence, the formation of $\mathrm{NaCl}$ vapor may be limited by the availability of chlorine To study the influence of chlorine on the vaporization of sodium species, a sample of Beulah Zap lignite was impregnated with sodium chloride solution so that its sodium concentration increased from 0.42 to $0.62 \mathrm{wt} \%$ and the chlorine concentration increased from $<0.01$ to $0.3 \mathrm{wt} \%$. The incipient wetness technique ( a technique in which the amount of added solution is restricted only to fill the void volume of the sample) was used so that the chloride was uniformly deposited throughout the pore structure of the coal particles. The impregnated coal was dried in air at room temperature.

The combustion run was started with the unadulterated Beulah lignite. With an air/coal ratio of 9.9 , the bed attained a steady-state temperature of $1000 \pm 50^{\circ} \mathrm{C}$ and the free board temperature settled at $950 \pm 10^{\circ} \mathrm{C}$. As in previous experiments under similar conditions, the mass spectrometric analysis of the gaseous components revealed that sodium species were present only at sub-ppm levels (Table 13). 
Table 13

SIGNAL INTENSITIES OF GASEOUS SODIUM SPECIES OBSERVED DURING COMBUSTION OF NaCI-ADDED BEULAH ZAP LIGNITE

SIgnal Intensity (Relative Unlts)

\begin{tabular}{ccc}
\multicolumn{3}{c}{ Slgnal Intensity (Relative Units) } \\
\hline & \multicolumn{2}{c}{ During Combustion } \\
\cline { 2 - 3 } No Coal_Feed & Unadulterated Coal Nacl-Added Coal \\
\cline { 2 - 3 } 2.5 & 71.0 & 36.3 \\
44.5 & 590.0 & 1815.0 \\
590.0 & 7.6 & 590.0 \\
5.5 & 25.7 & 9.0 \\
22.5 & 22.0 & 90.0 \\
19.0 & 0.0 & 36.0 \\
0.0 & & 4.5 \\
& &
\end{tabular}

a Normalized to constant Ar signal (AMU 40)

After $1 \mathrm{~h}$ of steady-state combustion, the $\mathrm{NaCl}$-impregnated lignite was introduced into the reactor. Immediately, signal intensities corresponding to sodium and chlorine species increased significantly. Increases in signal levels were observed at AMU $23\left(\mathrm{Na}^{+}\right), 36\left(\mathrm{HCl}^{+}\right), 58\left(\mathrm{NaCl}^{+}\right)$, $81\left(\mathrm{Na}_{2} \mathrm{Cl}^{+}\right)$, and $142\left(\mathrm{Na}_{2} \mathrm{SO}_{4}{ }^{+}\right)$. The signal at AMU 23 was not due to atomic sodium, but rather to the fragmentation of sodium compounds in the mass spectrometer ionizer. The signal intensities were converted to the concentrations by using the $\mathrm{NaCl}$ vaporization calibration curve and ionization cross sections. Table 14 lists the observed concentration of the sodium species. The $\mathrm{NaCl}$ vapor concentration increased by about a factor of 20 , although the concentration of sodium in the coal was increased only by a factor of two. These results show clearly that the concentrations of vapor phase sodium species is enhanced when sodium is present as chloride in the coal. The experiment also verifies the capability of the mass spectrometer system to determine alkali compounds present in hot coal gas at concentrations above $0.05 \mathrm{ppm}$. 
Table14

COMPARISON OF VAPOR PHASE SODIUM SPECIES DURING COMBUSTION OF BEULAH ZAP LIGNITEa

\begin{tabular}{|c|c|c|}
\hline \multirow[b]{2}{*}{ Specles } & \multicolumn{2}{|c|}{ Concentration of Vapor Specles (ppm) } \\
\hline & Orialnal Coalb & NaCl-Added CoalC \\
\hline $\begin{array}{l}\mathrm{NaCl}(\mathrm{g}) \\
\mathrm{Na}_{2} \mathrm{SO}_{4}(\mathrm{~g}) \\
\mathrm{HCl}(\mathrm{g})\end{array}$ & $\begin{array}{l}0.28 \\
0.02 \\
14.0\end{array}$ & $\begin{array}{l}6.0 \\
0.18 \\
350.0\end{array}$ \\
\hline
\end{tabular}

\section{Characterization of Ash Particles}

Ash particles retained in the bed and collected in the cyclone and the filter were examined by X-ray diffraction, electron-induced X-ray emission, Auger electron spectroscopy, and wet chemical analysis for total sodium and sulfate ion. Depending on the air velocity through the combustor, the fraction of ash particles collected in the filter varied from about 3 to $8 \mathrm{wt} \%$. The sodium content of these fine ash particles $(<5 \mu \mathrm{m}$ ) ranged from 26 to $30 \mathrm{wt} \%$, far in excess of the sodium content of the total ash. The sodium in this ash accounted for about 10 to $34 \%$ of the total sodium in the coal. The sulfate content was highest in the ash collected in the filter and the lowest in the bed ash. The ratio of sodium to sulfate on a molar basis indicates that sodium in the filter ash may be present as sodium sulfate. X-ray diffraction analysis of the ash collected in the filter also indicated that sodium sulfate was the predominant sodium compound present (Figure 12).

The fraction of particles retained in the bed varied from about 64 to $84 \mathrm{wt} \%$, depending on the experimental conditions. The sodium content of these coarse ash particles ranged from 4.5 to $5.6 \mathrm{wt} \%$, lower than the sodium concentration in the total ash. The particles collected in the cyclone generally accounted for about 3 to $8 \mathrm{wt} \%$, and their sodium content was slightly higher than that of the total ash. The particles retained in the bed accounted for about 58 to $64 \%$, of sodium in the coal whereas the particles collected in the cyclone accounted for about 3 to $8 \%$ of the sodium. X-ray diffraction analysis of the bed ash showed that it was mainly amorphous. The ash 


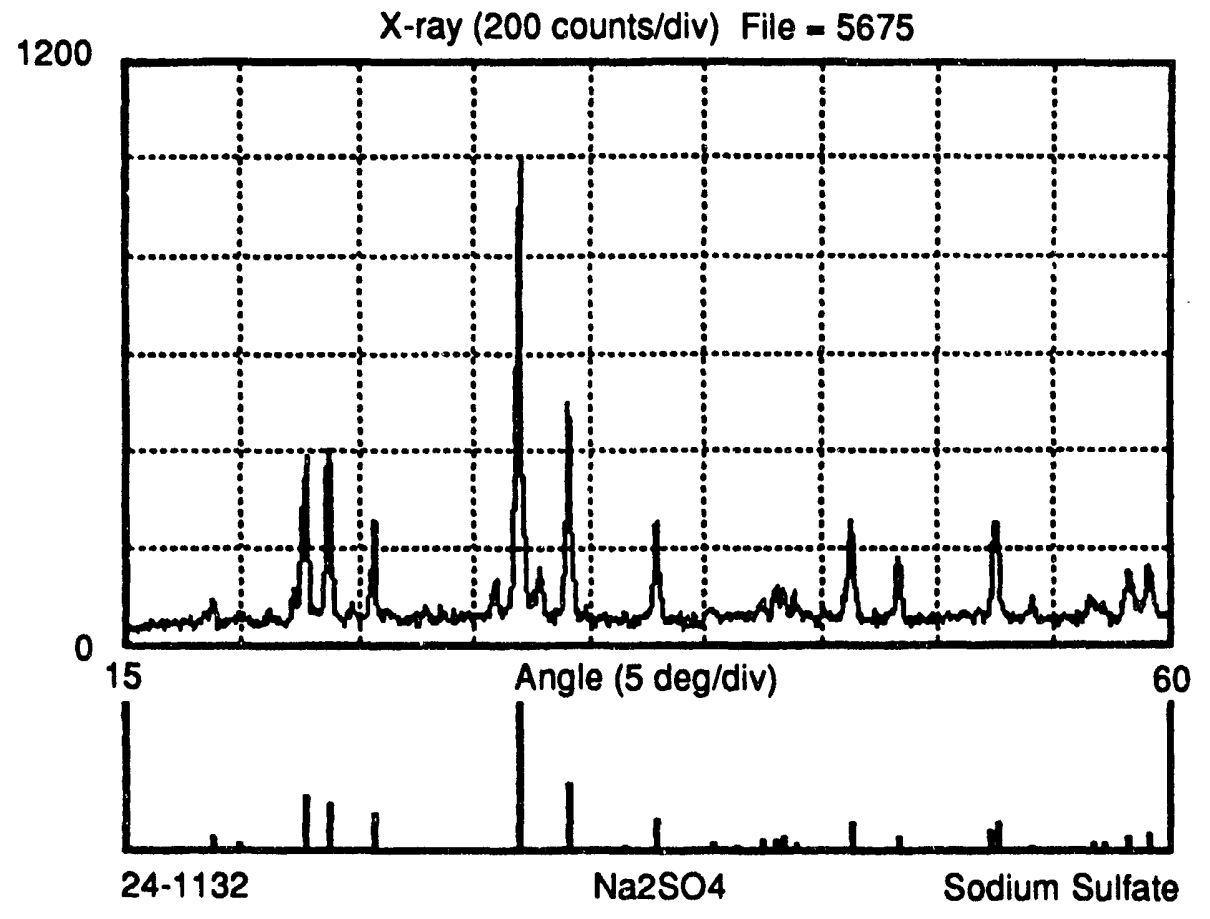

AM-4352-13

Figure 12. X-ray diffraction spectrum of ash collected in the filter. 
particles deposited on the walls of the reactor were also mainly amorphous, although minor amounts of sulfate ion were also detected (Figure 13).

The morphology and elemental composition of the collected ash particles were determined in a scanning electron microscope equipped with an X-ray fluorescence accessory (EDAX). The size of the ash particles retained in the bed varied from $10 \mu \mathrm{m}$ to $0.5 \mathrm{~mm}$. Microscopic observations indicated that the larger $0.5-\mathrm{mm}$ particles were agglomerates of small particles. No evidence of melting was observed. The particle size of ash collected in the cyclones varied from 1 to $50 \mu \mathrm{m}$. The ash particles collected in the ceramic filter were mainly in the sub-micrometer size to about $10 \mu \mathrm{m}$.

Semiquantitative $X$-ray fluorescence analysis of the ash particles collected from various locations confirmed the results of the wet chemical anlaysis. Sodium and sulfur were depleted in the bed ash but enriched in the filter ash (Table 15). However, calcium, aluminum, magnesium and silicon were higher in the reactor ash in comparison with the filter ash. These results indicate that the filter ash contains predominantly sodium sulfate whereas the bed ash consists mainly of silicates or calcium sulfate.

Table 15

\section{DISTRIBUTION OF ELEMENTS IN THE ASH PARTICLES DURING} COMBUSION OF BEULAH ZAP LIGNITEa

\begin{tabular}{lccc} 
& \multicolumn{3}{c}{ Concentration of Elements $(w t \%)$} \\
\cline { 2 - 4 } Element & Reacter & Evclene & Filter \\
$\mathrm{Na}$ & 3.5 & 8.2 & \\
$\mathrm{~K}$ & $\mathrm{~N} . \mathrm{D}$ & 1.3 & 19.2 \\
$\mathrm{Ca}$ & 72.7 & 36.9 & 3.4 \\
$\mathrm{Mg}$ & 5.3 & 1.4 & 2.5 \\
$\mathrm{Al}$ & 6.9 & 3.6 & $\mathrm{~N} . \mathrm{D}$ \\
$\mathrm{Si}$ & 5.5 & 5.8 & 0.9 \\
$\mathrm{~S}$ & 6.3 & 42.9 & 1.5 \\
$\mathrm{~N}$ & & & 72.6
\end{tabular}

a Semi-quantitative $X$-ray emission analysis. 


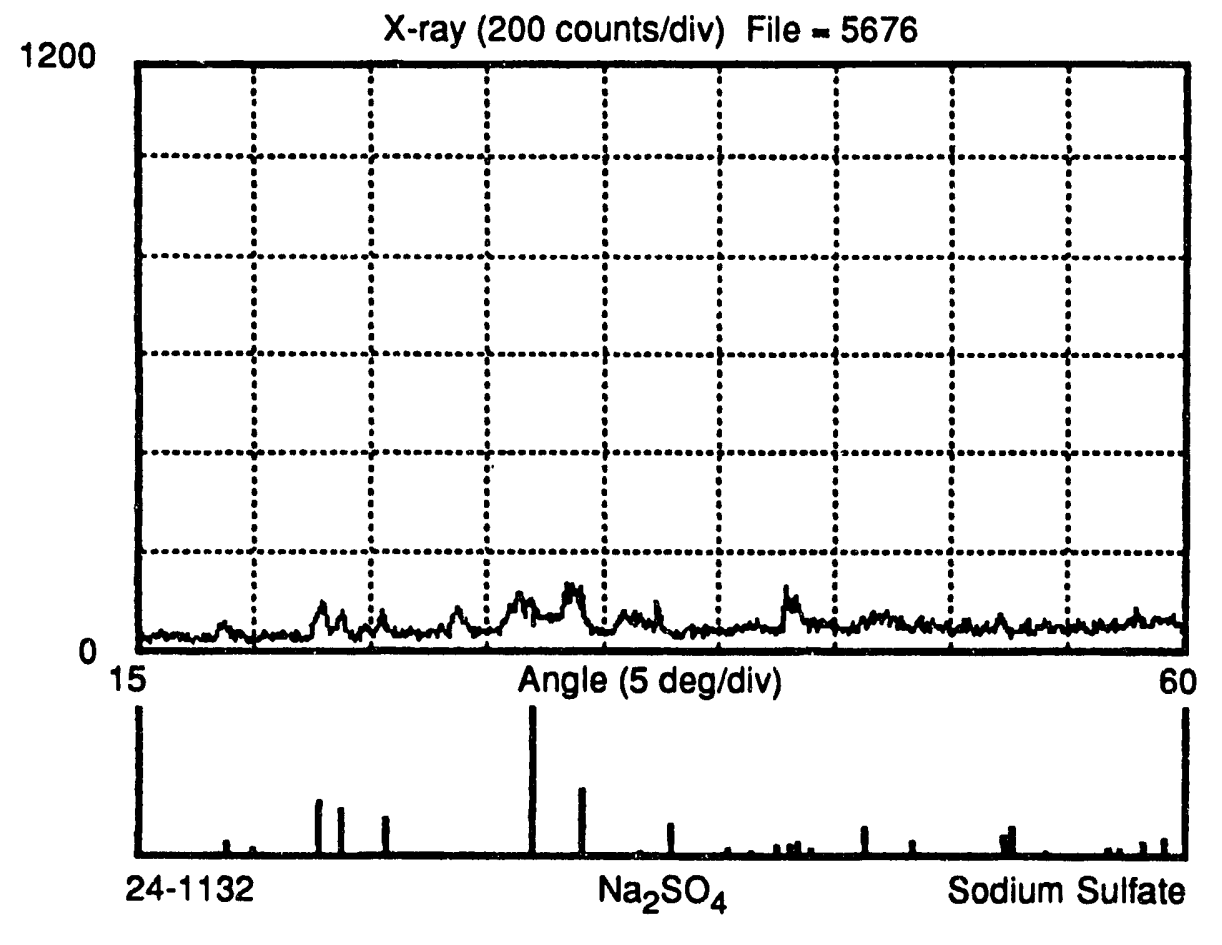

RM-4352-14

Figure 13. X-ray diffraction spectrum of ash deposited on the reactor interior walls. 
The ash samples from a combustion run using Beulah Zap lignite was analyzed by Auger electron spectroscopy (AES) to determine the elemental composition on the surface. AES is capable of identifying elemental constituents in the outer atomic layers to a depth of about $1 \mathrm{~nm}$ below the surface. This is in contrast to an analysis depth of $1000 \mathrm{~nm}$ for the $\mathrm{X}$-ray fluorescence analysis performed in conjunction with scanning electron microscopy.

During AES analysis, the specimen is bombarded with a medium energy $(\sim 2 \mathrm{KeV})$ monochromatic electron beam, which causes secondary electron emission from the specimen. Some of these secondary electrons consist of Auger electrons arising from electronic transitions in the atoms near the specimen surface. The emitted Auger electrons are energy-analyzed to provide a spectrum of peaks characteristic of the elemental components in the specimen surface. AES is a highly selective surface-sensitive technique because of the limited escape depth of the emitted electrons. The limit of detectability of a surface component by AES is about $1 \%$ of a monolayer.

Auger electron spectroscopic analysis of the various ash particles indicated that the surfaces of the bed ash particles were rich in calcium and silicon, while those of filter ash particles were rich in sodium and potassium. Figures 14 and 15 are the AES spectra of ash, respectively retained in the bed and deposited on the reactor wall. The spectra indicate that the major elements on the surface of the ash particles are calcium, sulfur, and oxygen. Minor quantities of magnesium, aluminum, silicon, iron, nickel, and sodium are also present. In contrast, the AES spectra of fine ash particles collected in the filter indicates that the major elements on their surfaces are sodium, potassium, oxygen, and sulfur (Figure 16). The indium peaks arise from the indium foil substrate on which the fly ash particles were mounted.

In AES, the relation between the peak amplitude and the atom concentration is a complex quantity that cannot be evaluated precisely from first principles, but semiquantitative estimates of the surface concentrations of the elements can be obtained by normalizing their peaks against peaks from a pure substance obtained under identical conditions. Table 16 lists the estimated atom fraction of elements in both wall ash and filter ash particles, using the indium foil as the calibration standard. 


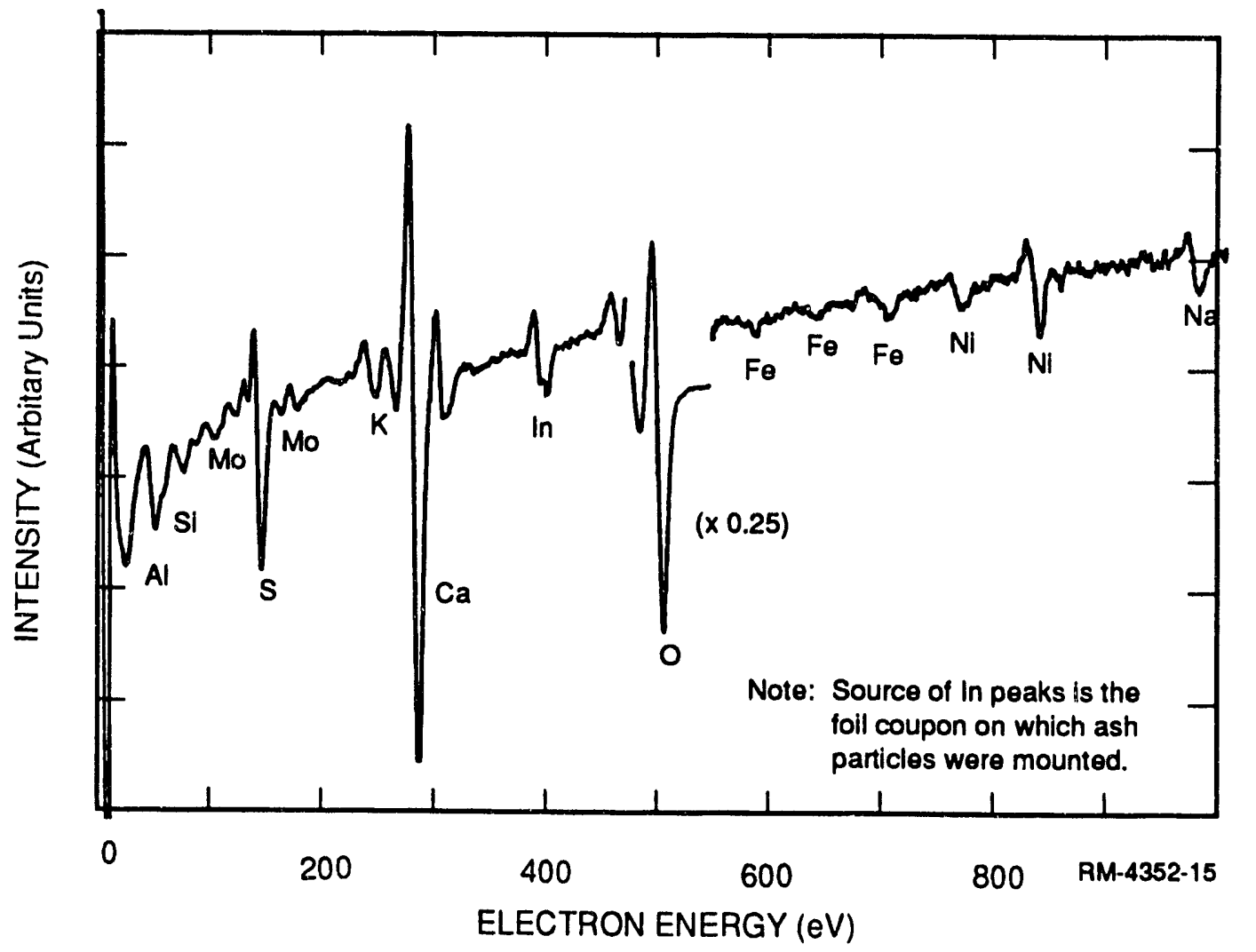

Figure 14. AES Spectrum of the ash retained in the bed. 


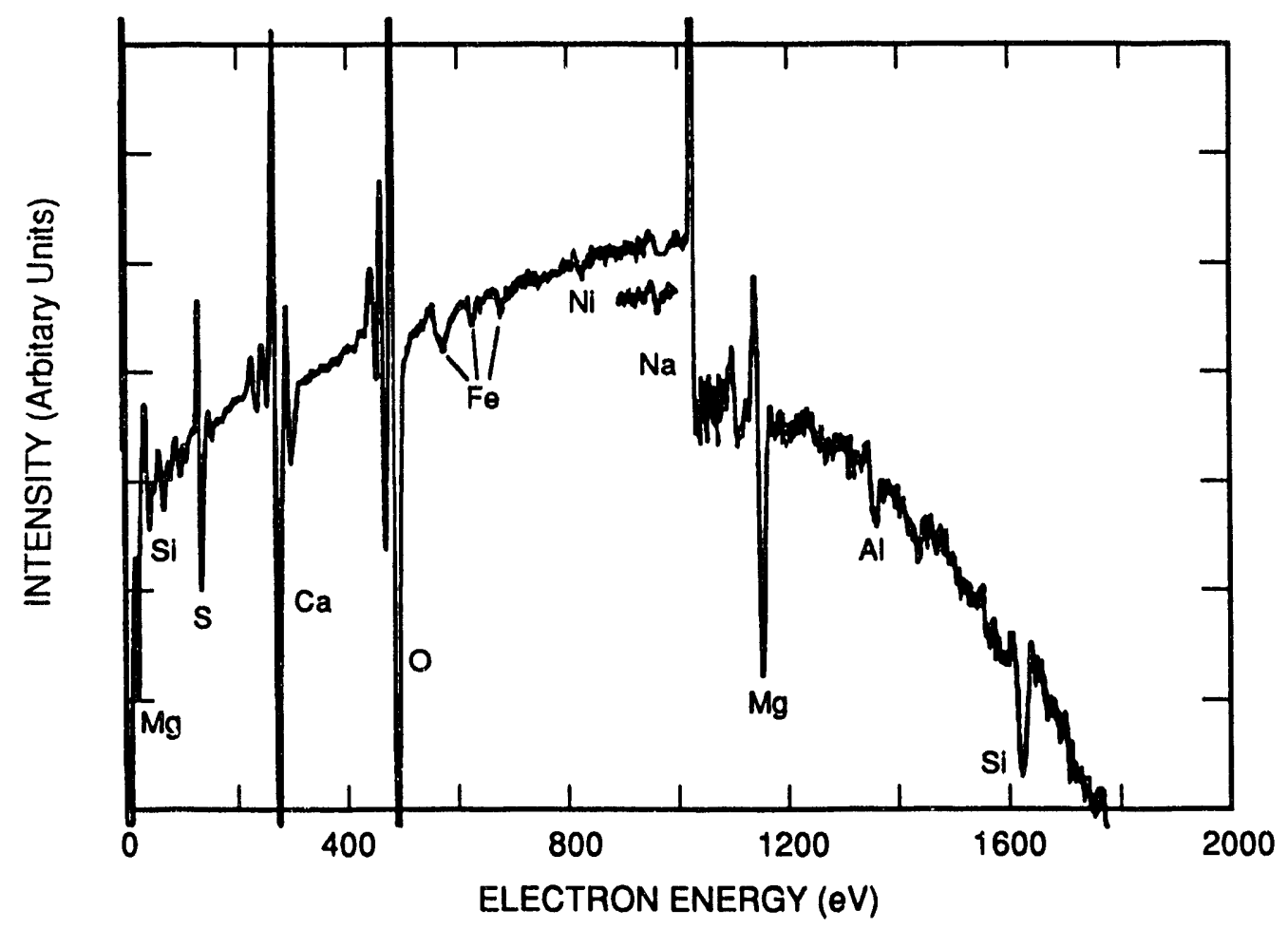

RM-4352-16

Figure 15. AES spectrum of the ash deposited on the reactor interior walls. 


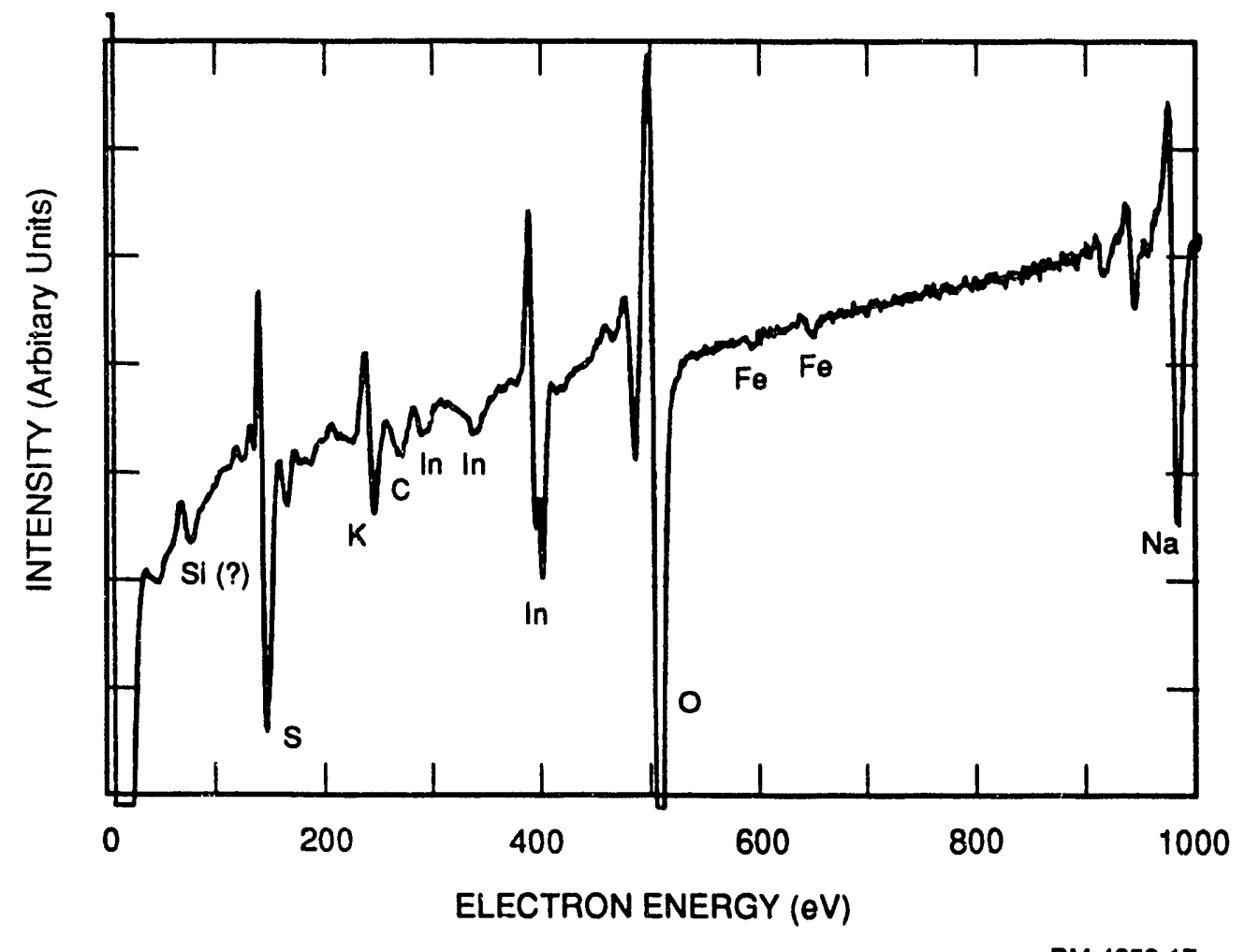

RM-4352-17

Figure 16. AES spectrum of the ash collected in the ceramic filter. 
Table 16

AUGER SPECTROSCOPIC ANALYSIS OF FLY ASH PARTICLE SURFACES

\section{Element}

$\mathrm{Na}$

$\mathrm{K}$

$\mathrm{Ca}$

$\mathrm{Si}$

$\mathrm{Mg}$

Al

$\mathrm{Fe}$

0

$\mathrm{s}$
Atom Fraction in Wall Ash

0.03

N.D.

0.34

0.19

0.12

0.04

$<0.01$

0.28

0.04

\section{Atom Fraction in Fllter Ash}

0.58

0.06

N.D.

N.D.

N.D.

N.D.

N.D.

0.25

0.10

N.D. $=$ Not detected

Oxygen concentrations in both samples were nearly the same, but calcium was predominant on the surface of the wall ash particles, whereas sodium was the predominant species on the surface of filter ash particles. The wall ash particles are coarser than the filter ash particles. Because of the comparatively large surface area of the fine particles, the surface concentration of the condensed alkali species could be higher with fine particles. Condensation of vapor phase alkali species during their travel from the combustion zone decreased the concentrations of other ash components such as magnesium, aluminum, and silicon species.

\section{GASIFICATION EXPERIMENTS}

A limited number of gasification runs were performed with Beulah Zap lignite. The coal particle size was in the range of 0.2 to $0.7 \mathrm{~mm}$, somewhat smaller than that used for the combustion runs. The air/coal ratio was $4.4 \mathrm{~g} / \mathrm{g}$, corresponding to $67 \%$ of that required for stoichiometric combustion. The steam/coal ratio was $8.8 \mathrm{~g} / \mathrm{g}$, and the temperature of the fluidized 
bed was maintained at $820^{\circ} \mathrm{C}$. The coal/air and steam/coal ratios are similar to those used in the KRW gasifier.

On-line mass spectrometric analysis of the gasifier gas stream gave a significant $\mathrm{NaCl}$ signal (AMU 58) corresponding to a $\mathrm{NaCl}$ vapor concentration in the gas stream of about $5 \mathrm{ppm}$. In addition to AMU 58, the sigual at AMU 23 also increased when coal was introduced and it reached a steady state after about $30 \mathrm{~min}$ (Figure 17, Table 17). he ratio of observed signal intensity at AMU 58 to that at 60 is less than the isotopic ratio of the two chlorine isotopes $\left(\mathrm{NaCl}^{35} / \mathrm{NaCl}^{37}=3\right)$ and this appears to be due to the contribution of $\mathrm{COS}$ vapor to the signal at AMU 60. COS is a known component in coal gasifier gas streams. It was not possible to estimate the quantity of $\mathrm{COS}$ in this experiment because other known signals (AMU 32, 28. and 44) arising from $\mathrm{COS}$ were masked by signals from $\mathrm{O}_{2}, \mathrm{~N}_{2}$, and $\mathrm{CO}_{2}$. Hence, the isotopic abundance ratio cannot be used to determine the contribution of $\mathrm{NaCl}^{35}$ vapor to the signal at AMU 58 .

Hydrocarbons such as acetone and butane can also yield signals at AMU 58, but they are unlikely to be present at a temperature of $820^{\circ} \mathrm{C}$ and hence it was assumed that the signal at AMU 58 was mainly due to $\mathrm{NaCl}^{35}$.

Table 17

TYPICAL SIGNAL INTENSITIES OF SODIUM SPECIES OBSERVED DURING GASIFICATION OF BEULAH ZAP LIGNITE AT $820^{\circ} \mathrm{C}$

Signal Intensity (Relative Units)

$\begin{array}{ccc}\text { AMU } & \text { No Coal Feed } & \text { During Gasification } \\ 23 & 4.5 & 29.2 \\ 36 & 39.0 & 700.0 \\ 40 & 630.0 & 630.0 \\ 58 & 29.0 & 112.0 \\ 60 & 72.0 & 182.0 \\ 81 & 49.0 & 77.0\end{array}$




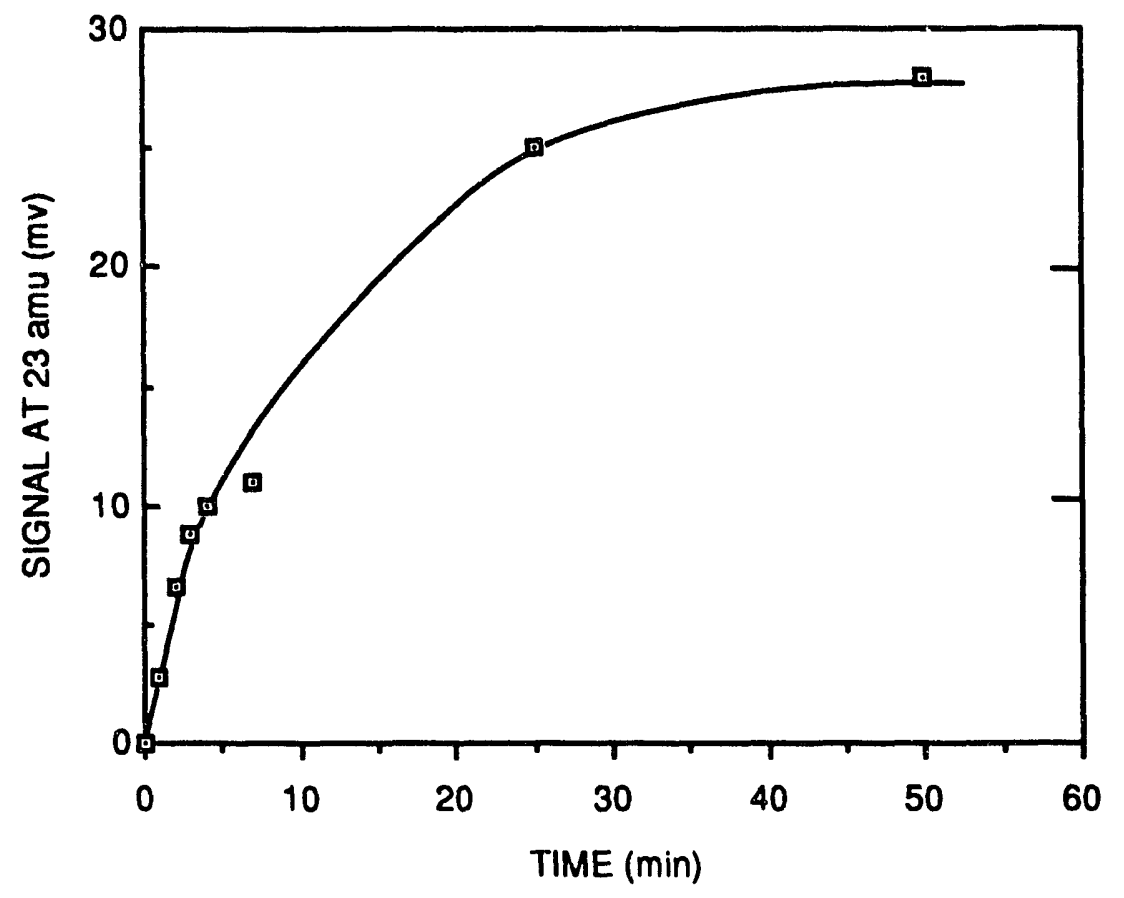

RA.M- $\mathbf{4 3 5 2 - 1 8}$

Figure 17. Evolution of vapor-phase sodium species during gasification of Beulah Zap lignite. 
The AMU 23 signal could be attributed to elemental $\mathrm{Na}(\mathrm{g})$ or to fragmentation of species such as $\mathrm{NaOH}$ or $\mathrm{NaCl}$ in the mass spectrometer ionizer. On an equivalent basis, the steady-state signal AMU 23 corresponds to about $14 \mathrm{ppm}$ of $\mathrm{NaCl}$. Hence, approximately $9 \mathrm{ppm}$ of the measured alkali must come from sodium species other than $\mathrm{NaCl}$. Because the mass spectrometric measurements were made with an ionization energy of $30 \mathrm{eV}$, it was not possible to distinguish between argon and $\mathrm{NaOH}$ (AMU 40). Thermodynamic calculations, described below, suggest that $\mathrm{NaCl}$ and $\mathrm{NaOH}$ are the most abundant sodium speries at $800^{\circ} \mathrm{C}$ under gasification conditions.

The amount of ash and char collected exceeded by about $12 \%$ the quantity of ash expected from the amount of coal fed o:uring the gasification run. About $64 \%$ of the ash remained in the bed, $45 \%$ was collected in the cyclone, and $3 \%$ was captured by the filter.

The release of sodium species from the Beulah Zap lignite ash samples containing small amounts of unreacted char was investigated in the temperature range of $600^{\circ}$ to $900^{\circ} \mathrm{C}$. Such ash is often used as a bed material in fluidized bed combustors, and it can be a source of sodium species. The ash used in our investigation was from an earlier combustion run. When the ash was heated in nitrogen, a sharp increase in the $\mathrm{Na}^{+}$signal (AMU 23) was observed but it decreased to a lower value within $30 \mathrm{~s}$. The burst in the $\mathrm{Na}^{+}$signal was likely to be caused by the volatilization of the organic sodium present in the residual coal. On further heating, no increase in $\mathrm{Na}^{+}$signal was noted until the temperature of the ash reached about $750^{\circ} \mathrm{C}$. As the temperature was raised above this level, the $\mathrm{Na}^{+}$signal continued to increase (Table 18). To identify the source of this signal, the ionization energy of the mass spectrometer was reduced to $12 \mathrm{eV}$, a level at which alkali compounds but not other inorganic species are ionized. The mass spectra obtained under these conditions indicated that the $\mathrm{Na}^{+}$signal observed during heating of the ash in nitrogen is due mainly to atomic sodium vapor. No other sodium species were observed.

The release of atomic sodium vapor is probably due to reduction by the char particles of sodium compounds present in the ash. Reducing potential sufficient for such reactions is consistent with conditions present within the pores of a burning coal particle, a location where most of the combustion oxygen has been consumed. Brittain et al. (1989) found atomic sodium vapor at temperatures above $1000^{\circ} \mathrm{C}$ in their mass spectrometric studies of coal specimens under vacuum conditions. Although their coal specimens were plasma-ashed to a near constant weight, enough unreacted carbon apparently remained in them to reduce sodium compounds in the ash. The observed simultaneous evolution of $\mathrm{CO}$ from these heated ash specimens further supports this hypothesis. 


$\begin{array}{ccc} & \text { Table } 18 \\ \text { OBSERVED CONCENTRATIONS OF ATOMIC SODIUM SPECIES DURING HEATING OF } \\ \text { BEULAH ZAP LIGNITE IN NITROGEN }\end{array}$




\section{THERMODYNAMIC EQUILIBRIUM CALCULATIONS}

Thermodynamic calculations, using the Gibbs energy minimization principle, were performed to identify equilibrium distribution of sodium species as functions of temperature and partial pressure of oxygen. These computations find the minimum Gibbs energy of a chemical system under constraints of temperature, pressure (or volume), and a fixed number of moles or chemical activities of the elements involved. Because the minimum Gibbs energy is the necessary and sufficient condition for chemical equilibrium, the minimization of Gibbs energy in a chemical system is equivalent to solving all the equilibrium constant equations of the system simultaneously. Several computational programs are available for these calculations. The program used here is an SRI-developed program (termed "CEQ") based on Villars-Cruise (Cruise, 1964). This approach uses linear algebra techniques to choose a basis set of chemical species from which all the included species can be generated, adjusts sequentially the amount of each chemical species present until all the equilibrium constant expressions for reactions that form species from the basis set are satisfied (Lamoreaux et al., 1986). The CEQ program is not prone to convergence failure, because the species present in negilgibly small quantities have little effect on the iteration process used to find the conditions that result in the minimum Gibbs energy. This program was also used to estimate the equilibrium vapor pressures of trace elements that might appear during coal gasification and combustion. Four-hundred different species were included in this calculation (Brittain et al., 1989).

Calculations were performed for temperatures of $800^{\circ}, 1000^{\circ}$, and $1200^{\circ} \mathrm{C}$ and oxygen partial pressures $\left[\mathrm{p}\left(\mathrm{O}_{2}\right)\right]$ of $10^{-15}, 10^{-10}, 10^{-5}$, and $0.1 \mathrm{~atm}$. The extremes in the value of oxygen partial pressure are representative of the respective environments in a coal gasifier and a coal combustor. In these calculations, the chlorine concentration of the coal was assumed to be 0.01 wt\% (minimum analytical limit), although the actual concentration could be lower. Tables 19 through 21 show the equilibrium distribution of various sodium species as a function of partial pressure of $\mathrm{O}_{2}$ and temperature. In these tables, the entry $0.00 \mathrm{E}+00$ represents a value smaller than $1 \times 10^{-10} \mathrm{~atm}$. 
Table 19

EQUILIBRIUM DISTRIBUTION OF SODIUM SPECIES PRESENT AT $800^{\circ} \mathrm{C}$ AS A FUNCTION OF OXYGEN PARTIAL PRESSURE

\begin{tabular}{|c|c|c|c|c|}
\hline \multirow[b]{2}{*}{ Specles } & \multicolumn{4}{|c|}{ Oxygen Partial Pressure (atm) } \\
\hline & $1.00 \mathrm{E}-15$ & 1.00E-10 & $1.00 \mathrm{E}-0.5$ & $1.00 E-01$ \\
\hline $\mathrm{Na}(\mathrm{g})$ & $1.74 \mathrm{E}-05$ & $1.63 E-08$ & $6.74 E-11$ & $8.68 E-13$ \\
\hline $\mathrm{NaCl}(\mathrm{g})$ & $1.06 \mathrm{E}-02$ & $1.42 \mathrm{E}-03$ & $1.38 E-04$ & $1.72 E-05$ \\
\hline $\operatorname{NaF}(g)$ & $8.68 E-05$ & $1.43 E-06$ & $1.05 E-07$ & $1.28 \mathrm{E}-08$ \\
\hline $\mathrm{NaOH}(\mathrm{g})$ & $5.41 E-04$ & $9.15 E-06$ & $6.74 \mathrm{E}-07$ & 8.21E-08 \\
\hline $\mathrm{NaAlSiO}_{4}(\mathrm{gl})$ & $2.47 E-04$ & $0.00 E+00$ & $0.00 E+00$ & $0.00 E+00$ \\
\hline $\mathrm{NaAlSi}_{2} \mathrm{O}_{6}(\mathrm{gl})$ & $7.04 E-07$ & $0.00 E+00$ & $0.00 E+00$ & $0.00 E+00$ \\
\hline $\mathrm{NaAlSi}_{3} \mathrm{O}_{8}(\mathrm{gl})$ & $1.92 E-08$ & $0.00 E+00$ & $0.00 E+00$ & $0.00 E+00$ \\
\hline $\mathrm{NaAlSiO}_{4}(\mathrm{~s})$ & 2.30E-01 & $0.00 E+00$ & $0.00 E+00$ & $0.00 E+00$ \\
\hline $\mathrm{NaAlSi}_{2} \mathrm{O}_{6}(\mathrm{~s})$ & $0.00 \mathrm{E}+00$ & $0.00 E+00$ & $0.00 E+00$ & $0.00 E+00$ \\
\hline $\mathrm{NaAISi}_{3} \mathrm{O}_{8}(\mathrm{~s})$ & $0.00 E+00$ & $0.00 E+00$ & $2.81 E-01$ & $2.81 E-01$ \\
\hline $\mathrm{Na}_{2} \mathrm{SO}_{4}(\mathrm{sl})$ & $6.45 E-01$ & $9.98 \mathrm{E}-01$ & 7.19E-01 & $7.19 E-01$ \\
\hline $\mathrm{Na}_{2} \mathrm{SiO}_{3}(\mathrm{l})$ & 4.13E-03 & $0.00 E+00$ & $0.00 E+00$ & $0.00 E+00$ \\
\hline $\mathrm{Na}_{2} \mathrm{Si}_{2} \mathrm{O}_{5}(\mathrm{l})$ & 3.33E-05 & $0.00 E+00$ & $0.00 E+00$ & $0.00 E+00$ \\
\hline $\mathrm{Na}_{2} \mathrm{SiO}_{3}(\mathrm{~s})$ & $0.00 E+00$ & $0.00 E+00$ & $0.00 E+00$ & $0.00 E+00$ \\
\hline $\mathrm{Na}_{2} \mathrm{Si}_{2} \mathrm{O}_{5}(\mathrm{~s})$ & $0.00 E+00$ & $0.00 E+00$ & $0.00 E+00$ & $0.00 E+00$ \\
\hline $\mathrm{Na}_{2} \mathrm{TiO}_{3}(\mathrm{~s})$ & 1.07E-01 & $0.00 E+00$ & $0.00 E+00$ & $0.00 E+00$ \\
\hline $\mathrm{Na}_{i} \mathrm{Ti}_{2} \mathrm{O}_{5}(\mathrm{~s})$ & $0.00 \mathrm{E}+00$ & $0.00 E+00$ & $0.00 E+00$ & $0.00 E+00$ \\
\hline Total & $9.98 \mathrm{E}-01$ & $1.00 E+00$ & $1.00 E+00$ & $1.00 E+00$ \\
\hline
\end{tabular}


Table 20

EQUILIBRIUM DISTRIBUTION OF SODIUM SPECIES PRESENT AT $1000^{\circ} \mathrm{C}$ AS A FUNCTION OF OXYGEN PARTIAL PRESSURE

Oxyoen Partial Pressure (atm)

\begin{tabular}{|c|c|c|c|c|}
\hline Specles & $1.00 E-15$ & $1.00 \mathrm{E}-10$ & $1.00 \mathrm{E}-05$ & $1.00 E-01$ \\
\hline $\mathrm{Na}(\mathrm{g})$ & $1.35 E-01$ & 8.19E-04 & $2.60 E-06$ & $4.12 E-08$ \\
\hline $\mathrm{NaCl}(\mathrm{g})$ & $1.72 E-02$ & $1.48 E-02$ & $6.30 \mathrm{E}-03$ & $1.89 E-03$ \\
\hline $\mathrm{NaF}(\mathrm{g})$ & $9.50 \mathrm{E}-03$ & 8.67E-04 & 4.98E-05 & 7.53E-06 \\
\hline $\mathrm{NaOH}(\mathrm{g})$ & $1.09 E-01$ & $1.94 \mathrm{E}-02$ & $1.09 E-03$ & $1.65 E-04$ \\
\hline $\mathrm{NaAlSiO}_{4}(\mathrm{gl})$ & $4.96 \mathrm{E}-04$ & $1.80 \mathrm{E}-03$ & $1.12 E-03$ & $0.00 E+00$ \\
\hline $\mathrm{NaAlSiO}_{4}(\mathrm{~s})$ & $0.00 E+00$ & 2.27E-01 & $2.06 \mathrm{E}-01$ & $0.00 E+00$ \\
\hline $\mathrm{NaAlSi}_{3} \mathrm{O}_{8}(\mathrm{~s})$ & $0.00 E+00$ & $0.00 E+00$ & $0.00 \mathrm{E}+00$ & $2.82 E-01$ \\
\hline $\mathrm{NaAlSi}_{2} \mathrm{O}_{6}(\mathrm{gl})$ & $4.64 E-08$ & $7.59 E-06$ & $6.42 E-05$ & $0.00 E+00$ \\
\hline $\mathrm{NaAlSi}_{3} \mathrm{O}_{8}(\mathrm{gl})$ & $1.20 \mathrm{E}-10$ & 8.91E-07 & $1.01 E-04$ & $0.00 E+00$ \\
\hline $\mathrm{Na}_{2} \mathrm{Cl}_{2}(\mathrm{~g})$ & $8.86 \varepsilon-05$ & $6.73 E-05$ & $1.24 \mathrm{E}-05$ & $1.01 E-06$ \\
\hline $\mathrm{Na}_{2} \mathrm{SO}_{4}(\mathrm{sl})$ & $0.00 E+00$ & $6.27 E-01$ & $7.85 E-01$ & $7.16 \mathrm{E}-01$ \\
\hline $\mathrm{Na}_{2} \mathrm{SiO}_{3}(\mathrm{~s})$ & $6.15 E-01$ & $0.00 E+00$ & $0.00 E+00$ & $0.00 E+00$ \\
\hline $\mathrm{Na}_{2} \mathrm{TiO}_{3}(\mathrm{~s})$ & $1.13 E-01$ & $1.09 E-01$ & $0.00 E+00$ & $0.00 E+00$ \\
\hline Total & $1.00 E+00$ & $1.00 E+00$ & $1.00 E+00$ & $1.00 E+00$ \\
\hline
\end{tabular}


Table 21

EQUILIBRIUM DISTRIBUTION OF SODIUM SPECIES PRESENT AT $1200^{\circ} \mathrm{C}$ AS A FUNCTION OF OXYGEN PARTIAL PRESSURE

\begin{tabular}{lcccc} 
& \multicolumn{4}{c}{ Oxygen Partial Pressure (atm) } \\
\cline { 2 - 6 } \multicolumn{1}{c}{ Specles } & $1.00 \mathrm{E}-15$ & $1.00 \mathrm{E}-10$ & $1.00 \mathrm{E}-05$ & $1.00 \mathrm{E}-01$ \\
$\mathrm{Na}(\mathrm{g})$ & $6.74 \mathrm{E}-01$ & $1.60 \mathrm{E}-01$ & $4.38 \mathrm{E}-03$ & $5.29 \mathrm{E}-05$ \\
$\mathrm{NaCl}(\mathrm{g})$ & $1.60 \mathrm{E}-02$ & $1.62 \mathrm{E}-02$ & $1.53 \mathrm{E}-02$ & $1.07 \mathrm{E}-02$ \\
$\mathrm{NaF}(\mathrm{g})$ & $8.03 \mathrm{E}-03$ & $6.04 \mathrm{E}-03$ & $3.07 \mathrm{E}-03$ & $3.87 \mathrm{E}-04$ \\
$\mathrm{NaOH}(\mathrm{g})$ & $1.38 \mathrm{E}-02$ & $3.57 \mathrm{E}-01$ & $1.85 \mathrm{E}-01$ & $2.12 \mathrm{E}-02$ \\
$\mathrm{NaAlSiO}$ & & $3.13 \mathrm{E}-02$ & $0.00 \mathrm{~g}+00$ & $0.00 \mathrm{E}+00$ \\
$\mathrm{NaAlSiO}_{4}(\mathrm{~s})$ & $2.19 \mathrm{E}-02$ & $0.00 \mathrm{E}+00$ & $2.33 \mathrm{E}-01$ & $2.14 \mathrm{E}-01$ \\
$\mathrm{NaAlSi}_{2} \mathrm{O}_{6}(\mathrm{gl})$ & $1.64 \mathrm{E}-01$ & $6.63 \mathrm{E}-05$ & $0.00 \mathrm{E}+00$ & $0.00 \mathrm{E}+00$ \\
$\mathrm{NaAISi}_{3} \mathrm{O}_{8}(\mathrm{gl})$ & $3.18 \mathrm{E}-04$ & $6.80 \mathrm{E}-05$ & $0.00 \mathrm{E}+00$ & $0.00 \mathrm{E}+00$ \\
$\left(\mathrm{NaOH}_{2}(\mathrm{~g})\right.$ & $3.55 \mathrm{E}-04$ & $1.36 \mathrm{E}-04$ & $3.64 \mathrm{E}-05$ & $4.31 \mathrm{E}-07$ \\
$\mathrm{Na}_{2} \mathrm{SO}_{4}(\mathrm{sl})$ & $2.05 \mathrm{E}-07$ & $0.00 \mathrm{E}+00$ & $4.10 \mathrm{E}-01$ & $7.07 \mathrm{E}-01$ \\
$\mathrm{Na}_{2} \mathrm{SO}_{4}(\mathrm{~g})$ & $0.00 \mathrm{E}+00$ & $2.08 \mathrm{E}-04$ & $4.22 \mathrm{E}-02$ & $4.68 \mathrm{E}-02$ \\
$\mathrm{Na}_{2} \mathrm{SiO}_{3}(\mathrm{l})$ & $7.60 \mathrm{E}-14$ & $3.17 \mathrm{E}-01$ & $0.00 \mathrm{E}+00$ & $0.00 \mathrm{E}+00$ \\
$\mathrm{Na}_{2} \mathrm{Si}_{2} \mathrm{O}_{5}(\mathrm{l})$ & $4.31 \mathrm{E}-02$ & $5.75 \mathrm{E}-03$ & $0.00 \mathrm{E}+00$ & $0.00 \mathrm{E}+00$ \\
$\mathrm{Na}_{2} \mathrm{Ti}_{2} \mathrm{O}_{5}(\mathrm{~s})$ & $5.34 \mathrm{E}-03$ & $0.00 \mathrm{E}+00$ & $0.00 \mathrm{E}+00$ & $0.00 \mathrm{E}+00$ \\
$\mathrm{Na}_{2} \mathrm{TiO}_{3}(\mathrm{~s})$ & $5.36 \mathrm{E}-02$ & $1.07 \mathrm{E}-01$ & $1.07 \mathrm{E}-01$ & $0.00 \mathrm{E}+00$ \\
$\mathrm{Total}$ & $0.00 \mathrm{E}+00$ & $1.00 \mathrm{E}+00$ & $1.00 \mathrm{E}+00$ & $1.00 \mathrm{E}+00$ \\
\hline & $1.00 \mathrm{E}+00$ & & & \\
\hline
\end{tabular}


Under gasification conditions $\left(\mathrm{P}_{\mathrm{O} 2}=10^{-15}\right)$ at $800^{\circ} \mathrm{C}$, only about $0.01 \mathrm{~mol}$ fraction of the sodium appears as vapor phase species; the remainder appears as $\mathrm{Na}_{2} \mathrm{SO}_{4}(\mathrm{~s}) \mathrm{NaAlSiO}_{4}(\mathrm{~s})$, or $\mathrm{NaTiO}_{3}(\mathrm{~s})$. However, at $1200^{\circ} \mathrm{C}$ the mol fraction of alkali in the vapor phase increases to about 0.7. $\mathrm{Na}_{2} \mathrm{SO}_{4}, \mathrm{NaAlSiO}_{4}$, and $\mathrm{Na}_{2} \mathrm{TiO}_{3}$ are the predominant solid phases at $800^{\circ} \mathrm{C}$, but above $1000^{\circ} \mathrm{C}$ the concentration of $\mathrm{Na}_{2} \mathrm{SO}_{4}$ (s) is negligibly small. $\mathrm{Na}_{2} \mathrm{SiO}_{3}$ and $\mathrm{Na}_{2} \mathrm{TiO}_{3}$ are the major solid phases at $1000^{\circ} \mathrm{C}$ whereas $\mathrm{NaAlSiO}_{4}(\mathrm{~s})$ and $\mathrm{Na}_{2} \mathrm{Ti}_{2} \mathrm{O}_{5}(\mathrm{~s})$ predominate at $1200^{\circ} \mathrm{C}$.

Under combustion conditions, the high value of $\mathrm{p}\left(\mathrm{O}_{2}\right)(0.1 \mathrm{~atm})$ produces a different equilibrium distribution of sodium species. Gaseous sodium-bearing species become significant at $1000^{\circ} \mathrm{C}$ where $\mathrm{NaCl}(\mathrm{g})$ is the predominant vapor species, accounting for about $0.002 \mathrm{~mol}$ fraction of the total sodium. At $1200^{\circ} \mathrm{C}$, the fraction of sodium present as $\mathrm{Na}_{2} \mathrm{SO}_{4}$ vapor $(0.05)$ exceeds that present as $\mathrm{NaCl}$ vapor $(0.01)$. $\mathrm{NaOH}$ vapor is also present at about 0.02 mol fraction at $1200^{\circ} \mathrm{C}$. $\mathrm{Na}_{2} \mathrm{SO}_{4}$ is the predominant solid phase in the temperature range of $800^{\circ}$ to $1200^{\circ} \mathrm{C}$, accounting for about 0.7 mol fraction of the sodium. The only other significant solid phases are various sodium aluminosilicates.

Figures 18 through 20 illustrate the calculated partial pressures of various species as a function of temperature and oxygen partial pressure. At $800^{\circ} \mathrm{C}, \mathrm{NaCl}(\mathrm{g})$ and $\mathrm{NaOH}(\mathrm{g})$ are present above $10^{-7}$ atm under gasification conditions and their partial pressures decrease as $\mathrm{p}\left(\mathrm{O}_{2}\right)$ is increased. At $1000^{\circ} \mathrm{C}$, the species present above a partial pressure value of $10^{-7} \mathrm{~atm}$ include $\mathrm{Na}(\mathrm{g}), \mathrm{NaOH}(\mathrm{g}), \mathrm{NaCl}(\mathrm{g})$, and $\mathrm{Na}_{2} \mathrm{SO}_{4}(\mathrm{~g})$. Whereas the partial pressures of $\mathrm{Na}(\mathrm{g}), \mathrm{NaCl}(\mathrm{g})$, and $\mathrm{NaOH}(\mathrm{g})$ decrease with an increase in $\mathrm{p}\left(\mathrm{O}_{2}\right)$, the partial pressure of $\mathrm{Na}_{2} \mathrm{SO}_{4}(\mathrm{~g})$ increases at higher $\mathrm{p}\left(\mathrm{O}_{2}\right)$. A similar trend is observed at $1200^{\circ} \mathrm{C}$.

These calculations indicate that the fraction of sodium in the coal released as vapor increases with increasing temperature. At low $\mathrm{p}\left(\mathrm{O}_{2}\right)$ the predominant vapor species are $\mathrm{Na}$, $\mathrm{NaOH}$, and $\mathrm{NaCl}$. Formation of $\mathrm{Na}_{2} \mathrm{SO}_{4}$ vapor in significant quantities $\left(>10^{-6} \mathrm{~atm}\right)$ requires temperatures higher than $1000^{\circ} \mathrm{C}$ and $\mathrm{p}\left(\mathrm{O}_{2}\right)$ greater than $10^{-10} \mathrm{~atm}$.

Measurement of the vapor phase sodium species in a fluidized bed gasifier or combustor using the molecular-beam sampling mass spectrometer indicates that the actual concentrations are less than those predicted by the thermodynamic calculations. The discrepancy between calculated and measured values is about an order of magnitude. In a fluidized bed reactor, a large number of ash particles are in intimate contact with the gas phase. Many of these particles in the free-board region are less than $10 \mu \mathrm{m}$ in diameter and thus constitute a solid phase with a very high 


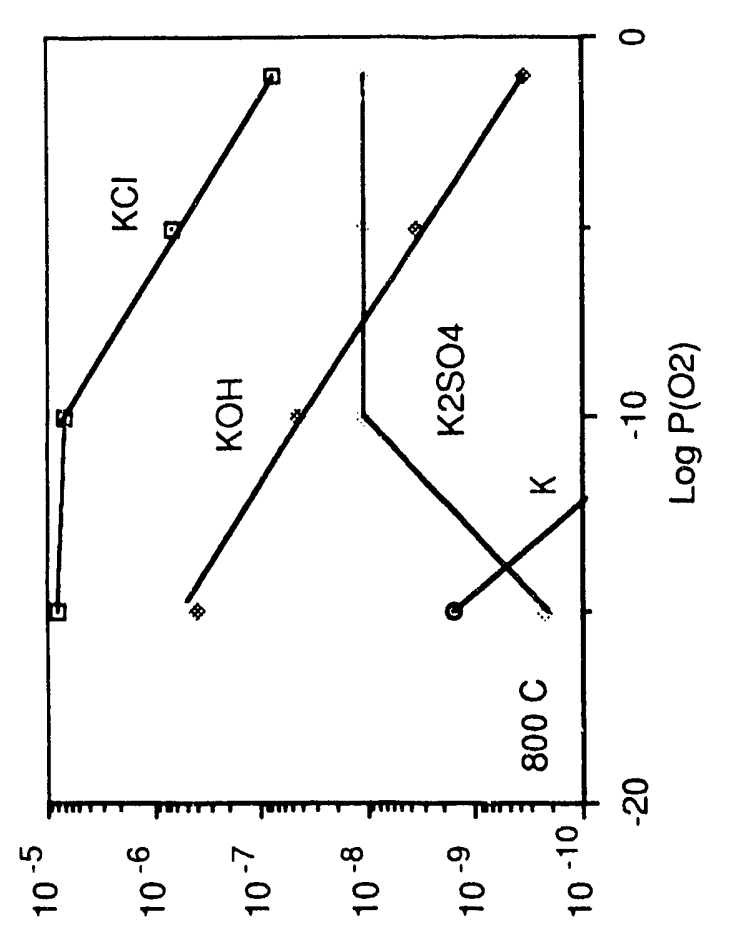

(ule) annssad le!nued

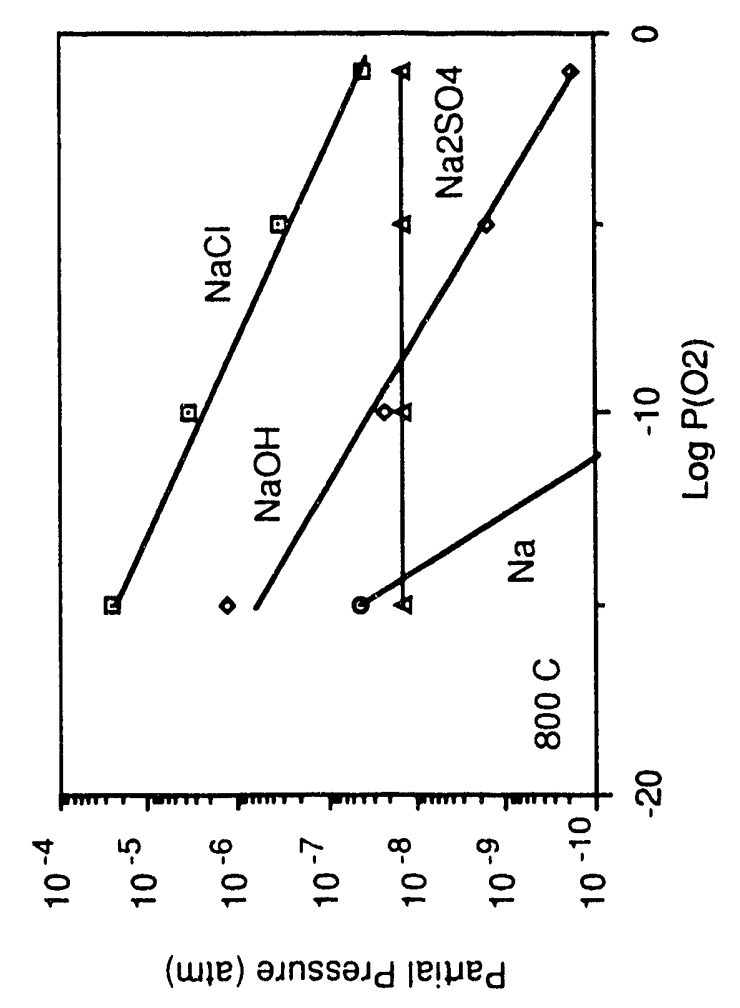

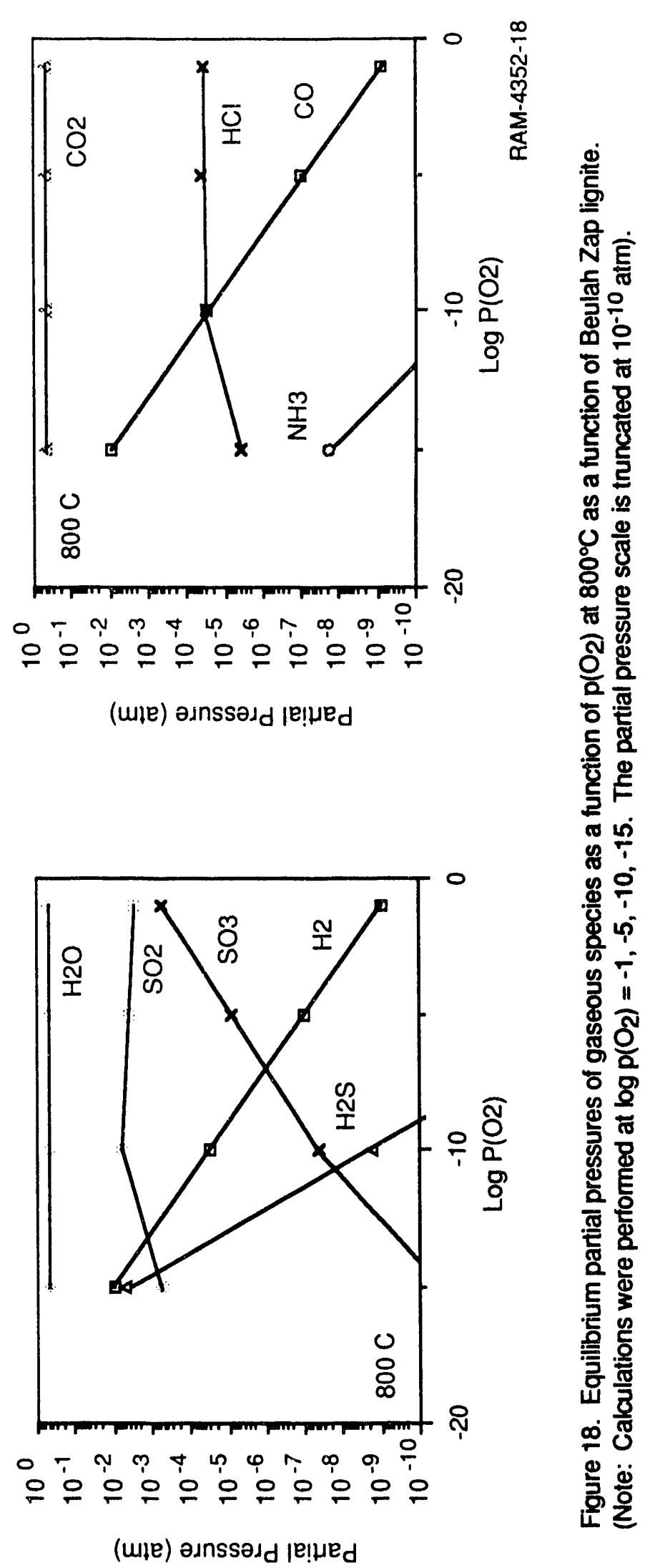




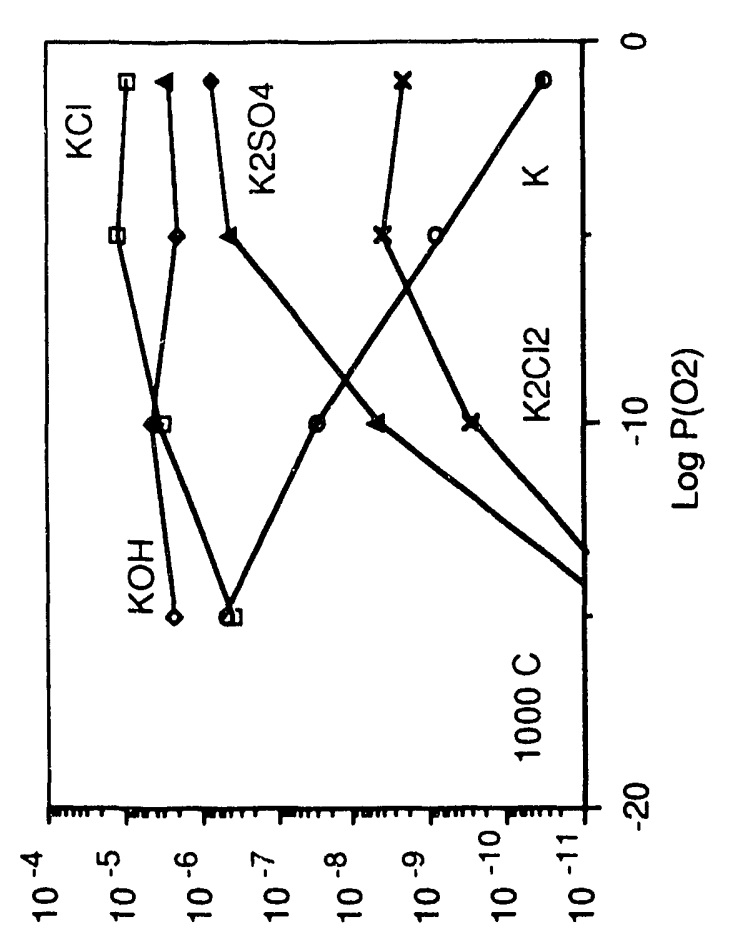

(ule) ounssedd le!̣lued

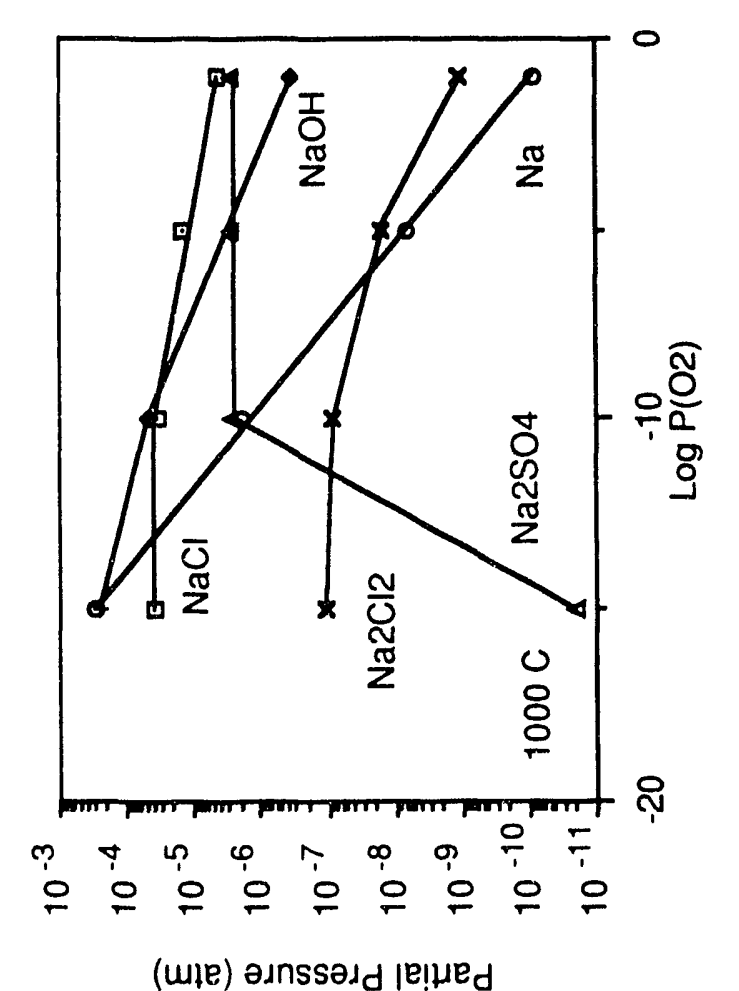

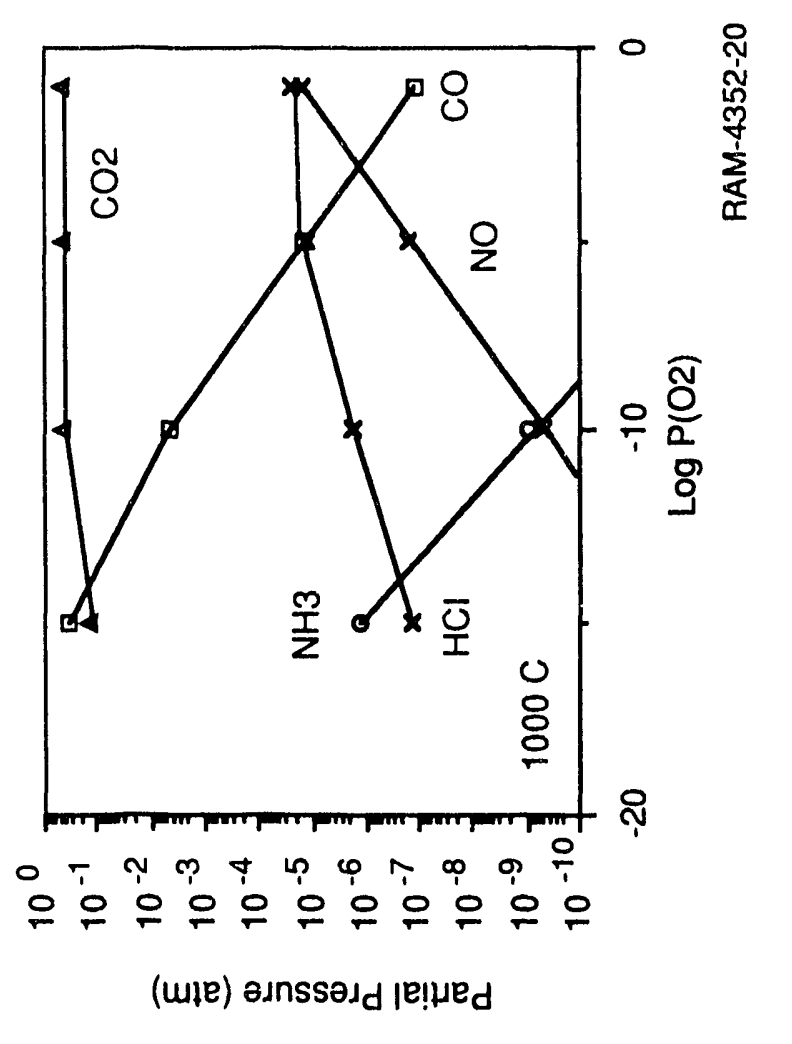

을

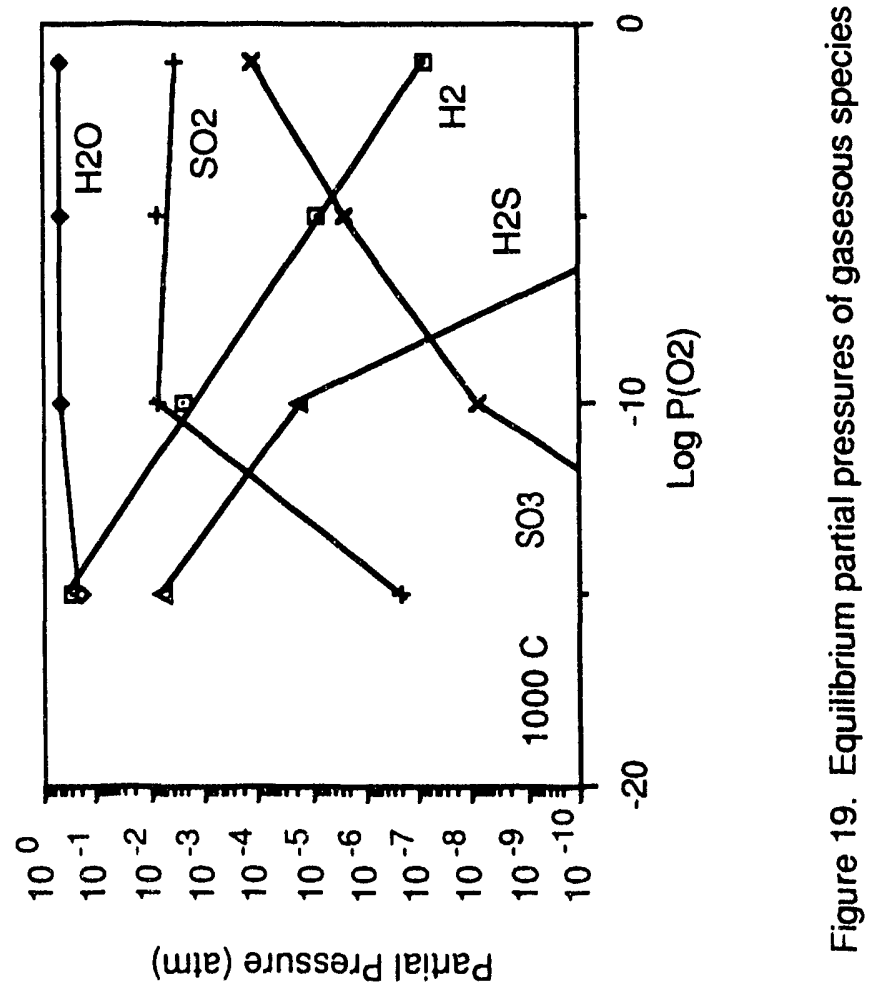




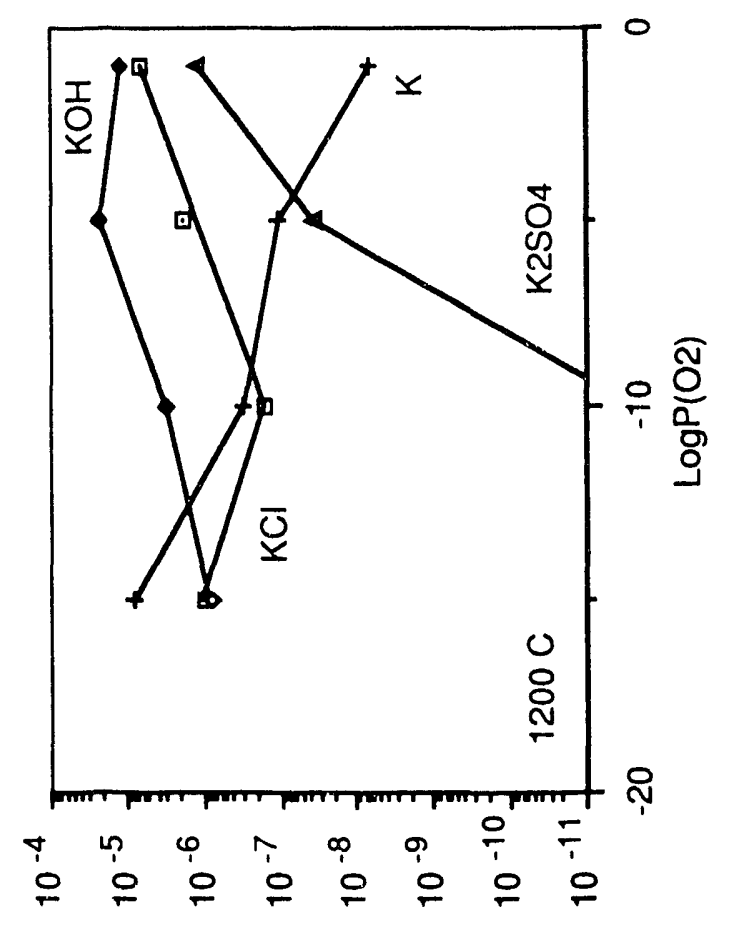

(wie) adnssadd ןe! hed

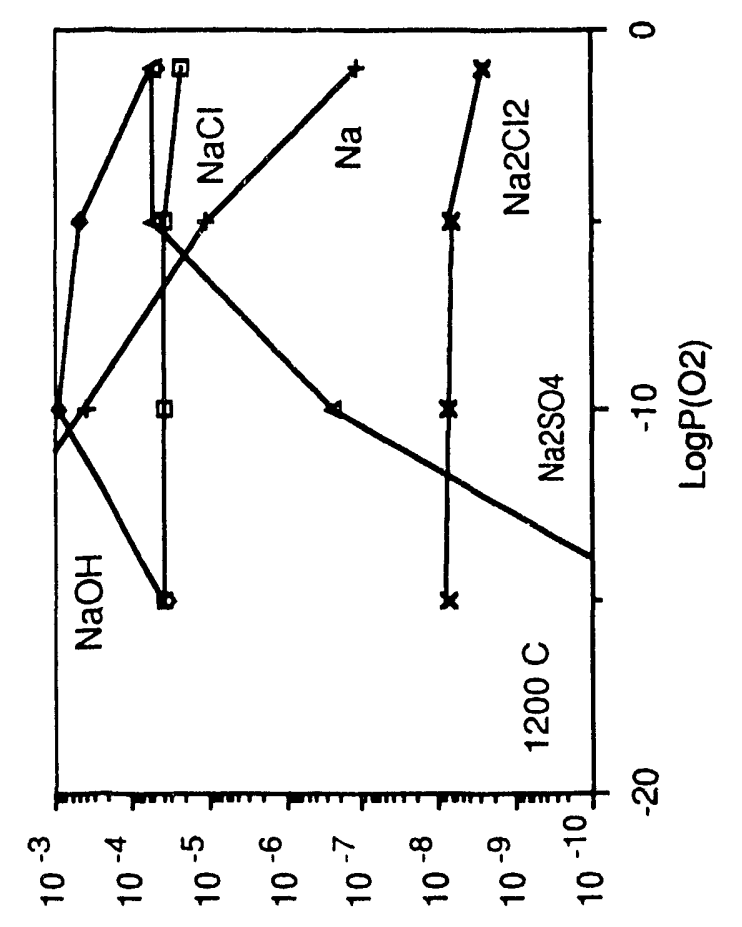

(uile) aunssadd je!nued

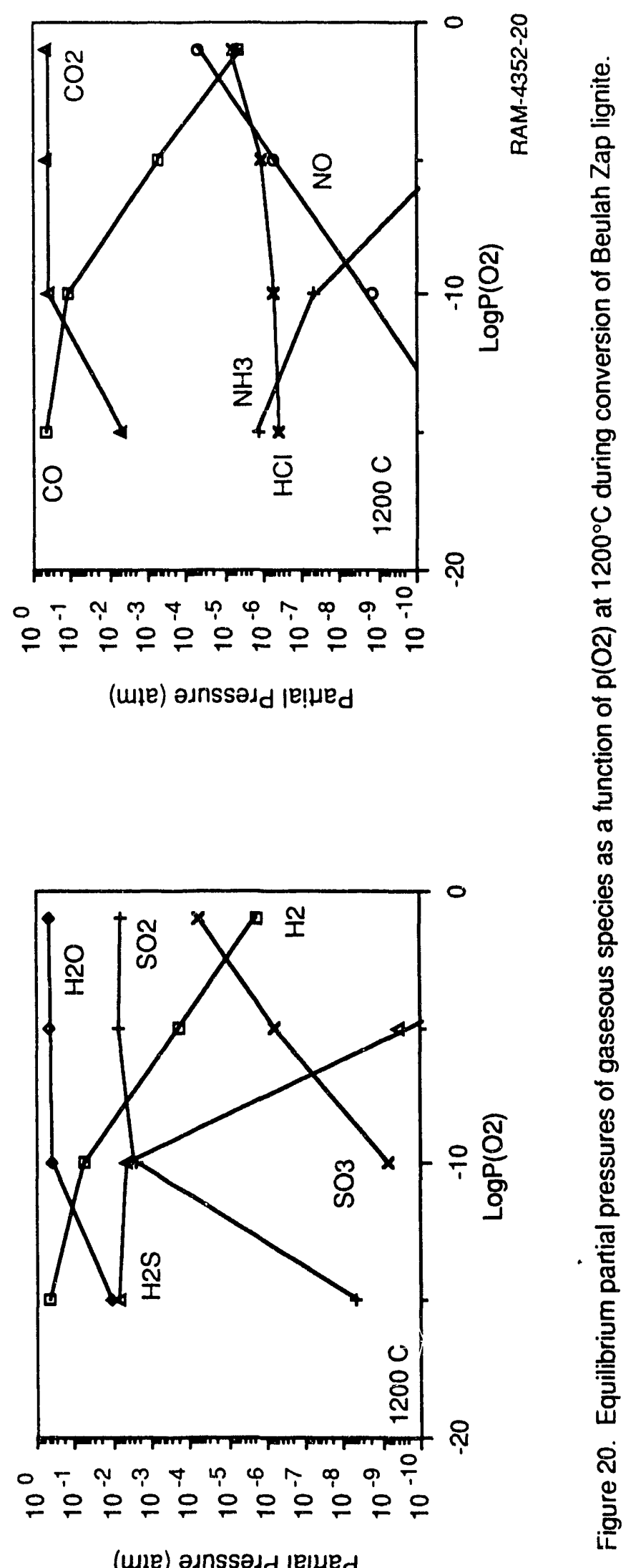

(uile) aגnssadd |e!̣นed 
surface/volume ratio. This phase is likely to act as an efficient sink on which the vapor phase sodium species adsorb.

Another explanation for the discrepancy between measured and calculated vapor phase alkali concentrations could arise from the values of thermodynamic properties of the various ash components used in the calculations. Accurate thermodynamic data are not available for several of these components, such as supercooled liquid or glassy phases. Following a common precedent, (Brittain et al., 1989; Hastie and Bonnell, 1985; Hastie et al., 1982) the assumption was made in the thermodynamic equilibrium calculations that mixtures of complex components were ideal solutions. In reality, the liquid ash particles may be far from ideal. In view of these assumptions, the discrepancy between the calculated and observed alkali vapor concentrations is not unreasonable. 


\section{CONCLUSIONS AND RECOMMENDATIONS}

The fate of alkali species during coal combustion and gasification was determined experimentally in a fluidized bed reactor. A molecular-beam sampling mass spectrometer was used to identify and measure the concentration of vapor phase sodium species in the high temperature environment. Concurrent collection and analysis of the ash established the distribution of sodium species between gas-entrained and residual ash fractions. The experimenal results were compared with predictions calculated for conditions of thermodynamic equilibrium. The results of the experimental and theoretical efforts led to the following conclusions.

- The molecular-beam sampling mass spectrometer can be used as a tool to measure trace-level alkali species from a high temperature reactor in which coal is gasified or burned under fluidized bed conditions. This technique provides unambiguous identification and measurement of important vapor species, including those containing sodium, without interference from entrained particles (fume).

- In the temperature range of $800^{\circ}$ to $950^{\circ} \mathrm{C}$, the concentrations of vapor phase sodium species $\left(\mathrm{Na}, \mathrm{Na} 2 \mathrm{O}, \mathrm{NaCl}\right.$, and $\left.\mathrm{Na}_{2} \mathrm{SO}_{4}\right)$ are equal to or less than 0.05 ppm under combustion conditions with excess air.

- Under gasification conditions with Beulah Zap lignite, sodium vapor species are present at about $14 \mathrm{ppm}$ at a temperature of $820^{\circ} \mathrm{C}$. Of this amount, $\mathrm{NaCl}$ vapor constitutes about 5 ppm and the rest is very likely $\mathrm{NaOH}$.

- Sodium present in coal as chloride enhances the vaporization of sodium species during combustion. Vapor phase concentration of both $\mathrm{NaCl}$ and $\mathrm{Na}_{2} \mathrm{SO}_{4}$ is increased when $\mathrm{NaCl}$ is added to the Beulah Zap lignite.

- Ash particles account for nearly $100 \%$ of the sodium in the coal during combustion in the investigated temperature range.

- Fine fly-ash particles $(<10 \mu \mathrm{m})$ are enriched in sodium. The amount of sodium species in this ash fraction may be as high as $30 \mathrm{wt} \%$ of the total.

- Sodium in the fine fly-ash particles generated during combustion of Beulah Zap lignite is mainly in the form of sodium sulfate.

- Sodium in the coarse ash particle phase retained in the bed is mainly in amorphous forms.

- Thermodynamic equilibrium calculations predict concentrations of vapor phase sodium species higher than those observed by about an order of magnitude. However, the calculations neglect any role of ash particles as adsorbents for 
vapor species and make simplifed assumptions to compensate for the unavailability of accurate thermodynamic data for mixed constituents. In view of these simplifications, the degree of agreement between measured and calculated values must be considered reasonable.

On the basis of these results and conclusions, the molecular beam sampling mass spectrometer used in this study is evidently a significant tool for measuring vapor phase alkali species in high-temperature, reactive, particle-laden, gaseous environments. Consequently, it should be the tool of choice in determining the fate of alkali species in advanced coal conversion systems,and it is recommended further work in this area be undertaken. The following specific recommendations are made:

- Use the molecular-beam sampling mass spectrometer to measure the vapor phase alkali species in a pilot-scale gasifier or combustor. Such measurements will provide reliable data on the severity of the vapor phase alkali problem at a practical level.

- Extend the bench-scale reactor study to include the temperature range and the coals that will be used in direct coal-fueled turbines. The concentration of vapor phase alkali in such systems is likely to be higher than in a fluidized bed combustor. 


\section{REFERENCES}

M. A. Alvin, J. E. Lane and T. E. Lippert (1989). Thermal/Chemical Degradation of Ceramic Cross Flow Filter Materials, Westinghouse Research Center, Topical Report - Phase I to U.S. Department of Energy under contract No: DE-AC21-88MC25034.

S. A. Benson and P. L. Holm (1985). Comparison of Inorganic Constitutents in Three Low-Rank Coals., Ind. Eng. Chem. Prod. Res. Dev., 24145.

D. W. Bonnell and J. W. Hastie (1979). 10th Materials Research Symposium on Characterization of High Temperature Gases and Vapors, NBS Special Publication, pp. 357

R. D. Brittain, R. H. Lamoreaux, K. H. Lau and M. E. Gusman (1989) Vaporization of Trace Inorganic Species from Coal Under Gasification and Combustion Conditions, SRI International, Report to U.S. Department of Energy under Contract No.: DE-AC21$86 \mathrm{MC} 23261$.

M. W. Chase, C. A. Davies, J. R. Downey, D. J. Frub, R. A. McDonald, and A. N. Syverud (1985). JANAF Thermochemical Tables, J. Phy. Chem. Reference Data, 14.

D. R. Cruise (1964). J. Phys. Chem., 683797.

N. B. Gallagher, L. E. Bool, J. O. Wendt and T. W. Peterson (1990). Combust. Sci. Tech., 74 211.

F. T. Greene, J. E. Beachey, and T. A. Milne (1979). 10th Materials Research Symposium on Characterization of High Temperature Vapors and Gases, edited by J. W. Hastie, NBS Special Publication 561/1, p 439.

F. T. Greene, J. E. O'Donnell, and D. Robaugh (1986). Proceedings of Sixth Annual Contractors Meeting on Contaminant Control in Coal-Derived Gas Streams, edited by K. E. Markel and D. C. Cicero, DOE/METC-86-6042, p. 37

F. T. Greene, J. E. O'Donnell, and D. Robaugh (1987). Provide Alkali Species Profiles Using a Well-Characterized Coal Combustor, Proceedings of the Annual Heat Engines and Gas Stream Cleanup Systems Contractors Review Meeting, edited by J. W. Byam Jr., and K. E. Markel Jr., DOE/METC-87/6077, p. 162

F. T. Greene, D. Robaugh, and J. E. O'Donnell (1988). "Provide Alkali Species Profiles Using a Well Characterized Coal Combustor," Final Report to U.S. Department of Energy under contract No.: DE-AC21-84MC21091, Midwest Research Institute .

W. J. Haas, D. E. Eckels, S. H. Lee, and R. F. Henry (1986). Recent Developments and Observations Pertinent to Real-Time Monitoring of Alkali Concentrations in the Hot Gas Streams from Fluidized Bed Combustion of Coal, Proceedings of the DOE Fifth Annual Contractors' Meeting on Contaminant Control in Hot Coal-Derived Gas Streams, edited by D. E. Cicero and K. E. Markel, DOE/METC-85-6025, p. 493 
G. B. Haldipur, D. K. Schmidt, and K. J. Smith (1.289). A 50-Month Gasifier Mechanistic Study and Downstream Unit Process Development Prigram for the Pressurized Ash-Agglomerating Fluidized-Bed Gasification System, Final Report by KRW Energy Systems Inc., to U.S. Department of Energy, Report No.: DOE/MC.21063-2740.

J. P. Hansel, D. R. Goff, R. G. Logan, R. Pineault, R. R. Romanosky and J. K. Wachter (1987). Rev. Sci. Instrum., 58, 1647.

J. W. Hastie and D. W. Bonnell (1985). High Temp. Sci., 19, 275.

J. W. Hastie, W. S. Horton, and D. W. Bonnell (1982). High Temp. Sci., 14, 669.

J. W. Hastie, E. R. Plante, and D. W. Bonnell (1981). Alkali Vapor Transport in Coal Conversion and Combustion Systems, U.S. Department of Commerce, NBSIR 81-2279.

D. L. Hildenbrand, K. H. Lau, T. D. Russell, E. G. Zubler, and C. W. Struck (1990). Thermodynamics of Gaseous Species in the Sodium-Scandium-Iodine System, $J$. Electrochem. Soc., 137, 3282.

N. J. Hodges and D. G. Richards (1989). The Fate of Chlorine, Sulphur, Sodium, Potassium, Calcium, and Magnesium During the Fluidized Bed Combustion of Coal, Fuel, 68, 440.

R. H. Lamoreaux, R. D. Brittain, J. Zieger, and S. C. Leach (1986). Determination of Solid Phase Boundaries in Coal Gas Desulfurization Sorbents, SRI International, Report to U.S. Department of Energy under Contract No.: DE-AC21-84MC21096.

S. D. Lee and E. L. Carls (1989). Measurement of Alkali Vapor Concentration in PFBC Flue Gas, International Conference on Fluidized Bed Combustion 1989, San Francisco, CA, American Society of Mechanical Engineers, p. 977

J. B. Mann (1967). J. Chem. Phy., 461646.

T. A. Milne and J. E. Beachey (1977). Combust. Sci. Tech., 16, 123.

M. Neville and A. F. Sarofim (1985). Fuel, 64, 384.

F. L. Robson and W. A. Blecher (1980). Assessment of Fuel Gas Cleanup Systems, United Technolgies Research Center, DOE/MC/12050-149.

M. N. Soltys and T. A. Milne (1982). The SERI High-Pressure Molecular Beam Mass Spectromutric Sampling System, Solar Energy Research Institute, SERI/TR-622-1172.

E. A. Sondreal, G. H. Gronhovd, and D. E. Severson (1985) Alkali Metals in Low-Rank Coals: A Critical Review and Analysis of Research Data on Their Occurrence and Effect in Combustion and Gasification Systems, Coal Energy Technology Consultants Inc.,

C. A. Stearns, F. J. Kohl, G. C. Fryburg and R. A. Miller (1978), in High Temperature Metal Halide Chemistry, edited by D. L. Hildenbrand and D. D. Cubicciotti, The Electrochemical Symposium Series No. 78. 
C. A. Stearns, F. J. Kohl, G. C. Fryburg and R. A. Miller (1979). Tenth Materials Research Symposium on Characterization of High Temperature Vapors and Gases, NBS Special Publication 561/1, p. 303

C. A. Stearns, R. A. Miller, F. J. Kohl, and G. C. Fryburg (1977). J. Electrochem. Soc, 124, p1145.

Westinghouse (1983). Gas Characterization from Fluidized Bed Coal Gasification, Report to U.S. Department of Energy DOE/MC/16024-1549. 
Appendix A

LASER-INDUCED FLUORESCENCE DETECTION STRATEGIES FOR SODIUM ATOMS AND COMPOUNDS IN HIGH-PRESSURE COMBUSTORS 
Laser Induced Fluorescence Detection Strategies for

Sodium Atoms and Compounds in High Pressure Combustors

\author{
Karen J. Rensberger, ${ }^{*}$ Michael L. Wise, and Gregory P. Smith \\ Molecular Physics Laboratory \\ SRI International \\ Menlo Park, CA 94025 USA
}

\begin{abstract}
A variety of laser induced fluorescence schemes were examined experimentally in atmospheric pressure flames to determine their use for sodium atom and salt detection in high pressure, optically thick environments. Collisional energy transfer plays a large role in the fluorescence detection. Optimum sensitivity, at the $\mathrm{ppb}$ level for a single laser pulse, was obtained with excitation of the $4 p-3 \mathrm{~s}$ transition at $330 \mathrm{~nm}$, and detection of the 3d-3p fluorescence at $818 \mathrm{~nm}$. Loss processes such as ionization (REMPI) and amplified spontaneous emission were examined. A new laser atomization - laser induced fluorescence technique was demonstrated for $\mathrm{NaOH}$ and $\mathrm{NaCl}$. A $248 \mathrm{~nm}$ excimer laser photodissociates the salt molecules present in the seeded flames prior to the atom detection laser pulse.
\end{abstract}

\title{
1. INTRODUCTION
}

The use of high-temperature, high-pressure reactors and turbines to produce electrical power from coal is limited by the presence of inorganic and organometallic impurities in the coal.[A] Gas turbines in power generating systems are susceptible to corrosion and deposition, especially from any remaining alkali metals and compounds, which may exist as solids, Iiquid aerosols, or vapors. The alkali content of most coal is in the 0.01 to 1.0 weight percent range. Alkali compounds are naturally present in the coal and are also formed by reactions with the indigenous sulfur, impurities, and agents added to control sulfur dioxide formation. [A,B] Economics set current upper limits on the total alkali species concentration in the coal gas used to drive turbines at $70 \mathrm{ppb}$ per gas heating value of $150 \mathrm{Btu} / \mathrm{scf}$. [B]

Proposed methods of control depend on the chemical and physical states of the alkalis in the hot coal gas. Gaining an understanding of the mechanism 
of alkali compound formation requires the measurement of both atomic and alkali salt concentrations in the reactor. Analysis of samples extracted from the reactor using mass spectrometry to identify the molecular states of gas phase inorganic species or by atomic emission spectroscopy to measure the total alkali content requires intrusive physical sampling. Laser-based optical spectroscopic techniques can make highly sensitive in situ measurements without significantly perturbing the chemical or physical state of the system. In this paper, we discuss the use of laser-induced fluorescence (LIF) to measure atomic sodium concentrations and laser-induced atomization (LIA) to dissociate sodium salts, which can then be detected using sodium atom LIF.

Laser-induced fluorescence is widely used in combustion diagnostics as a tool for measuring the concentrations of trace atomic and molecular species with spatial resolution, selectivity, and sensitivity.[D] Much of the previous work involving sodium atom detection concentrates on the use of laser saturated fluorescence, as the 3p-3s atomic transition (D-Iine) is saturated with easily obtainable laser fluences. But, the use of this atomic transition for the sodium detection of sodium in coal combustion systems is unsuitable for several reasons. The large strength of the atomic transition means that an absorption measurement will be nonlinear for the path lengths and high sodium levels present in the coal. This is because high laser intensities capable of saturation would be needed to get any signal through. For an LIF measurement, any fluorescence will be reabsorbed and emitted many times before reaching the outside of the reactor, making calibration difficult. Scattering of laser light into the LIF detection optics by particulates is a severe problem. To avoid these problems, we examine the use of several alternate one- and two-photon LIF techniques, in which higher electronic states of the sodium atom are accessed, to detect gas-phase atomic sodium concentrations ranging from $20 \mathrm{ppb}$ to $10 \mathrm{ppm}$. This work extends the previous work of Allen et al. [E] in which a laser excites the 3p, 3d, 4p, 5s, and 4d levels of sodium in an atmospheric pressure acetylene-air flame. Their study furnishes relative energy transfer and quenching rates for the higher electronic states, but little information on detection sensitivities. In our study, we measure the relative LIF signal sizes from these and other electronic levels, to select the best LIF measurement strategy for later use in a fluidized bed coal gasifier and combustor. The effects of multiphoton Ionization or enhanced 
collisional Ionization from these excited states, which can decrease the LIF signal, are also investigated using an ion probe.

The detection of alkali metal salts directly by LIF is more complicated, as the excited electronic states of these compounds are dissociative and the quantum yield for molecular fluorescence will be very small (probably less than $10^{-6}$ ). A variation on the LIF technique used to detect these and other molecules is the photofragment fluorescence (PF) technique. Laser excitation using sufficiently short wavelengths dissociates the molecule, leaving an electronically excited atomic fragment whose fluorescence forms the detected signal. For the sodium salts, light at $193 \mathrm{~nm}$ is energetic enough to dissociate all the common salts: $\mathrm{NaCl}, \mathrm{NaOH}, \mathrm{NaO}, \mathrm{Na}_{2} \mathrm{O}, \mathrm{NaO}_{2}$, and $\mathrm{Na}_{2} \mathrm{SO}_{4}$, and leave the sodium atom in the electronically excited $3 p$ state.[F] In the coal combustion system, detecting emission from this level has the problem of selfabsorption discussed before. We have applied a laser induced atomization (IIA) scheme which dissociates the salt compounds using less energetic photons at $248 \mathrm{~nm}$. Dissociation from the first excited molecular state produces sodium atoms in the ground stste, which are then observed as an enhancement in the atomic sodium LIF signal.

To perform the laboratory experiments, we simulate hot reactor conditions by using an acetylene-air flame on a slot burner. Aspiration of NaI solutions provides a controllable source of atomic sodium in the flame. We find that for two-photon excitation, significant ionization of the sodium occurs. The optimum system is single photon excitation of the 4p-3s transition near $330 \mathrm{~nm}$ and detection of the $3 \mathrm{~d}-3 \mathrm{p}$ fluorescence at $818 \mathrm{~nm}$, where population of the $3 \mathrm{~d}$ level occurs collisionally from the nearby excited 4p level. By running the flame lean and looking several $\mathrm{cm}$ above the burner we are also able to detect $\mathrm{NaOH}$, formed chemically in the flame, using the LIA/LIF technique.

\section{EXPERIMENTAI}

The experimental apparatus consists of three parts: a sodium atom and salt source that simulates high-temperature combustor environments, a laser system for laser-induced fluorescence and laser-induced atomization, and the detection optics and electronics.

For the high-temperature sodium atom and salt source, we use a slot burner from an atomic absorption spectrometer. Solutions of NaI ranging from 1000 to $1 \mathrm{ppm}$ (weight sodium) aspirate into a flame of acetylene and air, with 
most studies conducted using a $10 \mathrm{ppm}$ solution. Uncorrected thermocouple measurements show the temperature of the flame to be greater than $2000 \mathrm{~K}$. Measurements of the amount of solution aspirated compared to that returned through the drain from the nebulizer, and measurements of the gas flows, allows calibration of the amount of sodium present in the flame. The sodium flame concentrations measured this way agree to within a factor of 5 with those obtained from measuring the absorption of radiation from a sodium vapor lamp. A $1 \mathrm{ppm}$ (welght sodium) solution yields $-10^{11}$ atoms $\mathrm{cm}^{-3}$ of $\mathrm{Na}$ in the center of the flame $1 \mathrm{~cm}$ above the slot.

Photons from either a Nd:YAG-pumped dye laser or excimer-pumped dye laser excite the sodium atoms to one of several higher electronic states. The laser beam passes through the center of the flame about $1 \mathrm{~cm}$ above the burner along the $6 \mathrm{~cm}$ length of the slot. Table I lists the wavelengths needed for onephoton excitation from the 3 s state to the $3 p, 4 p$, or $7 p{ }^{2} p_{3 / 2}$ state or for two-photon excitation to the $4 d{ }^{2} D_{5 / 2}$ or $5 s{ }^{2} s_{1 / 2}$ state. The observation transitions and wavelengths for fluorescence are also listed. For the laserinduced atomization detection of sodium salts, an excimer laser operating on either ArF or KrF lines produces light at 193 or $248 \mathrm{~nm}$, respectively. This laser beam passes in the opposite direction and at the same height as the LIF laser beam, preceeding it in time, and with a larger beam diameter. For the two-photon excitation or laser-induced atomization, lenses of focal length between 100 and $175 \mathrm{~mm}$ focus the laser beam into the flame.

A lens (100 mm $\mathrm{fl}$ ) near the burner, at the same helght as the laser beam and perpendicular to $i t$, collects and collimates the fluorescence, and another lens (125 $\mathrm{mm} \mathrm{fl}$ ) focuses the light into a $0.35 \mathrm{~m}$ monochromator operated with a slit width of $1 \mathrm{~mm}$. The optics are easily aligned by observed the laser scatter off water aspirated without the flame burning. A R666S photomultiplier tube detects the dispersed fluorescence. The weaker signals are amplified $10 \mathrm{X}$ and $a l l$ are sent to a boxcar integrator with a gate width of $30 \mathrm{~ns}$. A chart recorder displays the output averaged over 10 laser shots. The construction of the ion probe is similar to that used by Cool to detect NO. [G] It consists of a Pt wire biased $+300 \mathrm{~V}$ with respect to a surrounding $P t$ spiral wire. The signal is detected across a load resistor with respect to ground.

3. RESULTS: SODIUM ATOM DETECTION 
As part of the initial construction of the burner apparatus, emission (no laser) from the easily observed 3p-3s transition was detected. Flame emission signals for solutions of NaI ranging from 0.5 to $4 \mathrm{ppm}$ are linear with solution concentration, and rise less than linearly for concentrations above that. This is evidence of optical trapping of $589 \mathrm{~nm}$ light emitted in the center of the flame being reabsorbed by flame sodium on its way out to the detection optics, across the short dimension of the burner.

The laser-induced fluorescence signal using this transition is linear for solution concentrations ranging from 1 to $10 \mathrm{ppm}$ and is saturated with a few microjoules of laser energy in a $0.2 \mathrm{~cm}^{2}$ beam. Absorption of the laser beam is also evident at these lower laser powers, and can be quite significant (>108) for a $4 \mathrm{ppm}$ solution over the $6 \mathrm{~cm}$ path length. This solution concentration corresponds to a total sodium concentration of $200 \mathrm{ppb}$ (mole) in the $2000 \mathrm{~K}$ flame.

Table II is a comparison of the relative signal sizes obtained at several observation wavelengths for other one- and two-photon excitation transitions to higher electronic states. The signals are observed using the same monochromator slit size and PMT voltage and are normalized for the sodium concentration (typically $200 \mathrm{ppb}$ ) and laser intensity (intensity squared for two photon excitations), but not for the monochromator and PMT response at each wavelength. The strong flame emission from sodium at $589 \mathrm{~mm}$ makes it difficult to observe fluorescence at this wavelength using the same PMT gain as at other wavelengths, where the flame emission is minimal. $\left(C_{2}\right.$ emission from the flame front is also seen at some of the other visible detection wavelengths.)

Fluorescence following two-photon excltation to the $5 \mathrm{~s}$ level can be observed at five different wavelengths, corresponding to emission from the $5 s$, 4d, 3d, 4p, and 3p levels. The excited Na atom undergoes collisions with the flame gases which change its electronic state, so light is observed from many levels. The strongest signal is from the 3p-3s transition; the $5 s-3 p$ signal is 30 times weaker. Fluorescence from the $4 \mathrm{~d}$ level is also observed, even though this level is $1300 \mathrm{~cm}^{-1}$ higher in energy than the initially excited $5 \mathrm{~s}$ level. The relative energy transfer and quenching rates in a fuel-rich acetylene-air flame have been previously measured[E], so we did not undertake an exhaustive study. Our measurements of the relative amount of light from each level agree qualitatively with this previous study. The other two-photon 
transition studied, excitation to the $4 \mathrm{~d}$ level, produces fluorescence signals somewhat smaller than for excitation to the $5 \mathrm{~s}$ level. The relative amounts of 4d fluorescence compared to $3 d$ fluorescence are different for the two different excitation schemes, in that the $4 \mathrm{~d}$ fluorescence is stronger when that level is directly pumped, rather than populated by collisions.

The dependence of the two-photon LIF signal on laser power for excitation to the $5 s$ or $4 \mathrm{~d}$ level does not show the expected slope of 2 for a $\ln$ signal vs. In laser power plot; rather, the slopes of the plots for LIF signals from the $3 d, 4 d$, and $5 \mathrm{~s}$ levels following excitation to the $5 \mathrm{~s}$ level are 1.2, 1.3, and 1.1, respectively. The power dependence for excitation to and fluorescence from the $4 \mathrm{~d}$ level is 1.0 . These results are obtained for laser pulse energies ranging from $200 \mu \mathrm{J}$ to $1.1 \mathrm{~mJ}$ in a beam focused to an area of $0.2 \mathrm{~cm}^{2}$ (5 mm dia). Signals using weaker laser power were too small to be measured. Both tighter or weaker focusing reduces the two-photon LIF signal intensity.

For both of these excitation tiansitions, strong ion signals are detected by the ion probe. The probe is placed horizontally across from the laser beam near the edge of the flame, close to the region where the LIF signal is viewed. The laser power dependence of the ion signal is 1.6 for the $4 \mathrm{~d}$ excitation transition. We surmise that the observed power dependences for the LIF signals are a result of ionization out of the $4 \mathrm{~d}$ or $5 \mathrm{~s}$ levels and that the ionization rates are comparable to the two-photon excitation rates. Therefore, many of the excited state sodium atoms ionize, rather than radiate. In the flame, we are able to detect these ions, but in a reactor, detection of the ions will be difficult. For a two-photon excitation scheme for sodium atom detection, ionization represents an important loss process, much like collisional quenching.

The results of three different one-photon excitation schemes to higher $p$ levels are now given. The energy needed for excitation to the 10p level is nearly coincident with the photon energy of a KrF excimer laser at $248 \mathrm{~nm}$; however, no fluorescence from any level using this laser source is observed, as the transition lies just outside the range of the excimer laser emission wavelengths by $0.2 \mathrm{~nm}$. Excitation to the 7p level, accomplished by using a $\beta$ $\mathrm{BaB}_{2} \mathrm{O}_{4}$ doubling crystal and an excimer-pumped dye laser, produces fluorescence in all the transitions listed in Table $I$. The signal levels for the stronger lines are included in Table II. The signal from the $3 \mathrm{~d}-3 \mathrm{p}$ transition is 
linear with laser power. Strong fluorescence was also observed from the $3 p$ level, using a much lower PMT voltage. It is evident that after excitation to this higher level, collisions spread out the sodium to all lower levels, as well as some higher levels. The observed signal levels are comparable to those using the two-photon excitation schemes, with most of the fluorescence (besides the $3 p$ ) from the $3 d$ and $4 d$ levels. 'This energy pooling into high $\ell$ levels has been observed previously. [L]

In addition to collisional energy transfer and quenching, and ionization (REMPI), a third process can reduce the LIF signal. In a three level system such as those explored here, amplified spontaneous emission (ASE) can occur along the laser beam.[I] In the above example of $330 \mathrm{~nm}$ excitation, gain might occur on the $4 \mathrm{p}-4 \mathrm{~s}$ transition at $2.2 \mu \mathrm{m}$ in the infrared once enough atoms are pumped up to the $4 \mathrm{p}$ level, provided the lower $4 \mathrm{~s}$ level remains relatively unpopulated by energy transfer collisions. The threshold and size of any ASE depend on both laser power and atom density. Recently, however, ASE has been shown to be a significant loss mechanism for LIF, even at relatively low concentrations and for two photon excitation in collisional environments.[I] The extent to which ASE depletes the LIF (and REMPI) signals for these sodium detection methods in flames was briefly examined. A lead sulfide or indium antimonide detector was placed in the forward direction of the laser beam $0.7 \mathrm{~m}$ beyond the burner, with appropriate glass filters to block the uv laser beam and stray $1.06 \mu \mathrm{m}$ YAG splash. ASE is observed above a concentration threshold of $40 \mathrm{ppm}$ in the flame. At this high concentration, our $4 \mathrm{~cm}$ flame is becoming optically thick to the laser beam. Thus it appears ASE is not an important LIF loss process for our lower sodium concentrations. No laser power dependence of the ASE signal is observed, down to $2 \mathrm{~mJ} / \mathrm{cm}^{2}$ (beam area $.01 \mathrm{~cm}^{2}$ ), which can be attributed to saturation of the excitation transition. Finally, we note that these observations differ from other recent atomic ASE observations in collisional environments by being in the infrared, and using a single photon pump transition which avoids the complication of degenerate four wave mixing processes associated with two photon excitation. One-photon excitation of sodium at $330 \mathrm{~nm}$ to the $4 \mathrm{p}$ level followed by detection of the fluorescence in the $3 d-3 p$ transition at $818 \mathrm{~nm}$ gives the highest signals of any of the systems examined, as listed in Table II. The fluorescence signal is linear with sodium concentration, as 11lustrated in the top of Figure 1. Clear evidence for the expected saturation of the excitation 
transition is given by the laser power dependence of the LIF signal in the lower portion of Fig. 1. ( REMPI $1+1$ signals are also observed, relative to IIF signals, at levels comparable to the $2+1$ process at $578 \mathrm{~nm}$. However, for our probe configuration and voltage, this REMPI signal is no longer linear with sodium concentration above $100 \mathrm{ppb}$, and even declined at high seeding levels.) Strong resonance fluorescence at $330 \mathrm{~nm}$ is also observed, along with a significant amount (108) of scattered light. The one-photon excitation to the 4p level followed by collisional relaxation of the sodium to the emitting 3d level appears to be much more efficient than direct two-photon excitation to the strongly emitting $4 \mathrm{~d}$ level, due to the ionization problem noted above in the two-photon scheme. We estimate a detection limit of $3 \mathrm{ppb}$ of sodium in an atmospheric flame, using a signal/noise ratio of 2 , is possible using only 10 laser shots. This limit can be extended easily to the low ppt range with longer averaging and a filtered PMT.

\section{RESULTS: SODIUM SALT DETECTION}

The detection of sodium salt.s by LIA/LIF in a hot collisional environment was tested by using equilibria in the atomic absorption burner flame burnt gases to prepare $\mathrm{NaOH}$ and $\mathrm{NaCl}$ in situ. This presents an advantage over the Los Alamos PF work, which used harder to maintain heated cells, but our collisional environment and salt concentrations are more difflcult to characterize. Two points can, however, be made. First, in actual applications as in the above sodium atom case, in situ calibrations will be made. Second, if the IIA step can be saturated, as demonstrated by a curvedover plot of signal versus excimer laser power, the total sodium salt concentration relative to sodium atoms can be measured.

Equilibrium calculations[S] can furnish an estimate of salt concentrations in the flame. Since atoms are favored at higher temperature, we add extra air to reduce the temperature to $1700 \mathrm{~K}$ (measured by thermocouple) and increase salt concentrations. In the normal NaI seeded flame, $\mathrm{NaOH}$ is the only salt of consequence. An equilibrium calculation for a $1700 \mathrm{~K}$ acetylene-air flame predicts $[\mathrm{NaOH}] /[\mathrm{Na}]-8$. (At the greater than $2000 \mathrm{~K}$ temperature used for the atom LIF experiments, no more than equal equilibrium concentrations are predicted. While $\mathrm{NaOH}$ will need to be considered in exact calibration runs, the previous estimates of LIF detection sensitivities should still be valid.) 
We first examined PF in the seeded burner to evaluate its potential in flames and to set up for the LIA/LIF experiments. Photodissociation using 193 $\mathrm{nm}$ ArF excimer laser light, focused to a maximum fluence of $0.02 \mathrm{~J} / \mathrm{cm}^{2}$, produced PF observed through an orange filter (to avoid third order laser scatter) and monochromator at the $589 \mathrm{~nm}(3 \mathrm{p}-3 \mathrm{~s})$ resonance 1 ine. The observed signal was linear in sodium (1.e., NaOH) concentration and photolysis leser power. However, significant laser absorption occurred along the $5 \mathrm{~cm}$ path through the flame (758). In spite of this complication and the fact that we did not achieve the optical intensities necessary to saturate $P F$, this clearly demonstrates that PF could be quantitatively applied to measure $\mathrm{NaOH}$ and other sodium salt concentrations in a flame, provided the $\mathrm{Na}(3 \mathrm{p}-3 \mathrm{~s})$ self absorption problem is minimal. This $\mathrm{NaOH} P F$ signal is independent of the original sodium source solution ( $\mathrm{NaOH}, \mathrm{NaI}, \mathrm{NaCl})$, as expected.

To form NaCl, a source of chlorine is also introduced, as $\mathrm{KCl}$ added to the aspirated solution. In the moist burnt gas environment, most of this chlorine will be tied up as $\mathrm{HCl}$, necessitating the introduction of large amounts of concentrated $\mathrm{KCl}$ solution. Calculations of this partial equilibrium $\mathrm{NaCl}$ concentration involves the species $\mathrm{Na}, \mathrm{NaOH}, \mathrm{Cl}$, and $\mathrm{HCl}$. Utilizing the Stanford equilibrium code and initial post flame front mole fractions of $.5 \mathrm{ppm} \mathrm{Na}$, and $16 \mathrm{ppm} \mathrm{Cl}$, we predict the mole fiactions listed in Table III. Since more species and equilibria are involved, the predicted NaCl could be off by a larger factor. However, the above indicates production of significant amounts of $\mathrm{NaCl}$ should be possible by varying the chlorine concentration.

When 100 times the amount of $\mathrm{KCl}$ is added, (run 2) the sodium salt PF signal increases fourfold. This can only be attributed to the fact that NaCl has a larger cross section than $\mathrm{NaOH}$ for photodissociation to excited $\mathrm{Na}(3 \mathrm{p})$ at $193 \mathrm{~nm},[F, J]$ and that $\mathrm{NaCl}$ has indeed been formed in the flame. The rough calculations predict a ratio of partial equilibrium salt concentrations $[\mathrm{NaCl}]$ (run 2)/[NaOH] (run 1 ) of 0.64 . This demonstrates viability for $\mathrm{NaCl} \mathrm{PF}$ in hot collisional environments and confirms our ability to generate NaCl for LIA/LIF studies.

We next changed the laser to $248 \mathrm{~nm}(\mathrm{KrF})$ to commence LIA/LIF studies. PF signals from $\mathrm{NaOH}$ were still observed, some 30 times below the level from $193 \mathrm{~nm}$, despite increased laser power (15 times) propagation, and focussing. The threshold for $\mathrm{NaOH}$ photodissociation to $\mathrm{Na}(3 \mathrm{p})$ is $130 \mathrm{kcal}$, or a 
wavelength of $220 \mathrm{~nm}$, so the PF signal must arise from $\mathrm{NaOH}$ with internal energy. The PF power dependence without focusing is linear, but using a 175 mm focussing lens we observe PF saturation near $1 \mathrm{~mJ}$, or about $0.3 \mathrm{~J} / \mathrm{cm}^{2}$ energy density. This is shown in Fig. 2 .

One question concerning PF measurements at high laser power to achieve saturation and maximum sensitivity is loss of signal due to ionization by a second ultraviolet photon. Excimer wavelengths are sufficiently short to ionize $\mathrm{Na}(3 \mathrm{p})$, but this state has a minimum in its cross section of $10^{-18} \mathrm{~cm}^{2}$ at these photon energies, [K] and no ion signals are observed with the REMPI probe during the PF experiments. Note that $248 \mathrm{~nm}$ photons cannot energetically lonize ground state sodium atoms from the LIA scheme.

Now the majority of the $\mathrm{NaOH}$ absorption at $248 \mathrm{~nm}$ is to the first dissociative state, forming ground state sodium which is the object of the LIA/LIF method. But the $248 \mathrm{~nm}$ PF saturation curve merely illustrates the nearly complete photodestruction of ground state $\mathrm{NaOH}$, to whatever combination of states. It applies equally to either PF via the second excited state or LIA/LIF via the first. We are blowing apart all the salt in the laser beam; saturation PF could also be applied here barring self-absorption problems, and the LIA/LIF will also be saturated. The published cross section[J] for $\mathrm{NaCl}$ absorption at $248 \mathrm{~nm}$ is $0.25 \AA^{2}$, so saturation is expected above $0.3 \mathrm{~J} / \mathrm{cm}^{2}$.

The same $248 \mathrm{~nm}$ PF saturation method could not be applied to demonstrate LIA/LIF saturation for NaCl, because the NaCl PF cross section at $1700 \mathrm{~K}$ is very small[F], and considerable amounts of $\mathrm{NaOH}$ are still present in the NaI + $\mathrm{KCl}$ seeded flame. All that is observed was saturation of the reduced $\mathrm{NaOH} \mathrm{PF}$ signal at similar power levels. However, the published cross section[J] for NaCl absorption at $248 \mathrm{~nm}$, applicable to the LIA dissociative state of $\mathrm{NaCl}$, of $2.5 \times 10^{-17} \mathrm{~cm}^{2}$ does predict an approach to saturation above laser energies of $.03 \mathrm{~J} / \mathrm{cm}^{2}$. Thus we are dissociating all the flame sodium salts in the laser beam at the $0.3 \mathrm{~J} / \mathrm{cm}^{2}$ power level. This is below the power levels at which breakdown or significant laser evaporation from condensed phase sodium contaling particulates is expected. If other major salts are expected, as $\mathrm{Na}_{2} \mathrm{SO}_{4}$ in coal combustors, further testing will be required, because convenient flame equilibrium synthesis methods appear difficult.

Next we demonstrate the LIA/LIF method, using the preferred scheme of 248 nm IIA, $330 \mathrm{~nm} \mathrm{LIF,} \mathrm{and} 818 \mathrm{~nm}$ detection. The results in Fig. 3 show a doubling for the $\mathrm{NaOH}$ case, and about 16 times the atom signal for $\mathrm{NaCl}$ (plus 
$\mathrm{NaOH}$ ) when the LIA laser is turned on. In this case the LIA power is not yet saturated, and the LIA laser beam overlaps the entire area being probed by the LIF laser beam. The delay between the lasers is $1.3 \mu \mathrm{s}$, but varying the delay beyond $10 \mu \mathrm{s}$ reduces the LIA/LIF signal greatly, showing a return to equilibrium amounts of sodium atoms and salts. The concentration dependence of the NaOH LIA/LIF signal was linear with sodium seeding (hence $\mathrm{NaOH}$ concentration). The detection limit for the LIA/LIF method should be roughly the same as that for sodium atoms, if the dissociation is saturated by the high excimer laser power. In principle, PF should be at least an order of magnitude more sensitive, given the relative fluorescence quantum yields, [E] provided the optical thickness for the resonance line is minimal and all lasers saturate. The equilibrium calculations described previously predict ratios of 8 and 20 for salt LIA/LIF versus atom LIF signals, but the excimer

energy density of $0.05 \mathrm{~J} / \mathrm{cm}^{2}$ is insufficient to saturate the photodissociation according to Fig. 2. Thus the NaCl seems easier to detect, as it was with $\mathrm{PF},[\mathrm{F}]$ probably due to a stronger absorption. [J]

\section{v. Conclusions}

The detection of sodium atoms by LIF in high temperature, high pressure environments is complicated by two main factors, self absorption of the fluorescence by even modest concentrations of ground state atoms, and collisional quenching effects. Thus the preferred strategy is excitation to higher lying electronic states other than the obvious and well known $589 \mathrm{~nm}$ resonance line, and observation of fluorescence to some third, intermediate level. Several one and two photon transitions were examined in the flame of an acetylene atomic absorption slot burner seeded with a sodium-containing solution. Losses to multiphoton ionization are observed directly, especially for the two photon transitions that require higher laser intensities. For all excitations, sizable fluorescence at $818 \mathrm{~nm}$, on the $3 d-3 p$ transition, illustrates the considerable effect of collisional energy transfer processes on the LIF. The optimum detection method selected is excitation of the 4p-3s transition at $330 \mathrm{~nm}$, with detection of fluorescence at $818 \mathrm{~nm}$. Single shot detection limits of less than $10 \mathrm{ppb}$ were demonstrated, and the transition can be saturated with laser energies of only $0.1 \mathrm{~mJ} / \mathrm{cm}^{2}$. While some amplified spontaneous emission was observed at high sodium concentrations, this does not appear a serious loss process for the chosen LIF scheme. 
Photofragment fluorescence techniques for detecting sodium salts, NaOH and $\mathrm{NaCl}$, were examined in seeded flames at $193 \mathrm{~nm}$ and $248 \mathrm{~nm}$. While. ionization does not appear to be a problem, self-absorption would be. In addition, large absorption of the $193 \mathrm{~nm}$ radiation by the flame gases is observed. The dissociative transitions are saturated at $0.3 \mathrm{~J} / \mathrm{cm}^{2}$.

To avoid the self-absorption problem, a new alternative method was developed. A $248 \mathrm{~nm}$ laser was used to dissociate the flame salts to ground state sodium, which was later detected by the above LIF technique. At the above-mentioned saturation fluences, this LIA/LIF method should offer the same sensitivity for sodium salts as for the atoms themselves. The quantitative linearity of both LIF and LIA/LIF methods was demonstrated. Due to the widespread collisional effects calibration will be required, but we plan to apply these methods to measure corrosive sodium species in a fluidized bed coal combustor and gasifier. 
Table I. Electronic transitions and wavelengths for sodium atom laserinduced fluorescence detection.

\begin{tabular}{|c|c|c|c|}
\hline $\begin{array}{l}\text { Excitation } \\
\text { Transition }\end{array}$ & $\begin{array}{c}\lambda \\
(\mathrm{nm})\end{array}$ & $\begin{array}{l}\text { Fluorescence } \\
\text { Transition }\end{array}$ & $\begin{array}{c}\lambda \\
(\mathrm{nm})\end{array}$ \\
\hline $3 p-3 s$ & 589 & $3 p-3 s$ & 589 \\
\hline $4 p-3 s$ & 330 & $4 p-3 s$ & 330 \\
\hline $7 p-3 s$ & 260 & $5 p-3 s$ & 285 \\
\hline $4 d-3 s$ & (2) $\times 578$ & $7 p-4 s$ & 781 \\
\hline \multirow[t]{8}{*}{$5 s-3 s$} & (2) $\times 602$ & $5 s-3 p$ & 615 \\
\hline & & $6 s-3 p$ & 515 \\
\hline & & $7 s-3 p$ & 475 \\
\hline & & $3 d-3 p$ & 818 \\
\hline & & $4 d-3 p$ & 568 \\
\hline & & $5 d-3 p$ & 498 \\
\hline & & $6 d-3 p$ & 467 \\
\hline & & $7 d-3 p$ & 449 \\
\hline
\end{tabular}

Table II. Normalized signal intensities.

\begin{tabular}{lllll}
\hline & \multicolumn{4}{c}{ Excitation Transition } \\
& $5 s-3 s$ & $4 d-3 s$ & $7 p-3 s$ & $4 p-3 s$ \\
$\begin{array}{c}\text { Fluorescence } \\
\text { Transition } \\
3 p-3 s\end{array}$ & 60 & & & \\
& & & & \\
$4 p-3 s$ & 0.05 & & 0.05 & 55 \\
$5 s-3 p$ & 2.0 & & 0.025 & \\
& & & & \\
$3 d-3 p$ & 3.0 & 0.25 & 0.35 & 100 \\
$4 d-3 p$ & 0.5 & 0.35 & 0.20 &
\end{tabular}


Table III. Calculated Equilibrium Concentrations at $1700 \mathrm{~K}$

$\begin{array}{lll}\text { Species } & \text { Mole fraction } & 8 \text { of sodium } \\ \mathrm{Na} & 2.4 \mathrm{e}-8 & 5 \\ \mathrm{NaCl} & 3.0 \mathrm{e}-7 & 57 \\ \mathrm{NaOH} & 2.0 \mathrm{e}-7 & 38 \\ \mathrm{Cl} & 2.6 \mathrm{e}-7 & \\ \mathrm{HCl} & 1.6 \mathrm{e}-5 & \\ \mathrm{Oh} & 8.3 e-5 & \end{array}$

Acknowledgements

This work was supported by the U.S.D.O.E. Morgantown Energy Technology Center through Contract DE-AC21-87MC24012.

* Current address Sverdrup Technology, Inc., Lewis Research Group, Cleveland, $\mathrm{OH}$

- Current address Dept. of Chemistry, Stanford University, Stanford,CA.

\section{REFERENCES}

A. J. W. Hastie, E. R. Plante, and D. W. Bonnell, "Alkall Vapor Transport in Coal; Conversion and Combustion Systems," U.S. Dept. of Commerce, NBSIR 81-2279, Washington, 1981.

B. F. L. Robson and W. A. Blecher, "Assessment of Fuel Gas Cleailup Systems," United Technologies Research Center, Report DOE/MC/12050$149,1980$.

D. David R. Crosley, Laser Probes for Combustion Chemistry, ACS Symposium Series $134,1980$.

E. John E. Allen, Jr., William R. Anderson, David R. Crosley and Todd D. Fansler, "Energy Transfer and Quenching Rates of Laser-Pumped 
Electronically Excited Alkalis in Flames," Seventeenth Symposium (International) on Combustion, 1979, p. 797.

F. Richard C. Oldenborg and Steven L. Baughcum, "Photofragment Fluorescence as an Analytical Technique: Application to Gas-Phase Alkali Chlorides," Anal. Chem. 58, 1430 (1986); R. C. Oldenborg and K. E. Apt, "Optical Detection of Corrosive Compounds," Los Alamos Report LA-UR-87-3877, 1987.

G. Terrill A. Cool, "The Quantitative Measurement of NO Density by Resonance Three-Photon Ionization," App1. Opt. 23, 1559 (1984). (check this one)

H. I. M. Humphrey, T. F. Gallagher, W. E. Cooke, and S. A. Edelstein, "Collisional Deactivation of Higher $\mathrm{Na} s$ and Manifold States by $\mathrm{N}_{2}, "$ Phys. Rev. A 18, 1383 (1978).

I. A. D. Sappey and J. B. Jeffries, "Detection of chlorine in R. F. Plasmas by Laser Excited Stimulated Emission," Appl. Phys. Lett. 55, 1182 (1989); M. Alden, W. Westblom, and J. E. M. Goldsmith, "Two Photon Excited Stimulated Emission from Atomic Oxygen in Flames and Cold Flows," Opt. Lett. 14, 305 (1989).

J. N. Futura, E. Yoshimura, H. Haraguch1, and K. Fuwa, "The Photodissociation of Alkall Halides in Air-Acetylene Flames as Studied by Molecular Absorption Spectroscopy," Spectr. Acta 33B, 715 (1978); P. Davidovits and D. C. Brodhead, "Ultr.riolet Absorption Cross Sections for the Alkall halide Vapors, " J. Chem. Phys. 46, 2968 (1967).

K. J. M. Preses, C. E. Burkhardt, R. L. Corey, D. L. Earson, T. L. Daulton, W. P. Garver, J. J. Leventhal, A. Z. Msezane, and S. T. Manson, "Photoionization of the Excited 3p State of Sodium: Experiment and Theory," Phys. Rev. A 33, 1264 (1985).

I. T. F. Gallagher, W. E. Gooke, and S. A. Edelstein, "Collisional 
Angular Momentum Mixing of $f$ States of Na," Phys. Rev. A 17, 904 (1978).

S. W. C. Reynolds, "The Element Potential Method for Chemical Equilibrium Analysis: Implimentation in the Interactive Program STANJAN," Dept. of Mechanical Engineering, Stanford University (1986). 


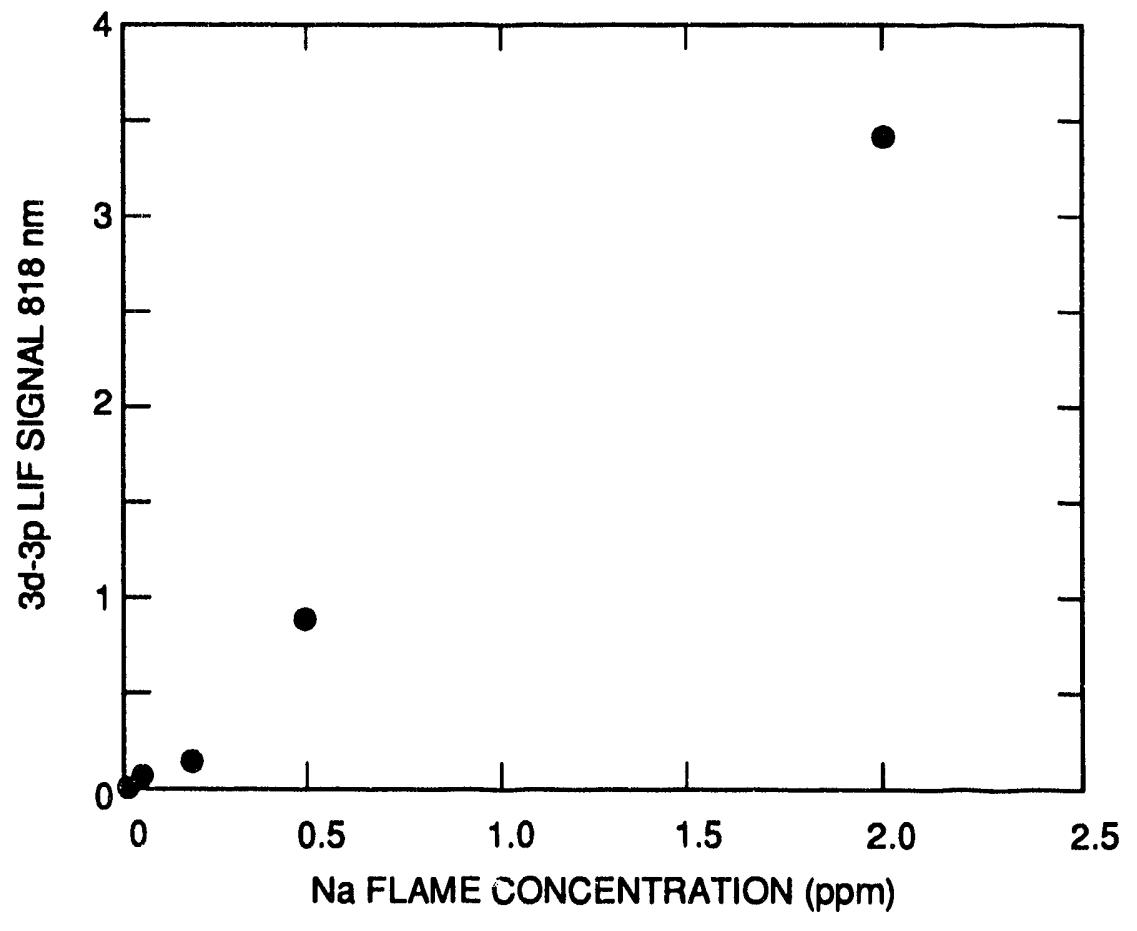

CM-320522-4

Figure A1(a). Sodium laser-induced fluorescence versus concentration escitation of the $4 \mathrm{p}-35$ transition at $330 \mathrm{~nm}$.

Note: the $818 \mathrm{~nm} 3 \mathrm{~d}-3 p$ signal is plotted as a function of the mole fraction in the flame. 


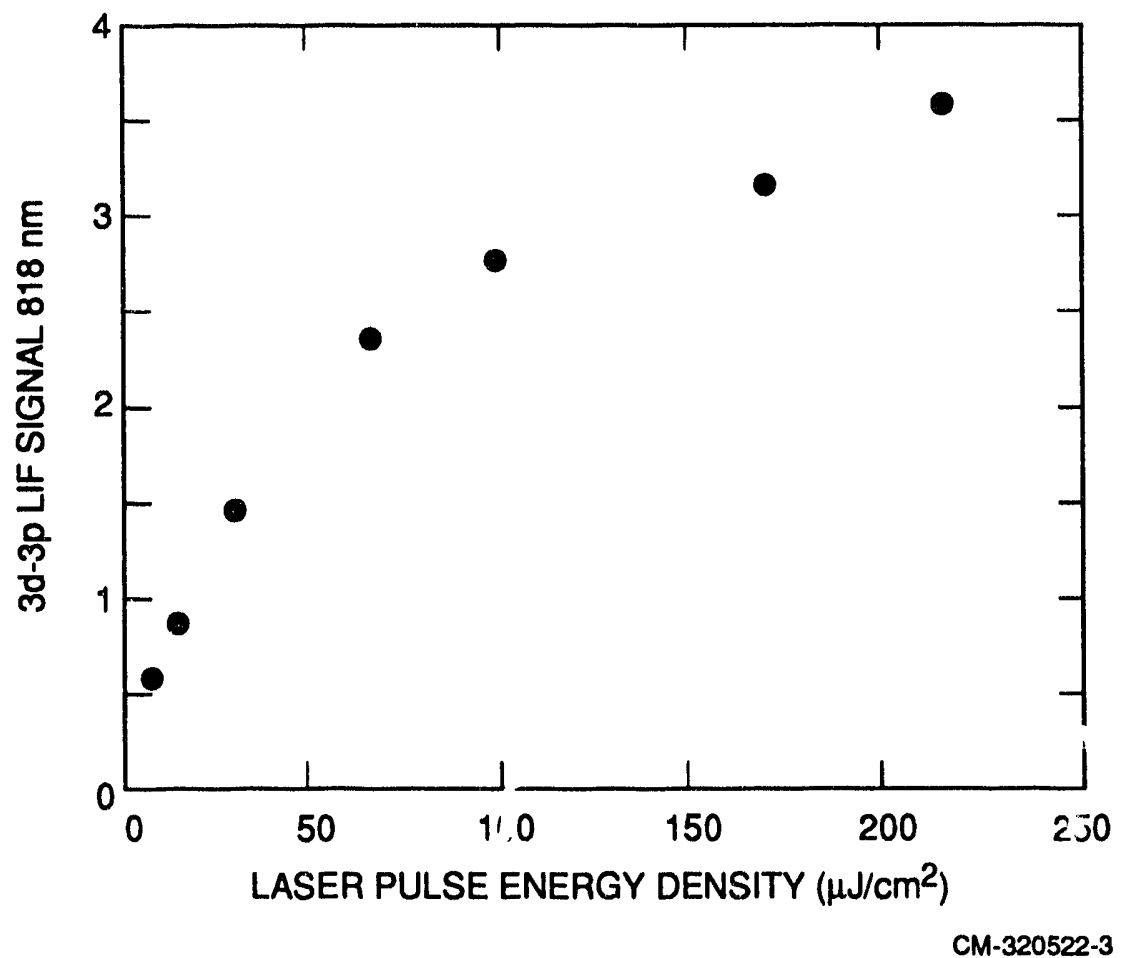

Figure $A 1(b)$. Saturation curve for the sodium laser-induced fluorescence signal.

Note: Signal is plotted as a function of laser fluence. 


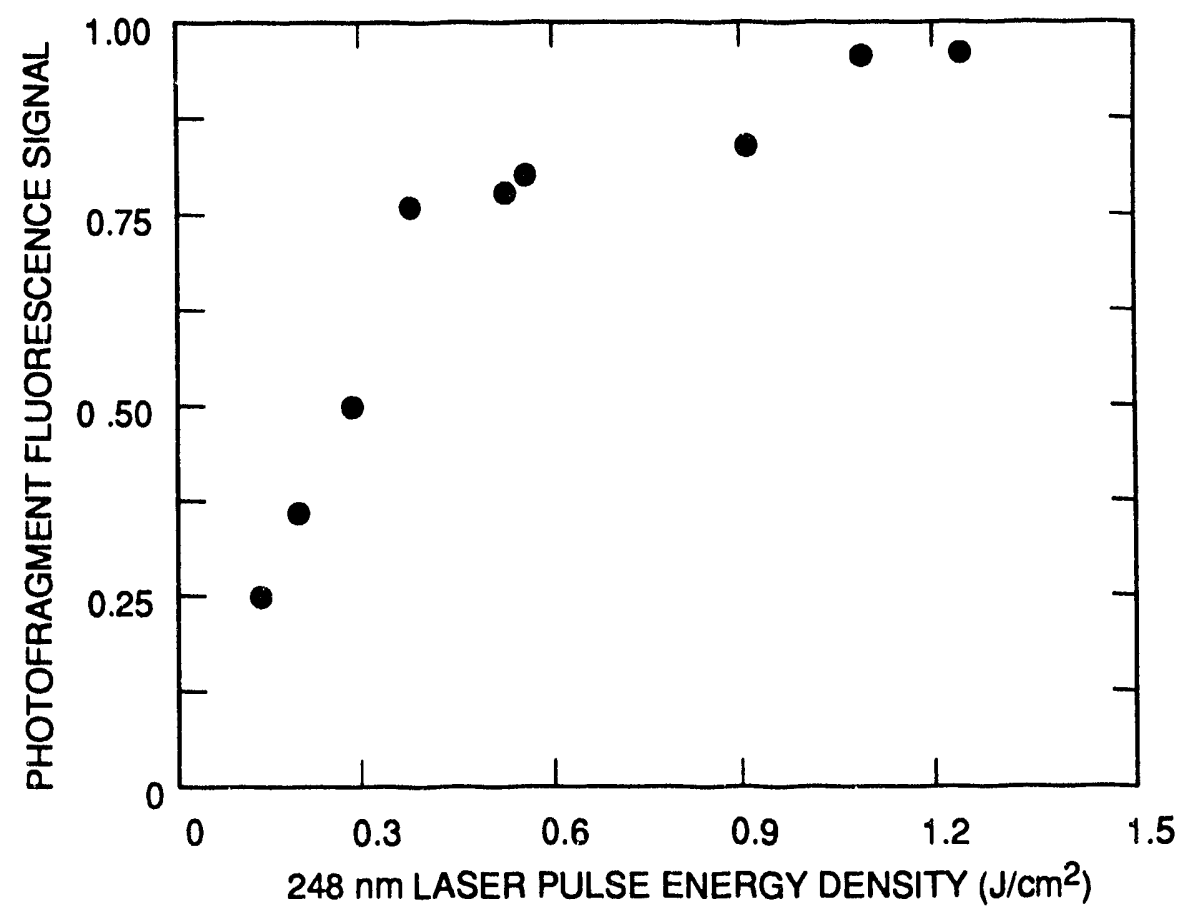

CM-320522-5

Figure A2. Photofragment fluorescence signal from sodium (4p) excited by the photodissociation of $\mathrm{NaOH}$ at $248 \mathrm{~nm}$ in a flame, as a function of excimer laser power. 


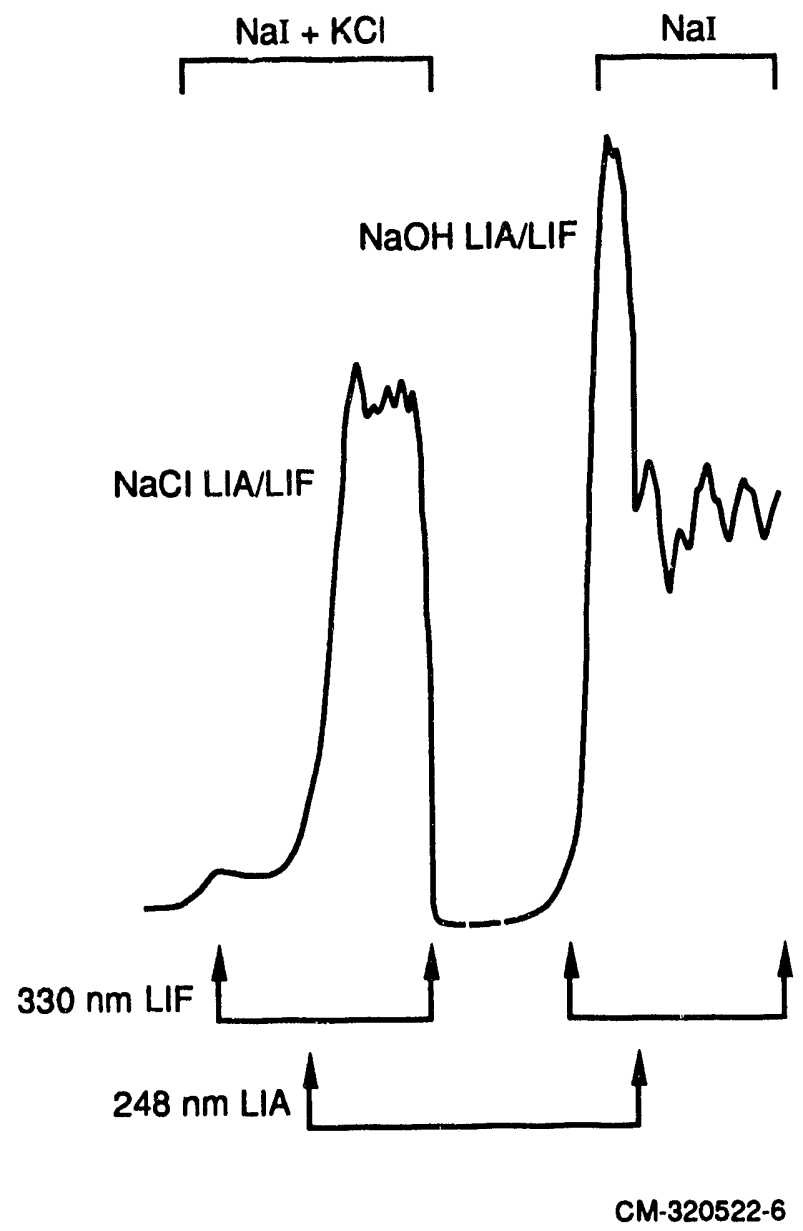

Figure A3. Laser induced atomization-laser-induced fluorescence signals for $\mathrm{NaCo}$ and $\mathrm{NaOH}$ in seeded flames compared with the atomic sodium LIF signals.

Note: Upper label indicated the seeding solutions, and lower label the time history of laser irradiation. scale change is arbitrary for the two solutions. 
Appendix B

DESIGN OF MOLECULAR-BEAM SAMPLING MASS SPECTROMETER 


\section{DESIGN OF MOLECULAR-BEAM SAMPLING MASS SPECTROMETER}

The design of the mass spectrometer built for measuring vapor phase sodium species during fluidized bed combustion or gasification was based on a system that has been in successful operation at Solar Energy Research Institute. Because the mass spectrometer must be able to sample from environments at pressures greater than $1 \mathrm{~atm}$, the speeds and capacities needed for a pumping system that could meet this requirement had to be calculated

The high pressure sampling system requires several pumping stages at successively lower pressures to extract the gaseous constituents of the sampled environment and deliver them to the ionizer of the mass spectrometer. In successive stages, the pressure is reduced from that of the pressurized fluidized bed reactor (PFBR), $\mathrm{P}_{0}$, to the operating pressure, $\mathrm{P}_{3}$, of the mass spectrometer $\left(<10^{-6}\right.$ torr). In the first stage, the sampled gas from the reactor flows through an orifice through which it expands as a supersonic free jet. Along the centerline of the jet, the gas molecules are moving in nearly the same direction at nearly identical velocities. A conical orifice (skimmer), placed inside the mach disk, selects the centerline beam, permitting it to enter a second chamber in which the pressure is sufficiently low that further interaction between gas molecules is minimized. The molecular beam emergilig from the skimmer is collimated by passage through an aperture into a third chamber in which the mass spectrometer is located.

The required pumping speed, $S_{1}$ (the volumetric flow rate of gas through the orifice), is given by 1

$$
S_{1}=\frac{\pi d_{0}^{2}}{4} \sqrt{\frac{\gamma R}{M}\left(\frac{2}{\gamma+1}\right)^{\frac{\gamma+1}{\gamma-1}} \frac{\mathrm{P}_{0} \mathrm{~T}_{1}}{\mathrm{P}_{1} \sqrt{\mathrm{T}_{0}}}}
$$

where $d_{0}$ is the orifice diameter; $\gamma$ is the specific heat ratio; $R$ is the gas constant; $M$ is the molecular weight; $P_{0}$ and $T_{0}$ are, respectively, the pressure and temperature in the reactor, and $P_{1}$ and $T_{1}$ are the pressure and temperature in the first stage chamber. The pumping speed is directly proportional to the pressure in the reactor, but inversely proportional to $\sqrt{T_{0}}$. Assuming that the sampled gas is nitrogen, $P_{1}$ is $20 \times 10^{-3}$ torr, and $T_{1}$ is $298 \mathrm{~K}$, the required first-stage pumping 
speed were calculated as a function of orifice diameter for two different conditions in the reactor (Figure B-1).

The chosen pressure level of $20 \times 10^{-3}$ torr is a trade-off between a tolerable collision frequency in the molecular beam and a pumping capability of reasonable size. At higher pressures, the number of collisions will increase, thereby increasing the risk of altering the beam composition. Attainment of lower presures, however, requires increased pumping speed.

Several types of pumps were considered for the first stage, including mechanical booster, Roots blower, oil vapor diffusion, and oil vapor diffusion ejector pumps. Cost consideration ruled out mechanical booster pumps and Roots blowers. Oil vapor diffusion pumps are capable of attaining lower ultimate pressure, but their pumping speed drops off rapidly at pressures greater than $10^{-3}$ torr. In contrast, oil vapor diffusion ejector pumps can operate at pressures up to about $50 \times 10^{-3}$ torr and are moderately priced. Consequently, this type of pump was considered the unit of choice. A review of commercially available pumps indicated that a $4000 \mathrm{l} / \mathrm{s}$ pump manufactured by Edwards High Vacuum Inc. offered the best combination of pumping capacity and price. Two of these pumps, working in parallel, will allow sampling from a 10-atm environment at $1273 \mathrm{~K}$ by using a $0.5 \mathrm{~mm}$ orifice.

The calculation of the required second-stage pumping speed is slightly more complicated, because the pressure and density of the gas near the centerline of the free jet must be known. Assuming that the density and velocity distributions in the free jet are functions of the conditions in the reactor and the Mach number at the skimmer, it can be shown ${ }^{1}$ that

$$
S_{2}=\frac{\pi}{4} \frac{P_{0}}{P_{2}} d_{s}^{2} T_{2} \sqrt{\frac{\gamma R}{M T_{0}}}\left[\frac{1}{\left(\frac{\gamma+1}{2}\right)^{\frac{\gamma+1}{2(\gamma-1)} \frac{A}{A^{*}}\left(M_{s}\right)}}\right]
$$

where $S_{2}$ is the required pumping speed for the second stage, $d_{S}$ is the diameter of the skimmer, $A / A^{*}$ is the isoentropic flow ratio, $T_{2}$ is the temperature at the second stage, and $M_{S}$ is the Mach number at the skimmer. McLean ${ }^{1}$ has published a correlation between the second-stage pumping speed and the Mach number for nitrogen at $293 \mathrm{~K}$; hence, $S_{2}$ can be calculated if $M_{S}$ can be estimated. 
The Mach number at the skimmer varies with the position of the skimmer with respect to the orifice. Under optimal conditions, the skimmer is positioned so that the beam interference caused by shocks in front of the skimmer is avoided. This criterion is met when the skimmer Knudsen number, $K n_{S}$, is $>10\left(\mathrm{Kn}_{\mathrm{S}}=\lambda_{\mathrm{S}} / \mathrm{d}_{\mathrm{s}}\right.$, where $\lambda_{\mathrm{s}}$ is the mean free path and $\mathrm{d}_{\mathrm{s}}$ is the skimmer diameter). For nitrogen the relation between $\mathrm{Kn}_{\mathrm{S}}$ and $\mathrm{M}_{\mathrm{S}}$ is given by

$$
\mathrm{Kn}_{\mathrm{s}}=\frac{4.9 \times 10^{-2}}{\mathrm{P}_{0} \mathrm{~d}_{\mathrm{s}}}\left(1+0.2 \mathrm{M}_{\mathrm{s}}^{2}\right)^{2.4}
$$

where $P_{0}$ is the pressure at the reactor in torr. Assuming that $\mathrm{Kn}_{\mathrm{S}}$ is $10, \mathrm{M}_{\mathrm{S}}$ was calculated as a function of $P_{0}$ for a skimmer diameter of $1.4 \mathrm{~mm}$. This skimmer diameter was chosen because of its satisfactory performance reported by Solar Energy Research Institute (SERI). ${ }^{2}$ From the published correlation between $S_{2}$ and $M_{S}, S_{2}$ was calculated as a function of the reactor pressure (Figure B-2). The required pumping speed increases sharply for pressures lower than $10^{-6}$ torr.

In the second stage, the pressure level is lower than can be attained using oil vapor booster diffusion pumps; conventional oil vapor diffusion pumps are more suitable. To sample the gas from the reactor at 10 atm and $1273 \mathrm{~K}$, the required pumping speed is about $3650 \mathrm{l} / \mathrm{s}$ for a secondstage pressure of $1 \times 10^{-6}$ torr. A 10 -in. diffusion pump will provide this pumping speed. A liquid nitrogen trap is essential to prevent oil migration from the pump to the chamber.

The pumping requirement for the third stage can be about an order of magnitude less than that for the second stage and a turbomolecular pump of 400-1/s capacity was chosen. Turbomolecular pumps are capable of attaining pressures $<10^{-9}$ torr without the need for a liquidnitrogen-cooled trap. This latter feature has two advantages: (1) A smaller capacity pump can be used because the pump is directly connected to the chamber (liquid nitrogen traps normally reduce the pumping speed by about $50 \%$ ), and (2) the mass spectrometer chamber can be kept under "clean" vacuum without a constant source of liquid nitrogen. These advantages compensate for the higher price of a turbomolecular pump over a comparably sized oil vapor diffusion pump.

The mechanical design of the mass spectrometer chamber is shown in Figure B-3. Table B-1 lists the specifications of the various components. In contrast to the cube-shaped chamber used at SERI, a cylindrical geometry was designed that minimized construction costs and permitted tie mass spectrometer ionizer to be mounted in either a cross- or an axial-beam configuration. Also, the capacity of the vacuum pumps has been nearly doubled over that used in the SERI design 
to permit sampling from an environmental pressure up to $15 \mathrm{~atm}$. A commercially available gate valve with a remote actuator is used to isolate the third stage when the reactor gases are not being analyzed.

\section{REFERENCES}

1 W. J. McLean (1971). "Direct Mass Spectrometric Sampling from High Pressure Sytems," Ph.D. thesis submitted to University of California, Berkeley, December 1971.

2 M. N. Soltys and T. A. Milne (1982). "The SERI High Pressure, Molecular-Beam Mass Spectrometric Sampling System", Report No. SERI/TR-622-1172 . 
Table B-1

\section{SPECFICATIONS FOR THE HIGH PRESSURE SAMPLING \\ MASS SPECTROMETER SYSTEM}

\section{Component}

Vacuum chamber

Stage 1

Primary pump

Oil vapor trap

Backing pump

Gauges

Stage II

Primary pump

Backing pump

Oil vapor trap

Isolation valve

Gauges

Stage III

Primary pump

Backing pump

Isolation valve

Gauges

\section{Capacity}

Stain!ess steel, $45.7-\mathrm{cm}$ diameter, $61.0-\mathrm{cm}$ high, 3 compartments with internal baffles (SRI design)

$4,000 \mathrm{l} \cdot \mathrm{s}^{-1}$ oil vapor booster diffusion pumps (2 each)

$40.6-\mathrm{cm}$ baffle and isolation valves ( 2 each)

300-cfm single-stage mechanical vacuum pump

Pirani gauge

15-cm diffusion pump $\left(2,500 \mathrm{l} \cdot \mathrm{s}^{-1}\right.$ capacity)

17-cfm double-stage mechanical vacuum pump

$2,000 \mathrm{Vs}$ cryotrap (with refrigerant)

$25.4-\mathrm{cm}$ aluminum slide valve

Cold cathode ionization and thermocouple gauges

$400 \mathrm{l} \cdot \mathrm{s}^{-1}$ turbomolecular pump

15-cfm double-stage mechanical vacuum pump

1.9-cm gate valve (between stages II and III)

Ionization and thermocouple gauges 


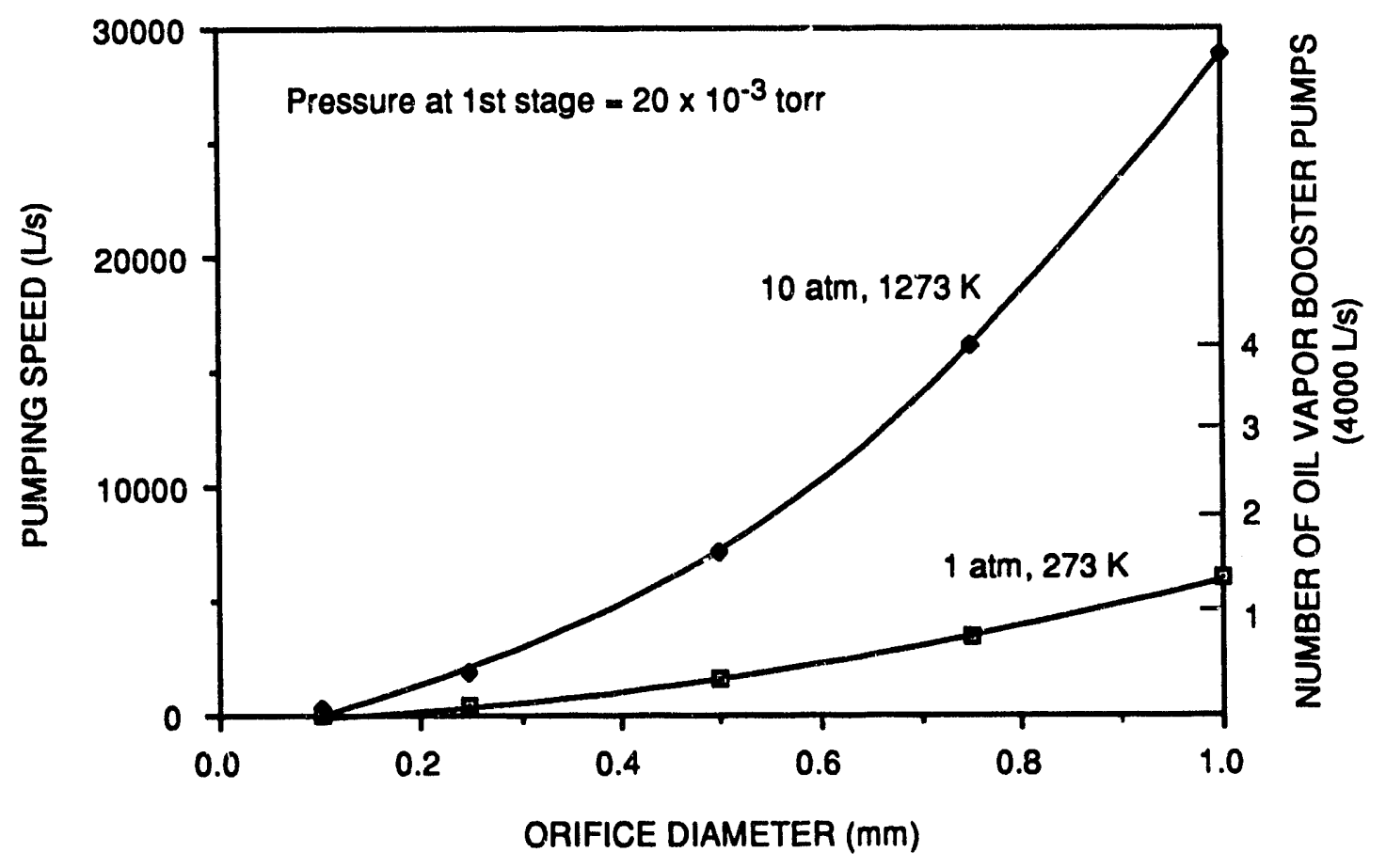

RAM-4352-22

Figure B-1. Calculated pumping speed for the first stage as a function of orifice diameter and reactor conditions. 


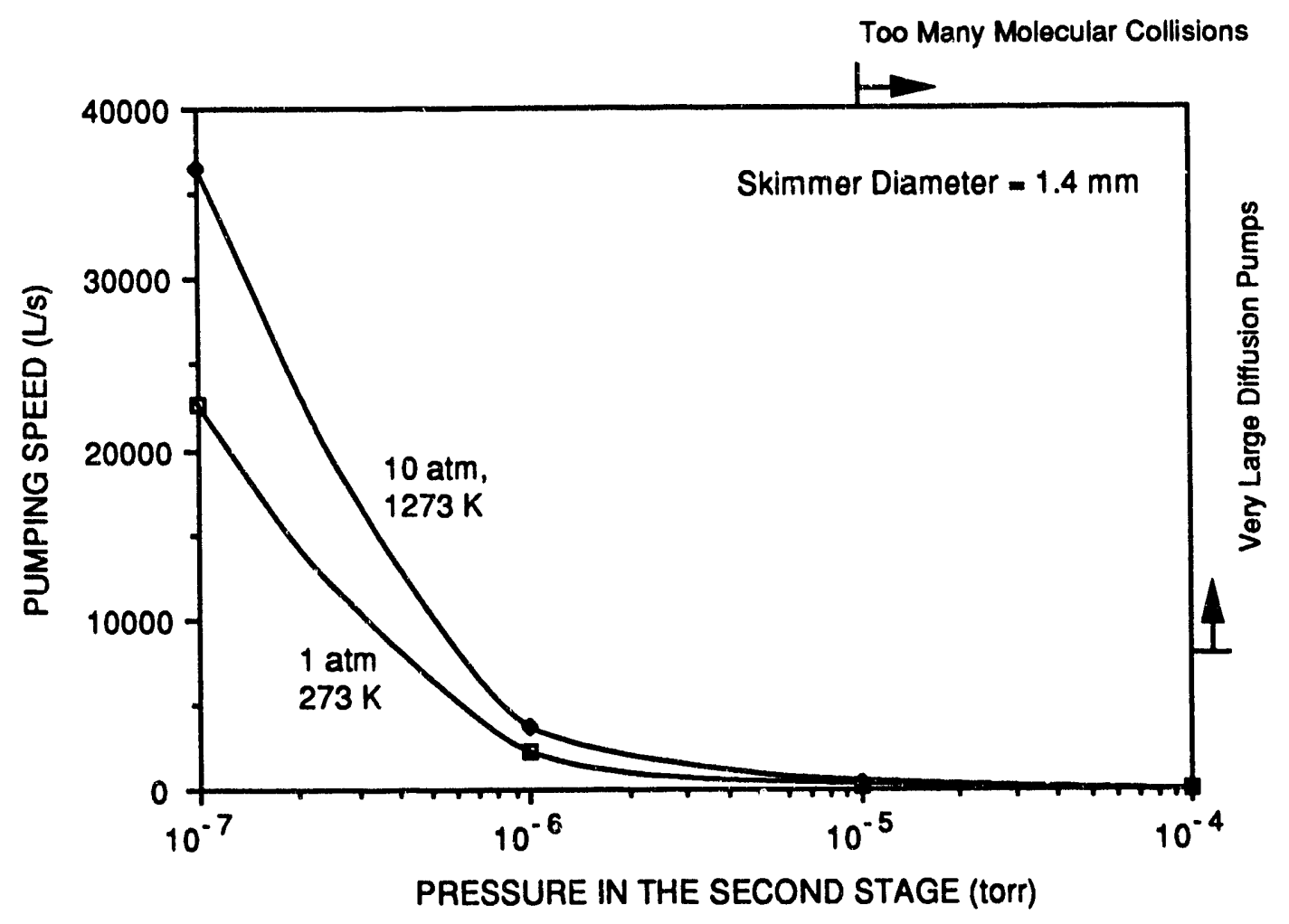

RAM-4352-23

Figure B-2. Calculated pumping speed for the second stage as a function of second stage pressure and reactor conditions. 


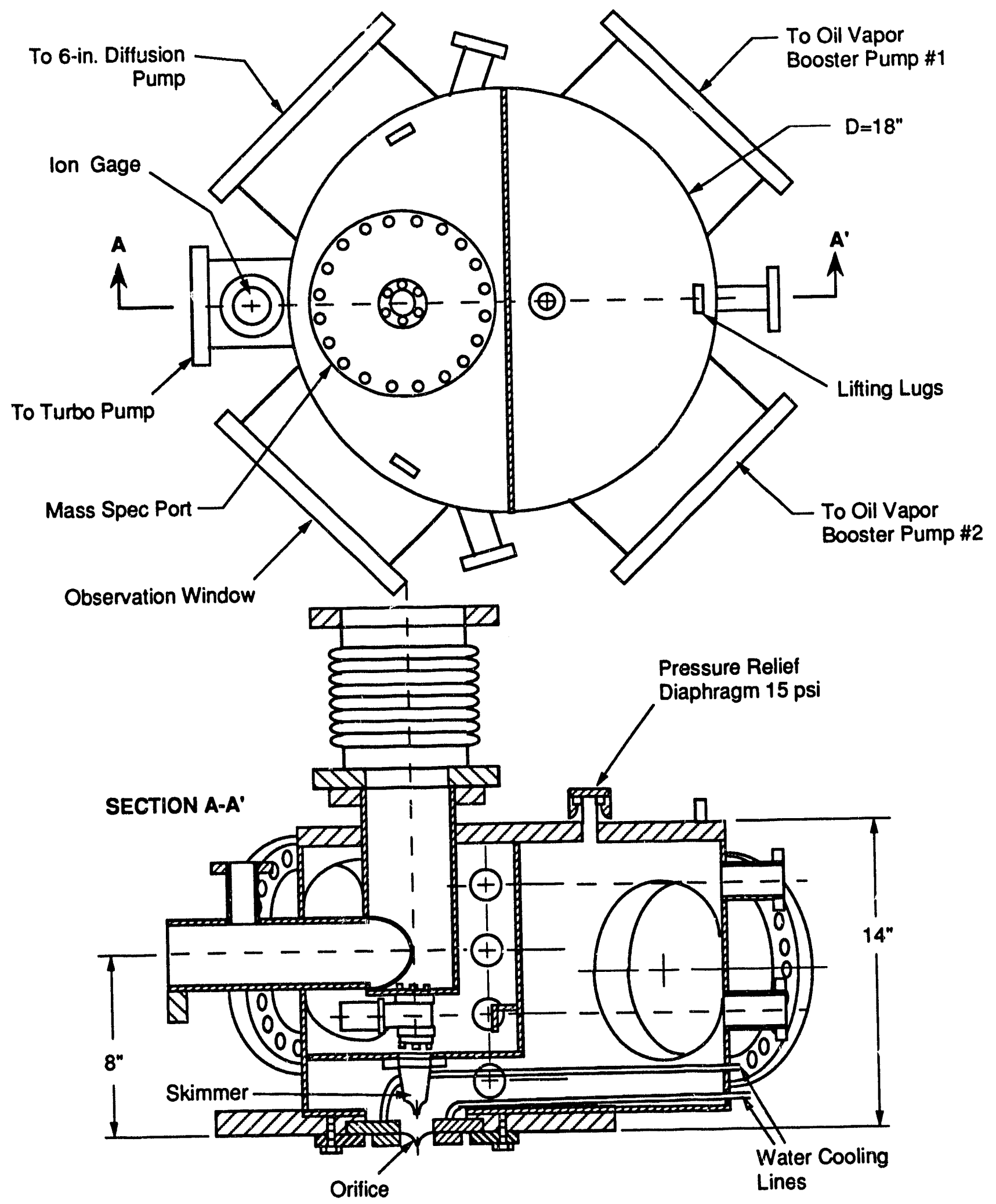

RAM-4352-24

Figure B-3. A cross-sectional view of the vacuum chamber. 

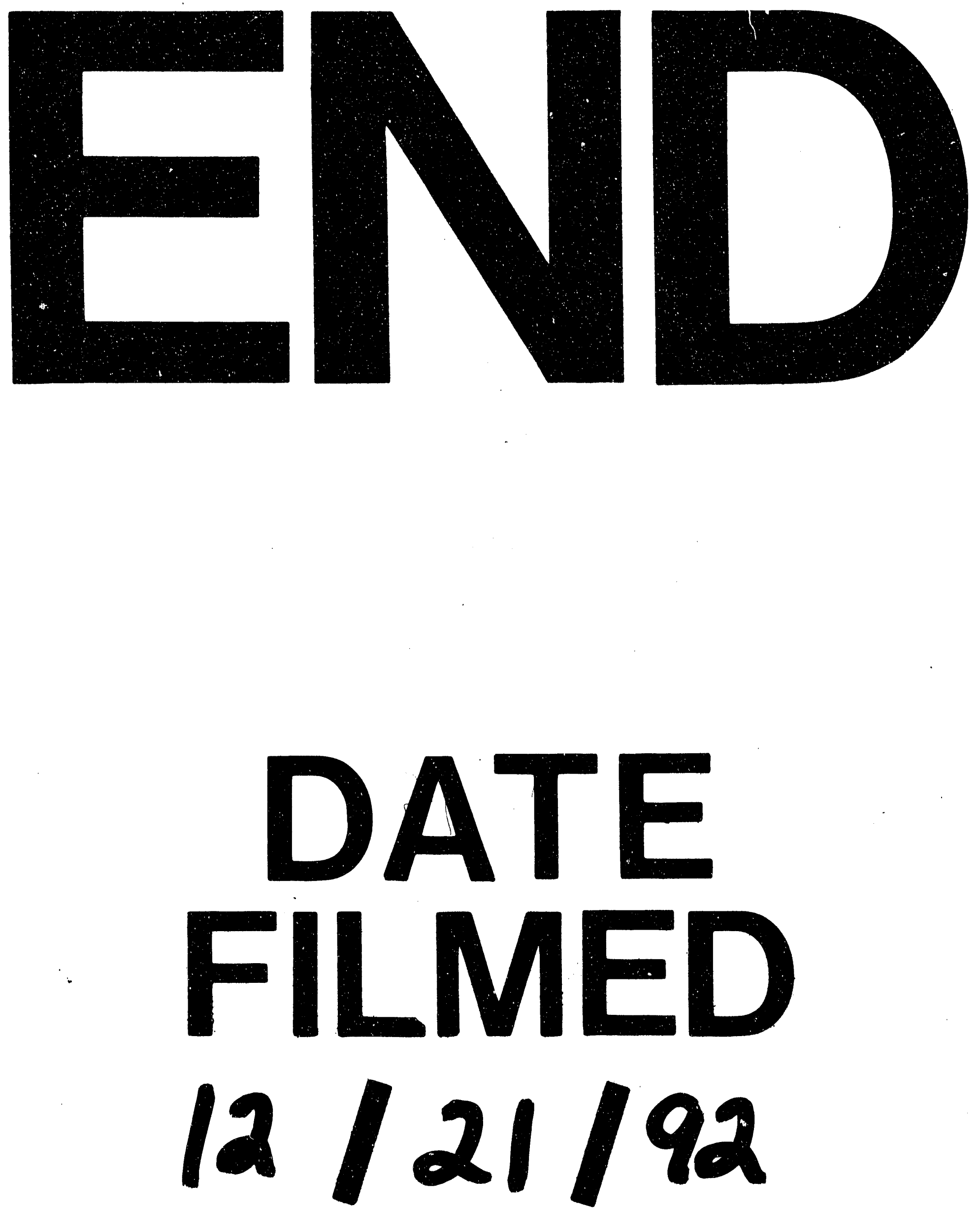
